\title{
APPLICANT ATTITUDES ACROSS THE RECRUITMENT PROCESS: TIME IS OF THE ESSENCE
}

\author{
A Dissertation \\ by \\ BRIAN WILLIAM SWIDER \\ Submitted to the Office of Graduate Studies of \\ Texas A\&M University \\ in partial fulfillment of the requirements for the degree of \\ DOCTOR OF PHILOSOPHY
}

May 2012

Major Subject: Management 
Applicant Attitudes across the Recruitment Process: Time is of the Essence Copyright 2012 Brian William Swider 


\title{
APPLICANT ATTITUDES ACROSS THE RECRUITMENT PROCESS: TIME IS OF THE ESSENCE
}

\author{
A Dissertation \\ by \\ BRIAN WILLIAM SWIDER
}

\begin{abstract}
Submitted to the Office of Graduate Studies of
Texas A\&M University

in partial fulfillment of the requirements for the degree of

DOCTOR OF PHILOSOPHY
\end{abstract}

Approved by:

Chair of Committee, Murray R. Barrick

Committee Members, Bradley L. Kirkman

Ryan D. Zimmerman

Stephanie C. Payne

Head of Department, $\quad$ Ricky W. Griffin

May 2012

Major Subject: Management 


\begin{abstract}
Applicant Attitudes across the Recruitment Process: Time is of the Essence.

(May 2012)

\section{Brian William Swider, B.S.B.A, University of Florida \\ Chair of Advisory Committee: Dr. Murray R. Barrick}

While extant research on recruiting has highlighted a number of applicant attitudes that predict future attitudes and decisions, questions regarding how attitudes develop over time and differentially predict applicant job choice have received scant attention. To address this currently impoverished research area, this study utilizes three prominent recruitment frameworks (signaling theory, fit, and image) to theoretically and empirically examine how applicant attitudes towards possible future employers develop over the course of the recruitment process. Also, this study explores the possible divergent patterns of development of these applicant attitudes by examining taking a job offer and passing on a job offer as two separate decision-making processes. Finally, this study investigates the pattern of relationships between proximal predictors of job choice (organizational attraction and acceptance intentions) and applicant decisions to take or pass on a job offer.

Participants in this study were 178 undergraduates seeking internships during a five-month recruitment period. Applicant attitudes about organizational image, fit, attraction, acceptance intentions as well as recruiter trustworthiness and timeliness of a 
consistent set of firms were assessed eight times over the five-month period. Results of this study indicate that recruiting, from an applicant perspective, is a dynamic decisionmaking process where applicants gather and assimilate information in distinct patterns prior to making job choice decisions. Specifically, across six applicant attitudes that have previously been shown to predict recruiting outcomes such as job choice, applicant attitudes toward the organization they take an offer from increase, and at a faster rate, over time relative to organizations whose offers they pass. These attitudes significantly differ between offers that are ultimately taken and passed on as early as the start of the recruitment process (i.e. image) or as late as slightly more than three weeks (i.e. fit) into a five-month recruitment process. 


\section{DEDICATION}

To my mother, Elizabeth (Betsy) Swider, and father, John (Fly) Swider 


\section{ACKNOWLEDGEMENTS}

I must acknowledge the efforts, advice, and support of those who made my education up to this point possible. While I never plan to stop learning, a number of people are directly responsible for me even making it this far.

First, I want to acknowledge my family, for ensuring that I would be the only one to question my decision to embark on such an odyssey. When I needed help (e.g., spelling words, paying bills, having fun), Mom, Dad, Matt, and Brett were always up to the task. And to Marsha, who continues to be the co-author of my life story.

Next, Murray Barrick, my chair, deserves more recognition than I can give him in this brief paragraph. Murray was never anything less than supportive of my ideas; fostering the good ones, amending the bad ones, and working tirelessly to see them reach their full potential.

I also want to individually thank Ryan Zimmerman, for not only his efforts as a co-author on several manuscripts and a committee member for this dissertation, but also a wonderful friend. Ryan was the first person to believe in my ability to research, before I even contemplated such a notion. Similarly, my co-author on several manuscripts, Wendy Boswell, deserves acknowledgement for repeatedly making me apart of her family, if only for a day, when distance separated me from my family.

I must thank both Brad Kirkman and Stephanie Payne for their service as committee members and continued efforts to help me fully develop the ideas in this dissertation. In addition to my outstanding committee members, I would like to thank 
Talya Bauer, Derek Chapman, Tim Judge, Rob Ployhart, and Sara Rynes whose comments helped guide this dissertation in its early stages. Also, much of my research, including this dissertation, was made possible by the financial support of the Mays Business School.

I want to also thank Drs. Tihanyi, Paetzold, Jones, Woodman, Porter, Kwok, Short, Willson, Arthur, and Yoon for facilitating my development in their courses on a plethora of topics. Likewise, the remainder of the faculty and staff in the management department must be acknowledged, as they fostered such a fertile garden from which my education could continue to grow.

Finally, I want to thank my fellow $\mathrm{PhD}$ students. From those students that showed me the ropes (e.g., Justin Webb, Mike Holmes) to those who let me think I am returning the favor, you all made coming to, and spending time away from, the office a little more exciting.

Thank you. 


\section{TABLE OF CONTENTS}

Page

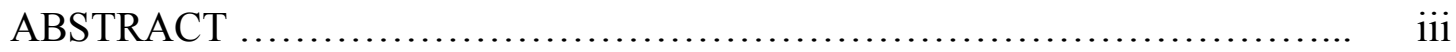

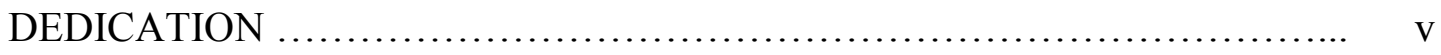

ACKNOWLEDGEMENTS .............................................. vi

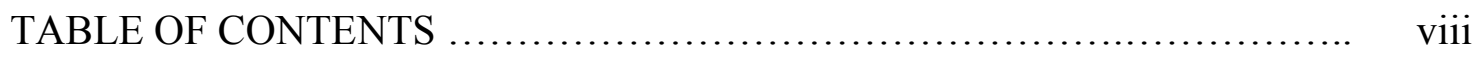

CHAPTER

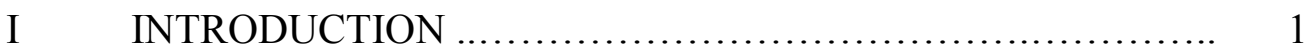

II THEORETICAL DEVELOPMENT AND HYPOTHESES ...... 15

Review of Recruitment Stages ........................... 15

Preference Development in Decision Making: Role of Predecision Information Distortion ................................... 21

Signaling: Theory and Influence on Applicant Attitudes Over Time .................................................... Image: Review of Research and Its Influence on Applicant Attitudes Over Time ............................................. 40 PO Fit: Role in Recruitment and Influence on Applicant Attitudes Over Time ............................................... 51 Attraction and Acceptance Intentions: Distinguishing Attitudes..... 63

III RESEARCH METHODOLOGY ............................ 72

Participants and Procedures ................................... 72

Measures ................................................. 75

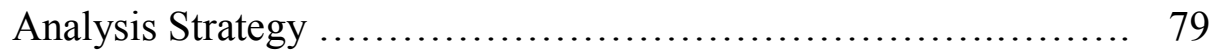

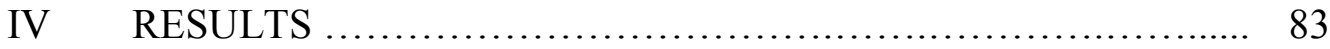

Motivation and Preference Check ............................... 83

Modeling Procedure ........................................ 84

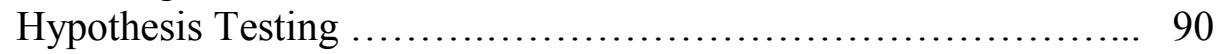

$\mathrm{V} \quad$ DISCUSSION AND CONCLUSION ...................... 97

Theoretical Contributions $\ldots \ldots \ldots \ldots \ldots \ldots \ldots \ldots \ldots \ldots \ldots \ldots \ldots . \ldots . \ldots \ldots$ 
Practical Implications ..................................... 107

Limitations and Future Research Directions ...................... 114

Conclusion .............................................. 123

REFERENCES............................................................. 125

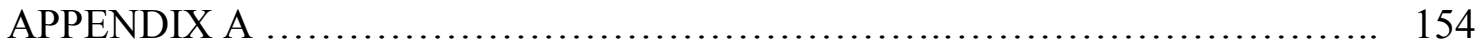

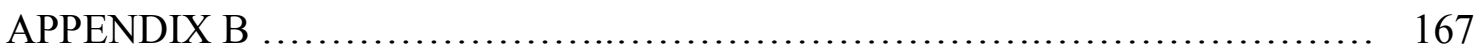

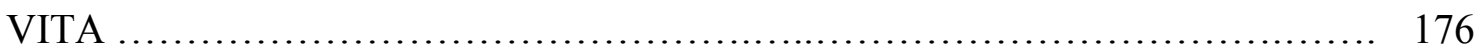




\section{CHAPTER I}

\section{INTRODUCTION}

Although an applicant may be offered a job by an organization, this does not mean that he or she will take the job. Applicants who obtain job offers from organizations but pass up the offers in lieu of other, more attractive, alternatives can potentially undermine an organization's selection process (Behling, Labovitz, \& Gainer, 1968). Using estimates derived from utility equations, Murphy (1986) was able to quantify the consequences of organizations' inability to influence applicants to take job offers. When organizations are using top-down selection systems to hire a fixed number of new employees but have applicants pass on offers, they must be replaced with less able applicants. Results of Murphy's (1986) study indicate that under realistic conditions, organizations that have half of their offers passed on are expected to see productivity gains of their selection system cut by nearly 76 percent relative to organizations that only have 10 percent of their offers passed on by applicants. As such, a slew of practices have been developed and studied over the last 50 years aimed at influencing applicant attraction and decisions during what is referred to as the recruiting process.

Given the criticality of applicant attitudes and decisions to practitioners looking to hire new employees, it is not surprising that a number of scholars have investigated the recruiting process, each offering their own definitions of recruitment. Chapman, Uggerslev, Carroll, Piasentin, and Jones (2005) define recruiting as "ways to attract and

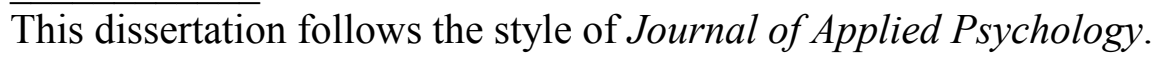


influence the job choices of top candidates” (p. 928). Rynes (1991) provides a slightly more inclusive definition of "all organizational practices and decisions that affect either the number, or type, of individuals that are willing to apply for, or to accept, a given vacancy" (p. 429). In what may be the most complete definition, Breaugh (2008) defines recruitment as "encompassing an employer's actions that are intended to: (a) bring a job opening to the attention of potential job candidates who do not currently work for the organization, (b) influence whether these individuals apply for the opening, (c) affect whether they maintain interest in the position until a job offer is extended, and (d) influence whether a job offer is accepted" (p. 103-104). For this paper, recruiting is defined as organizational efforts to attract and influence potential applicant attitudes towards the job or organization as well as applicant job choice.

The purpose of this study is to gain a better understanding of the recruitment process by using constructs previously employed to explain the recruitment and job choices of future employees. The process by which applicants develop attitudes and preferences among job alternatives is not fully understood but is of extreme interest to both researchers and practitioners. Yet, as Simon, Krawczyk, Bleicher, and Holyoak (2008) note, individuals' preferences develop over the course of the decision making process and are "more like the product of architecture than archaeology" (p. 1). To better understand how applicant attitudes and preferences are "built" during the recruitment process, researchers need to focus on how applicants assimilate and use information to make decisions about future employment (Ryan \& Huth, 2008). Findings of this study are expected to illuminate when and how applicant attitudes about an organization and 
its' agents (recruiters) develop and meaningfully predict job choice over the duration of the recruitment process.

While it is essential to provide a clear definition of what the focus of a study is, it is also imperative to outline what will not be addressed and the rationale behind such a decision. Two other research areas also involve applicant attitudes and job choice but are distinguishable from recruiting: job search and applicant reactions. Job search research focuses on individuals' behavior and effort during the pursuit of new employment (Kanfer, Wanberg, \& Kantrowitz, 2001). While applicants being recruited are often searching for jobs, recruiting research is focused on organizational efforts and influences on applicants and not the activities applicants engage in to gather information and generate employment alternatives (Boswell, 2006; Saks, 2005). Researchers investigating applicant reactions seek to predict typical "recruiting" outcomes (i.e., organizational attraction and job choice) using applicant perceptions of the selection process itself (Hausknecht, Day, \& Thomas, 2004). Recruitment research on the other hand, looks to explain why organizational attempts to draw in, rather than select-out, applicants result in outcomes such as attraction and job choice (Chapman et al., 2005). So, while applicant job search and reactions to selection procedures are important factors when predicting job outcomes, they are distinguishable from variables of interest in recruitment research. Therefore, job search behaviors and applicant reactions are not directly addressed in this manuscript.

A discussion about differences between related yet clearly definable research streams and recruitment research parallels the distinctions made by researchers within 
the recruitment literature. Specifically, a number of theories and frameworks contribute to our understanding of the recruiting process; each using different sets of tactics, behaviors, or cognitions to explain how organizational efforts influence applicant attitudes and choices (Ehrhart \& Ziegert, 2005). In light of these overlapping, yet independently developed frameworks, Ployhart (2006) warns of the possible splintering of recruitment research into uninterpretable and unusable fragments. Instead of further developing the nuances of existing theories, he advocates refocusing on key aspects and common underlying tenets that are pervasive in existing areas of recruitment research. While the definitions above have some level of disagreement and vary in scope, a fundamental aspect of each is that recruitment is a process of dynamic change over time. Organizational recruitment occurs over a period of time and influences applicant attraction differently at various stages of the selection process (Barber, 1998; Rynes \& Cable, 2003). In short, prior definitions of recruitment indicate organizations only hiring people that apply for a job without organizational influence, or direct applicants, are not recruiting. Thus, this study examines three popular streams of recruitment research that have discussed the notion of change over time, even if it is infrequently studied as such: signaling, organizational image, and fit.

Signaling theory discusses how various characteristics of recruiting tactics, such as timeliness and trustworthiness, are used by applicants to make inferences about organizational characteristics which influence applicant attitudes toward organizations during the recruitment process (Rynes et al., 1991). Research on organizational image describes how exposure to image-focused recruitment activities that highlight unique, 
favorable, and desirable attributes of organizations influence potential applicant attitudes toward organizations and intentions (Collins \& Stevens, 2002). Finally, the fit literature suggests that job seekers develop perceptions of their similarity with organizations based on interactions with organizations and their representatives, with applicants selfselecting in or out of the hiring process based on perceived congruence (Cable \& Judge, 1996). Through these various mechanisms, organizations affect applicant attraction to the organizations and intentions to accept job offers, both of which are expected to influence job choice decisions (Chapman et al., 2005). And while Chapman et al.'s (2005) empirical review of recruiting research provides a comprehensive portrait of half a century of research, it also brings to light a number of existing shortcomings of recruitment research to date, including studies focused on signaling, organizational image, and fit.

One of the most prominent weaknesses of existing recruitment research is that the incorporation of change in applicant attitudes over time is underdeveloped theoretically and is infrequently assessed when studies are conducted (Chapman \& Webster, 2006; Ployhart, 2006). That is, much of our knowledge about recruiting has been developed in static, cross-sectional studies that have left researchers unable to speak to the dynamic process of change that is recruiting (Rynes et al., 1991; Ployhart, 2006; Wanous, Keon, \& Latack, 1983). For instance, Collins and Stevens' (2002) seminal work investigating the influence of organizational image in recruiting attempted to explain why exposure to an organization (at one specific time) predicted job choice two months later. These static approaches to studying recruiting are not limited to 
investigations addressing image but are prevalent across all recruiting research (Chapman et al., 2005). That is not to say these studies are incorrectly designed or poorly conducted, as many of the studies are high-quality and well-equipped to answer the focal research questions. However, static designs capture different forms of variance and require different theories to explain hypotheses than more dynamic study designs (Ployhart \& Vandenberg, 2010). This seemingly ubiquitous reliance on static studies to explain the dynamic process of recruitment has left our knowledge and understanding of recruitment rudimentary as "time must be explicitly incorporated into a theory (and not just treated as a boundary condition) if a theory is to provide an ontologically accurate description of a phenomenon" (p. 658, George \& Jones, 2000). Thus, theoretical development is required to clarify the temporal nature of recruitment predictors and capture possible within-applicant changes in attitudes and perceptions over the course of the recruitment process.

At their core, recruitment studies look to explain how organizational efforts influence applicant decisions about employment (Breaugh, 2008; Taylor \& Collins, 2000). Thus one of the more, if not the most, important outcomes for recruitment researchers are actual job choices made by applicants who are being recruited (Ma \& Allen, 2009). Job choice is defined as decisions made by job seekers after receiving one or more offers from organizations (Boswell, Roehling, LePine, \& Moynihan, 2003). Yet, many studies that attempt to capture job choice do so in a manner that limits the conclusions researchers can draw from the results. First, measurement of job choice is frequently a one-item measure asking whether an individual takes or passes on a given 
offer (e.g., Taylor \& Bergmann, 1987). However, binomial measures of actual job choice preclude researchers from separately investigating the processes resulting in taking a job and passing on a job. In fact, Dineen and Soltis' (2010) review explicitly mentions the unexplored nature of competing offers, where applicants must take a job and pass on others, and how these separate choices were affected by the recruitment process. This is especially true in the current study, as applicants are expected to accumulate a number of job offers, simultaneously evaluate each, and take one job from a set of alternatives rather than sequentially eliminate alternatives over time (Barber, 1998). Second, some studies attempt to explain job choice using "simulated job offers" and have individuals choose which offers they would accept utilizing a policy-capturing approach (Bazerman, Schroth, Shah, Diekmann, \& Tenbrunsel, 1994; Chapman \& Webster, 2006). Yet job choices made in a laboratory research setting may depart significantly from job choices in actual recruitment settings (Breaugh, 2008). By studying recruitment over time using real applicants making simultaneous job choices, one can examine job taking and job passing as two separate, albeit related, decisionmaking processes.

Also, results from the Chapman et al. (2005) meta-analysis indicate that studies assessing actual job choice are quite rare. For instance, 69 correlations were found for the relationships between recruiter behaviors (signals) and the recruiting outcomes of organization attraction and acceptance intentions, combined, whereas they were only able to locate 4 studies that reported a correlation between recruiter behaviors and job choice. One reason for the preponderance of studies using organization attraction or 
acceptance intentions as the focal dependent variable rather than actual job choice is the pervasive use of policy-capturing methodologies as described above. However, this reliance on applicant attitudes and intentions in lieu of actual decisions does not allow researchers to test how the proximal mediating variables of organization attraction and acceptance intentions actually relate to the behavioral outcome of most interest, job choice. That is not to say applicant attraction to the organization and acceptance intentions are not important. Chapman et al. (2005) indicated population coefficients of .19 and .33 for organization attraction and acceptance intentions, respectively (no credibility or confidence intervals were reported making claims of generalizability untenable), with path models supporting the assertion that these attitudes mediate predictor-job choice relationships. However, these findings do not provide information about how these variables operate over time.

In the terminology developed by Baron and Kenny (1986), the strength of relationships between mediators (i.e., organization attraction and acceptance intentions) and dependent variable (job choice), or path $b$, may depend on when mediators were measured (MacKinnon, 2008). For instance, if measures of organization attraction are taken at the same time job choice is made, one cannot be sure if the relationship between these two variables reflects actual attitudes about applicant job choice or is distorted by applicant desire to justify their decision (Weber \& Johnson, 2009). Similar problems can be found in other literatures such as turnover, where perceptual measures are believed to be the most proximal mediators to separation but are weakly related to behavior as they fail to capture all the factors that go into actual decisions (Griffeth, Hom, \& Gaertner, 
2000). Not surprisingly, Kammeyer-Muller, Wanberg, Glomb, and Ahlburg (2005) investigated the intercepts and slope difference between stayers and leavers and found that withdrawal and job search (variables believed to mediate predictor-turnover relationships) did not have similar patterns of relationships with turnover or with each other. That is, two proximal predictors of a decision (i.e., turnover) that were believed to have similar patterns of influence on the decision, exhibited different prediction patterns for stayers and leavers over time. Kammeyer-Muller et al.'s (2005) study underscores the possible divergence between job takers and job passers one might expect when studying applicant attraction to the organization and acceptance intentions over time. Investigating the pattern of relationships between these attitudinal outcomes of recruiting and job taking and passing should provide insight into how these more proximal applicant attitudes (relative to theoretically more distal attitudes such as PO fit) influence job choice as well as clarification of the modest meta-analytic correlations.

Depicted in Figure B1 is a graphical representation of the model to be tested in this study. As described above, applicants (Level-3) are recruited by a number of different organizations (Level-2) and are expected to have changes in attitude towards each organization (i.e., signals, organizational image, PO fit, etc.) over the course of the recruitment process $($ Level-1). Each applicant $(\mathrm{K})$ can take only one job offer $($ Take $=1)$ and will have to pass on all other offers received $($ Take $=0)$. Applicant perceptions of recruiter signals, organizational image, $\mathrm{PO}$ fit, organization attraction, and acceptance intentions may differ initially $\left(T_{1}\right)$, over time $\left(T_{2}-T_{k}\right)$, or both, and these differences are expected to vary based on whether they take or pass on the offer given by an 
organization. Hierarchical Linear Modeling (HLM) specifications are reported in Figure B2. The coefficient $\gamma_{000}$ represents the mean applicant attitude (i.e., organization attraction) towards an organization at the beginning of the recruitment process (Time 1) whose offer the applicant ultimately passed. Significance of the coefficient $\gamma_{010}$ indicates that applicant attitudes towards an organization the applicant took an offer from differed at the beginning of the recruitment process from attitudes towards an organization whose offer they passed. The slope or trajectory of each attitude may vary by time, with the coefficient $\gamma_{100}$ representing the slope between time and applicant attitudes towards organizations whose offer was passed on by the applicant. Finally, the difference from that slope value, $\gamma_{110}$, indicates the extent to which applicant attitudes towards an organization changed over time diverged between organizations whose offer was passed on compared to taken. Significant $\gamma_{010}$ and $\gamma_{110}$ would indicate that applicant attitudes toward organizations they ultimately chose differed initially and over time, respectively, from those organizations whose offers they passed.

Findings of this study will be of significant value to practitioners. Results will highlight recruiting practices and applicant attitudes that change over the recruitment process. This information will have great value to organizations as they develop their recruitment objectives and strategies (Breaugh, 2008). Findings of this study will allow organizations to better focus their recruitment strategies on activities and practices that are shown to affect recruiting outcomes initially as well as over time (Rynes, 1991). Conversely, findings should indicate whether applicant initial attitudes or perceptions would make future successful recruiting unlikely. By assessing and identifying recruiting 
targets early that are less likely to be attracted to, or accept an offer from, an organization, organizations would be able to minimize recruiting costs and maximize recruiting effectiveness.

This study also makes three theoretical contributions. First, this study will focus on different recruitment literatures (signaling, organizational image, and PO fit) and develop the theoretical underpinnings of why and how applicant attitudes change during the course of the recruitment process. Empirical results will give preliminary insight into whether variables from each framework predict recruiting outcomes initially, over time, or both. To do so, both between- and within-applicant changes in these variables are examined and contrasted with applicants who accept (takers) or reject (passers) a job offer once it is extended by an organization. Existing research indicates that some recruiting tactics and behaviors may influence applicant attitudes early in the recruiting process while others will be more influential over the course of the recruitment process (Dineen \& Soltis, 2010). Yet, only a handful of studies have empirically examined these questions (e.g., Carless, 2005; Chapman \& Webster, 2006) leaving many critical propositions concerning these attitudes untested. It is possible that applicant perceptions of recruiter trustworthiness differ over time but not initially for organizations whose offer was taken rather than passed, or PO fit perceptions differ initially but do not change over time for organizations whose offer was taken rather than passed. This study will further recruitment research by providing preliminary findings that address these possibilities and provide theoretical insight into the influence of a set of time-variant predictors on job choices. 
Second, this study will identify how applicant attitudes differentiate between job takers and passers over time. Empirical results of applicant attitudinal variables predicting actual job choice have been modest at best (Chapman et al., 2005). Perhaps these weak results are neither the product of range restriction created by self-selection nor the inherent attenuation of effect sizes (that was not corrected) when there is an unequal split of the dichotomous job choice variable described above is used (e.g., samples with greater than 50 percent passers; Hunter \& Schmidt, 2004), but rather that applicant attitudes and responses to recruiting tactics do not significantly differ from the job offer they take compared to the offers they pass. While most recruiting theories describe how positive applicant attitudes towards organizations should result in the choice of a given job offer over alternatives, research indicates that processes underlying a choice differ from those underlying a rejection (Shafir, 1993). As such, the current state of the recruitment literature leaves one unable to determine if certain applicant attitudes explain which jobs will be taken or whether they indicate which jobs will be passed. Using job choice decisions from up to four different recruiting organizations allows for the comparison of intercepts and slopes of applicant attitudes toward organizations whose offers are taken or passed (Kammeyer-Muller et al., 2005). That is, comparing these two "groups" over time (albeit nested within applicants to account for non-independence) will allow this study to determine if differences in applicant attitudes expected to distinguish between takers and passers manifest themselves initially, result in negative changes in applicants that ultimately pass on offers, result in positive changes in applicants that ultimately accepted offers, or some combination of the three. 
Finally, this study will investigate the nature of the relationship between proposed mediating applicant attitudes toward the organization (i.e., organizational attraction and acceptance intentions) and taking or passing on job offers. While Chapman et al.'s (2005) meta-analytic path model indicates that attraction is often partially mediated by acceptance intentions when predicating job choice (referred to as the attitude mediated model), the temporal ordering was based purely on statistical grounds. Even in their best fitting model, Chapman et al. found the relationships to be quite modest. These modest findings could be the result of applicants not getting offers (attenuating observed relationships), assessing applicant attraction and intentions too early (thereby being unable to account for meaningful changes that occur during the recruitment process), or that applicant attraction and acceptance intentions do not substantially discriminate between job takers and passers. This study proposes the processes by which organizational attraction and acceptance intentions attitudes develop over time as well as when and why they distinguish between job takers and job passers. Determining when the recruiting tactics of interest meaningfully predict a given dependent variable (i.e., job choice) is critical to both theoretical development and designs of future recruitment studies looking to measure both predictor and outcome variables (Mitchell \& James, 2001).

The remainder of the paper is structured as follows. First, recruitment literature is reviewed with focus given to the stages applicants progress through coupled with organizational efforts during the given stage of the recruitment process. Then, a review of decision making literature is provided and highlights how information about choice 
alternatives is distorted by individuals prior to making a decision. Using both of these literatures, hypotheses are then developed concerning how applicant perceptions of signals, organizational image, PO fit, attraction to the organization, and acceptance intentions are "built", and distorted, over the course of the recruitment process. A brief description of the sample, measures, and methodologies to be used for hypothesis testing is provided followed by formal tests of the study hypotheses. Finally, theoretical contributions, practical implications, limitations, and future research directions are discussed. 


\section{CHAPTER II}

\section{THEORETICAL DEVELOPMENT AND HYPOTHESES}

\section{REVIEW OF RECRUITMENT STAGES}

The attraction and hiring of high quality applicants is a critical element to the success and survival of organizations (Barber \& Roehling, 1993; Taylor \& Collins, 2000). Effective recruiting results in organizations ultimately bringing in a diverse set of employees with the knowledge, skills, and abilities required to perform the job (Chapman et al., 2005). As organizations' selection processes are contingent upon the number of quality applicants who apply to the organization (Ployhart, 2006), organizations that are better able to attract these desirable individuals, and do so as efficiently as possible, should develop a sustainable source of competitive advantage (Turban \& Greening, 1997). Conversely, organizations that are inefficient, or implement ineffective recruiting strategies, not only miss out on acquiring valuable human capital but also waste resources in the process. Therefore, it is critical to both researchers and practitioners to understand how applicants organize and process information that results in their attraction to, and choice to work for, organizations (Ehrhart \& Ziegert, 2005).

Researchers looking to summarize our current knowledge of the dynamic process of recruitment have utilized one of two primary frameworks. Barber (1998), as well as subsequent reviews (Dineen \& Soltis, 2010; Ma \& Allen, 2008), group research findings into three time-ordered stages of recruitment: generating suitable applicants, maintaining interest of applicants, and influencing job choice decisions. This organization of recruitment research lends itself the discussion of recruitment from an applicant 
perspective, as stages are distinguished by decisions applicants make throughout the recruitment process. Counter to this model, Breaugh and colleagues (Breaugh, 2008, Breaugh, Macan, \& Grambow, 2008; Breaugh \& Starke, 2000) synthesize prior research in a manner that facilitates the discussion of recruitment as a series of strategic organizational practices. Specifically, Breaugh and Starke (2000) outline the sequential decisions organizations have to make concerning recruitment including to outline recruitment objectives, develop recruitment strategies, choose recruiting activities and tactics, as well as to influence intervening process variables (i.e., applicant attraction) and evaluate results. That is not to say these two perspectives do not summarize the same research; they do. However, given the focus of this study is on applicant attitudes and perceptions of the organization, Barber's (1998) classification system, which accounts for both applicant and organization goals and motivations during the recruitment process (Ma \& Allen, 2009), is used to broadly review recruitment research efforts to date.

During the first stage of the recruitment process, organizations are looking to capture the attention of individuals in order to generate enough applicants to apply for available jobs (Barber, 1998; Ma \& Allen, 2004). To do so, organizations must set objectives concerning recruitment outcomes (e.g., applicant KSAs, time frame for filling positions, number of applicants; Breaugh, 2008) to help determine how wide a net they must cast to meet these goals while keeping costs to a minimum (Taylor \& Collins, 2000). In turn, organizations must decide on the content of the recruitment message, target population of the recruitment message, and method of recruitment message 
distribution, as all are factors that influence applicant intentions and actual decisions to apply for jobs (Dineen \& Soltis, 2010). Research on the content of recruitment messages during the applicant generation stage has been extremely diverse, with studies focusing on levels of realistic job information given to an individual by a friend (Phillips, 1998) to usability and aesthetics of organization websites (Cober, Brown, Keeping, \& Levy, 2004). While the majority of recruitment research uses attraction of graduating college students as the target population (Highhouse \& Hoffman, 2001), other studies have addressed more specific populations of applicants including minority/underrepresented groups (Avery \& McKay, 2006), bridge employees (part-time employees that have formally retired from long-term jobs; Adams \& Rau, 2004), and even from competitors in the focal organization's industry (Rao \& Drazin, 2002). Recruitment researchers (Breaugh, 2008; Dineen \& Soltis, 2010; Ma \& Allen, 2004) have investigated a host of methods organizations can use to bring job openings to the attention of individuals, including formal (e.g., newspaper ads, employment offices) and informal (e.g., referrals) methods as well as more technologically advanced methods (e.g., organizational websites, social networking sites, message boards). The role of applicants during this stage is simply to act as receivers of organizational recruitment activities and possibly activate intentions to apply (Barber \& Roehling 1993; Taylor \& Collins, 2000). As such, research during this stage focuses on how applicants process and encode the recruitment message (Larson \& Phillips, 2002; Taylor \& Giannantonio, 1993), which influences their choice to respond/apply. 
The second stage of recruitment, known as maintaining applicant status (Barber, 1998), begins when applicants decide to formally apply for the available job as organizations begin their selection process (Dineen \& Soltis, 2010). During this stage, organizations are looking to maintain the interest of applicants while still assessing and measuring KSAs necessary for the job (Barber, 1998; Rynes \& Cable, 2003). A key element for organizations during this stage is to assess applicant suitability while simultaneously avoiding unwanted withdrawal by applicants (Ma \& Allen, 2009; Ployhart, 2006). Organizations that mistreat applicants may find applicants self-selecting out of the process as applicants attend to perceived fairness of selection procedures as well as the characteristics of interactions with organizational representatives (Chapman et al., 2005; Dineen \& Soltis, 2010; Gilliland, 1993). This possible negative reaction by applicants occurs because during this stage, applicants are still gathering information about the job and organization to use when making a possible job choice (Ma \& Allen, 2009). The dual-nature of interactions during this stage has been recognized by researchers. Given the dual-role organizations hold during this stage, as well as applicant search for information and interpretation of contact with organizational representatives, researchers have tended to focus on the interview as the key element of this stage in recruitment. Research indicates that the level of interview structure as well as the proportion of recruiting relative to job-related questions asked during the interview can influence applicant attitudes toward organizations (Chapman \& Rowe, 2002; Chapman \& Zweig, 2005; Dineen \& Soltis, 2010). 
The final stage of recruitment begins when organizations have concluded their selection process and try to influence job choice which extends through to starting the actual job (Barber, 1998). Assuming suitable applicants were identified and remain interested in the job opening during the selection process, organizations will seek to persuade applicants they desire to accept their offer and put closure to the recruitment process (Dineen \& Soltis, 2010; Ma \& Allen, 20009). Clearly organizations are concerned about the number of quality applicants that accept job offers extended (Murphy, 1986); however, little research has been done on this stage of recruitment (Breaugh \& Stake, 2000). This is evident in the relative paucity of studies Chapman et al. (2005) identified that investigate job choice in addition to applicant attitudes. However, one aspect of this stage that has been repeatedly shown to influence job choice is timing of an offer. Specifically, lag time between final interviews and job offer extension has been shown to be negatively related to the likelihood of offer acceptance (Becker, Connolly, \& Slaughter, 2010). In fact, these delays may result in organizations losing out on the most sought after applicants (Rynes \& Cable, 2003), as delays will give them time to reconsider offers or receive offers from other organizations (Ma \& Allen, 2009). Another option for applicants that are unsatisfied or unsure whether they will accept or reject an offer is to continue to search for more information (Highhouse \& Hoffman, 2001). Subsequently, applicant site visits during this stage of recruitment have frequently been studied, as they are often the last chance for applicants to gather information before making their job choice (Boswell et al., 2003). Not surprisingly, site visits have been shown to have a significant impact on applicant job offer acceptance 
(Rynes et al., 1991), and these effects are even more pronounced for underrepresented or minority applicants (Breaugh, 2008; McKay \& Avery, 2006).

Whether focused on the recruitment process from an organizational (e.g., Breaugh, 2008) or applicant stand point (Dineen \& Soltis, 2010), researchers agree that the recruitment process concludes with applicants evaluating all job alternatives and choosing from acceptable alternatives. To facilitate this decision, applicants are constantly obtaining new information, integrating the new information with prior attitudes about the organizations, and updating preference ordering throughout the recruitment process (Murphy \& Tam, 2004). Researchers' explanations of how this information is assimilated by applicants when making job choices have relied on a variety of "decision" models, including Bayesian, compensatory, and minimum requirements (Mitchell, 1974; Murphy \& Tam, 2004; Osborn, 1990). However, results of empirical tests of these models have been scarce, with results being equivocal. These scattered studies led Ryan and Huth (2008) to note that studies "incorporating an understanding of the actively processing applicant should help us to see what information is considered, how it is weighted, and what effects it has on applicant perceptions" (p. 172). Thus, before describing the various applicant attitudes that have been shown to predict job choice decisions, a discussion of how information is assimilated and structured before individuals make decisions is necessary. 


\section{PREFERENCE DEVELOPMENT IN DECISION MAKING: ROLE OF}

\section{PREDECISION INFORMATION DISTORTION}

Decision making research is focused on how people combine their desires, values, and goals with their beliefs, knowledge, and expectations to choose a course of action (Hastie, 2001). When making a decision, individuals seek out information from both external (e.g., family, friends, environment) and internal (e.g., memory) sources (Weber \& Johnson, 2009). This information, whether objective or subjective, is used to form impressions of the overall value of each alternative set of actions or choices (Shah \& Oppenheimer, 2008). However, individuals' decisions, and the information that they are based on, are not always optimal. While humans are expected to accurately weigh information and make rational decisions, violations and biases in the decision making process have been shown to repeatedly affect individuals' choice amongst alternatives (Mellers, Schwartz, \& Cooke, 1998). Decision making researchers have shown that counter to stimulus sampling models, where information retrieval is expected to be randomly sampled and independent of the evaluation of a given alternative, individuals' choice in settings like recruiting are based on a biased, path dependent, information gathering processes (Weber \& Johnson, 2009). Yet, the extent to which decisions are biased or inefficient can be difficult to determine.

In management research, irrational decisions made by individuals are often investigated using a behavioral decision model (Moore \& Flynn, 2008), whereby actual decisions are compared to optimum decisions which are known. While this is an appropriate manner to assess accuracy of decisions, it is not useful when expected 
payouts are unknowable such as instances where individuals must make decisions between alternatives that do not have a "dominant" or optimum choice (i.e., decision between job alternatives). Thus, evaluating individual biases when developing preferences during the decision making process, which are subjective in nature and have no objectively correct answer, can only be compared to individual baseline (or previous) preferences (Weber \& Johnson, 2009). That is, when there is no way of knowing which is the "correct" preference, researchers used previous preference ratings (often assessed prior to the decision making task) to understand the extent to which preferences have been distorted or biased. The pattern of divergence in the attributed values of alternatives relative to the values given before the decisions making process begins is referred to as predecision information distortion (PDID).

Researchers have consistently shown that following decisions, individuals will distort information in favor of their choice relative to alternatives to reduce anxiety driven by cognitive dissonance (Elliot \& Devine, 1994; Festinger, 1957). While the pervasiveness of these confirmatory cognitions has been well established for some time (Nickerson, 1998), more recent studies have started to address the possibility that similar information distortion may occur prior to the decision. Decision makers' PDID, which has been labeled "the search for dominance structure" by Montgomery (1983), involves interpreting and assimilating information about alternatives in such a way that they are overly favorable to the alternative that is the early favorite or currently ahead while they are overly unfavorable to the lesser preferred alternatives (Brownstein, 2003; Russo, Carlson, \& Meloy, 2006; Russo, Meloy, \& Wilks, 2000). That is, decision makers often 
talk themselves into selecting the alternative that was the early favorite or out of the early trailing alternatives in order to proactively avoid possible dissonance between desired and actual choice (Russo et al., 2006). Thus, individuals will restructure information prior to choice to make one alternative appear to dominate all other alternatives (Montgomery, 1983). By distorting information before making a decision, individuals can incur numerous benefits including maintain notions that the world is predictable, receive ego support, use less effort, and finish quicker when going through the decision making process (Russo, Medvec, \& Meloy, 1996).

Russo et al. (1996) identified two sources by which individuals base PDID: preexisting preferences prior to the start of the decision making process and preferences derived from information received during the decision making process. In the model used in this paper, these two sources would be the intercepts and slopes, respectively, of applicant attitudes over time. Russo et al. (1996) serves as a useful example of a typical PDID study. In their study, Russo et al. had participants rate the favorability of five pieces of information about two fictitious restaurants and had to select one for a meal. There were two conditions of the study; one group of participants was told that one of the restaurant owners gave a free dinner to a charity raffle (an endowment; treatment) while the other group was not told of any ancillary factors about the restaurant (control). Following the treatment, participants were presented with a series of attributes (one at a time) about each of the two restaurants that was nondiagnostic (did not favor either alternative) and asked participants to rate how strongly the attribute favored one alternative. Any deviation from neutrality would indicate that identical information 
about two alternatives was illegitimately distorted by participants. Results indicated that attributes of the endowed option were rated higher, the distortion increased as more information was given, and that the endowed option was chosen by 24 of 26 participants. Results also indicated that when no endowment was provided (the control condition), the developing preferred alternative led to the distortion of new information. That is, the perceived diagnosticity of Attribute 1 led to the distortion of Attribute 2 in favor of the restaurant that was rated as having a more favorable Attribute 1. Results from subsequent studies indicate that attributes of the alternative that is eventually chosen may be more favorably rated initially and over time, thus becoming increasingly consistent with the eventual decision, while the preferences for the attributes of the soon to be rejected choice decrease over time (Simon, Krawczyk, \& Holyoak, 2004). In fact, the effect of PDID has been shown to be powerful enough to overcome the true value of the objectively superior alternative (Russo et al., 2006). Thus, Russo et al. (1996) and subsequent studies indicate that preferences develop via distortion of information, distortion is likely to increase over time, and direction of the distortion can be meaningfully predicted by initial attitudes or attitudes that develop early in the decision making process.

While conceptually similar to the notion of confirmation bias (Nickerson, 1998), PDID is used to describe individual preferences between alternatives rather than beliefs or desired outcomes that have already been decided on by individuals (Russo et al., 1996). However, the distortion of information to form preferences or attitudes of alternatives has been shown to be equally susceptible or even larger than information 
used to confirm choices (Montgomery et al., 1994; Russo et al., 1996). In fact, PDID and confirmatory processes may be reinforcing, as Simon et al. (2004) found that individuals making a single decision shifted attribute values of alternatives at the beginning of the decision-making process, prior to making the decision, and just after the decision was made. These findings are in line with Svenson's (1992; 1999) differentiationconsolidation theory, where individuals differentiate alternatives until a superior choice emerges, and continue to consolidate the chosen alternative's advantages shortly following the decision. Also, the influence of endowment, or the first piece of information in lieu of an endowed option, may lead one to erroneously assume PDID is equivalent to the primacy effect (or towards the end of the decision making process, recency effect). However, PDID differs from both primacy and recency effects because PDID influences values given to attributes, not the weighting of information about those attributes (Bond, Carlson, Meloy, Russo, \& Tanner, 2007; Russo et al., 2006). In terms of OLS regression, the primacy effect would represent an increase in the values of $\beta 1$ (or $\beta z$ in the case of the recency effect) while PDID would represent an actual increase (or decrease) in the observed predictor X.

Recent research has attempted to outline situations, or boundary conditions, where PDID will not occur, or where it is substantially reduced, in an effort to understand how pervasive this bias is for decision makers. Results, however, have not provided much indication that PDID can be curbed. One hypothesized way to reduce PDID was to reduce the number of alternatives, as individuals with fewer options would have less incentive to distort information. Yet, results from three different experiments 
(Bond et al., 2007) indicate individuals that knowingly have only one option still sought to generate a "dominance structure" by distorting information in the direction of the lone alternative. Even when put in a situation where individuals were merely asked which alternative "was winning the horse race" (to indicate that no choice was going to be made and preferences were not in a fixed order), subsequent information is still distorted to favor the preferred alternative (Russo, Meloy, \& Medvec, 1998). A third proposed method to reduce PDID was to alter the decision making context to reduce the demands of the decision task. This was done by increasing decision maker experience or asking decision makers to withhold judgment until all information had been presented. Yet even when the decision makers were experts (Russo et al., 2000) or instructions specifically asked individuals to reserve judgment (Carlson \& Russo, 2001), PDID was not eliminated. Thus, to date, researchers have been unable to prevent individuals from distorting information when evaluating alternatives prior to making a decision.

While PDID appears to be pervasive across a variety of decision making settings, individuals appear unaware PDID is occurring. In a sample of individuals that distorted information to favor the clearly inferior choice resulting in a majority $(62 \%)$ of study participants choosing the objectively inferior alternative, Russo et al. (2006) found correlations near 0 between level of information distortion and participant response to items assessing the extent to which participants perceived they were distorting information to conform to current beliefs. Perhaps the most critical finding of research on PDID was made by Simon et al. (2008), as results indicated that the change in attribute attractiveness of the preferred option were transient, with reductions in attribute 
attractiveness of the chosen alternative occurring as quickly as 15 minutes. While these results may not generalize to real world settings, or at least the speed in which attractiveness returns to baseline, presence of these "reality checks" may be driving the repeatedly observed "honeymoon-hangover effect" when studying new job entrants (Boswell, Boudreau, \& Tichy, 2005; Boswell, Shipp, Payne, \& Culbertson, 2009) or that realistic job previews during the recruitment process have such small effects on actual work outcomes (Phillips, 1998).

However, the trajectories of information and attitude distortion towards alternatives over the course of decision making process can take many forms. Individuals presented with new information about alternatives may overvalue information about the current favorite that will ultimately be chosen (positive slope over time), undervalue information about the lesser preferred alternative(s) that will ultimately be rejected (negative slope over time), or both (Simon et al., 2004). One possible determinate of the directionality of distortion may be individuals' ability to attribute the information to internal or external factors. Montgomery and colleagues (Montgomery, 1994; Montgomery \& Willen, 1999) note this possibility, as information regarding alternatives that is self-focused is expected to bring positive attributes of the promising alternative into focus, bolstering attitudes towards this alternative.

Conversely, information concerning alternatives that is externally focused is expected to bring negative attributes of the lesser alternatives into focus, denigrating attitudes towards these choices. These arguments are in line with tenets of attribution theory. Specifically, positive perceptions are more likely to be attributed to the individual in an 
act of self-enhancement (i.e., applicants perceived they fit with an organization) while negative perceptions are more likely to be attributed to external factors in an act of selfprotection (i.e., the applicant perceives the organization does not fit; Zuckerman, 1979). Thus, Brownstein (2003) concludes that "dominance structuring can then be seen as a process of taking an inside perspective on a promising alternative and an outside perspective on other alternatives" (p. 551) when spreading alternatives prior to making a choice.

Thus, PDID and subsequent attitudinal changes are expected to occur as applicants progress through the recruitment process, given distortion is likely to occur in situations with loose structure of information presentation (i.e., various recruitment tactics used by organizations) and low clarity of what constitutes a "successful" decision (i.e., applicants cannot be certain which is the optimum job; Russo et al., 1996). Furthermore, Brownstein (2003) outlined a number of other situational characteristics that increase the amount of PDID expected, many of which align with characteristics of the recruitment process. Those characteristics include having to make a decision amongst a number of alternatives with similar traits and expected payoffs, where evaluations can be kept private, and when the information provided is reasonable across alternatives. Also, the distortion of predecision information may occur in a positive or negative direction; in a manner that continues to favor the preferred (and ultimately chosen) alternative or to disparage the lesser preferred alternatives. Shafir (1993) notes that individuals will prefer an option (i.e. take an offer) for its relative advantages and reject an option for its disadvantages, and not vice versa, leading one to expect the slopes 
of the same attitude (i.e., PO fit) across organizations within applicants may be positive, negative, or both. Thus, it would appear likely that applicants improperly value information generated during recruitment, resulting in suboptimal or erroneous job choices at worst or making the right choice for the wrong reasons at best (Murphy \& Tam, 2004).

\section{SIGNALING: THEORY AND INFLUENCE ON APPLICANT ATTITUDES OVER}

TIME

While not ideal and divergent from rational models of decision making, individuals are often forced to make decisions with incomplete information about alternatives (Weber \& Johnson, 2009). According to Spence's signaling theory (1973), when making a decision under conditions of less than perfect information, individuals will make inferences about alternatives based on observable characteristics and attributes of each alternative. Simply put, signals are any observable characteristics attached to an alternative that is under the alternative's "control". Yet, the value and accuracy of signals are expected to vary, as signals may be more discriminant or important in some situations than others. Further, Spence (1973) is sure to note that signaling theory is not a static theory but rather consists of feedback loops, thereby allowing for assessments to be disconfirmed or reinforced by new information. As such, signaling theory aids researchers looking to explain recruitment, as applicants are forced to make decisions in a dynamic process with less than perfect information.

In the recruiting setting, signals serve to help reduce uncertainty of decision makers (i.e., applicants) as they have imperfect information and limited personal contact 
with organizational representatives (Barber, 1998; Breaugh \& Starke, 2000). Similar to employers hiring applicants based on imperfect information collected using various selection tools, "so also will applicants be imperfectly informed about the qualities of jobs and work environments" (p. 356; Spence, 1973). With an inability to gather complete information, applicants will attempt to interpret, process, and organize information they have about organizations, including recruiters, as signals of organizational characteristics (Ehrhart \& Ziegert, 2005; Rynes, 1991; Turban, 2001). This information can come from a variety of sources. Research has shown that applicants use organizational products and "brands" as a signal of organizational values as well as "personality” of organizations (Slaughter, Zicker, Highhouse, \& Mohr, 2004). Even the design of organization websites have been shown to serve as signals and influence applicant impressions of hiring organizations and subsequent attractiveness attitudes (Thompson, Braddy, \& Wuensch, 2008).

However, a majority of the research on signals has focused on specific characteristics or behaviors of recruiters, and the extent to which they account for applicant impressions and attitudes towards the organization (Connerley \& Rynes, 1997). In their seminal work, Rynes et al. (1991) found a number of recruitment experiences were interpreted by applicants as symbolic or emblematic of organizational characteristics that were related to, or under the direct control of, recruiters. As such, recruiter behaviors and attitudes are considered signals to applicants because they can be controlled and do vary. However, characteristics such as organization industry or size are actual characteristics of the organization and are known in signaling theory terms as 
indices (Spence, 1973), as they are not alterable (at least by recruiters). While indices are important influences on applicant job choices (Barber, Wesson, Roberson, \& Taylor, 1999), they do not require interpretation from applicants.

Early work on recruitment into organizations (Behling et al., 1968) noted that recruiters are critical contacts for applicants and that recruiter behavior would influence applicant job choice. More recently, researchers have argued that recruiters will impact the way applicants view and make inferences about organizational characteristics, as recruiters are representatives of the organization (Harn \& Thornton, 1985; Ma \& Allen, 2009). Recruiters serve as not only gatekeepers but also windows into important but unobservable organization-based characteristics such as professionalism, supervisory support, interpersonal relationships, and diversity climate (Bretz, Rynes, \& Gerhart, 1993; Cable \& Judge, 1996; McKay \& Avery, 2006; Rynes \& Miller, 1983). Recruiters that are unprepared, uninformative, or engage in other forms of "sloppy" recruiting practices may signal to applicants that the organizations they represent lack professionalism or are disinterested in the applicants who witness these behaviors (Barber \& Roehling, 1993; Breaugh \& Starke, 2000). But while signals given off by recruiters are expected to influence applicant attitudes and job choice, research regarding the effects of recruiter behaviors and characteristics were not always so optimistic.

Early research on the influence of signals given off by recruiters found weak effects or that effects diminished quickly after the start of the recruitment process. Rynes (1991) even noted that "recruiters probably do not have a large impact on actual job choices" (p. 413). This conclusion was based on results from a handful of studies 
that showed little if any influence of recruiters on job decisions. One of those studies (Rynes \& Miller, 1983) found recruiting behavior had the greatest impact as a tie breaker when job characteristics were neither attractive nor unattractive while another study (Taylor \& Bergmann, 1987) found that signals from recruiters predicted early applicant attitudes but did not add incremental predictive validity over job characteristics when predicting attitudes later in the recruitment process. Results showing a lack of improvement in predicting recruiting outcomes beyond job attributes confirmed those found in a prior study (Powell, 1984). However, Taylor and Bergmann's (1987) study was plagued with small samples ( $N$ 's of 23 to 37); including treatment at a site visit (a signal) resulted in non- and marginally-significant changes in $\mathrm{R}^{2}$ of .09 and .11 for intentions and attraction, respectively. Results of another study indicated slightly more positive results with recruiters having a strong indirect effect through how job attributes were seen, with a small direct effect on acceptance intentions (Harris \& Fink, 1987).

These findings, while not overwhelmingly supportive, highlighted what both practitioners and researchers suspected; recruiters, and more importantly the signals they give off, matter for recruitment outcomes. The consequences of poor recruiting were underscored in a later study that found that half of all respondents reported that recruiter behavior and attitude had a negative effect on applicant intentions (Boswell et al., 2003). However, faced with equivocal existing empirical results, researchers were charged with investigating why recruiter effects on recruiting outcomes were so weakly supported.

One possible explanation for modest results of recruiter influence on applicant attitudes and decisions was a ubiquitous lack of recruiter training. That is, recruiters 
were not very effective at recruiting, resulting in weak empirical results. A plethora of research exists indicating that training an individual on a given task is likely to increase their future performance of that task (for a full discussion see Arthur, Bennett, Edens, \& Bell, 2003). Initially, non-HR representatives that were given the job of recruiting new applicants were very unlikely to receive training, as recruiting was seen as a secondary task relative to their actual job (Rynes et al., 1991). However, training interventions focused on recruiter behaviors have subsequently been developed. These interventions should address recruiter interpersonal skills, procedural knowledge, attitudes, cognitive strategies, and motor skills (Connerley, 1997). Results indicated that after controlling for organizational characteristics, recruiter effectiveness was shown to improve as the number of hours of training and level of organization support increased (Connerley \& Rynes, 1997). Presumably stemming from these supportive results, a recent study found that the recruitment process is now being assessed, evaluated, and adjusted in most firms, both big and small (Barber et al., 1999).

Another fruitful line of research investigating the reasons for modest findings was (lack of) signal consistency (Spence, 1973). Like any form of extrapolation, interpreting signals about an organization based on limited information may be inaccurate (Chapman, Uggerslev, \& Webster, 2003). Research indicates that this is a possibility, as applicant perceptions of signals do not often correspond to what the recruiter might be sending, or applicants might be inferring different signals at different times from similar behaviors (Cable \& Judge, 1996). This may increase the amount of error in measuring signals and reduce the reported effect sizes of signal-recruiting 
outcome relationships. Furthermore, and keeping with the notion that recruiting can be developed into a sustainable competitive advantage, Cable and Judge (1996) showed that some organizations were able to send clearer signals than others.

Researchers also recognized that signals were not only a function of recruiters and their characteristics. Applicant characteristics also influence the effectiveness of recruiter signals on job choice decisions. One of the first characteristics explored was applicant work experience. Early research found the expected effect; more experienced applicants (i.e., more years of full-time employment) gave less weight or were less influenced by signals given off by recruiters (Goltz \& Giannantonio, 1995). Exploring the underlying processes of this finding, peripheral signals (i.e., professional appearance of recruiter) had greater influence on inexperienced applicants while experienced applicants were more likely to attend to, and be influenced by, the information delivered (Walker, Feild, Giles, \& Bernerth, 2008). Also, applicants who perceived they offer more value will use signals more discriminately (Harold \& Ployhart, 2008), while individuals with lower self-efficacy will be more influenced by signals (Larsen \& Phillips, 2002).

The progression of recruitment literature from Rynes' (1991) notion that recruiters have a limited role in influencing applicants is perhaps best seen in the results of a recent meta-analysis focused on recruitment. Chapman et al. (2005) found that recruiter behaviors had positive and generalizable effects across all recruitment outcomes. With true-score correlations between recruiter behaviors and outcomes of 29 for intentions and attraction as well as .10 (CI does not include zero; no CV reported) for 
job choice, the general conclusion one can draw from this meta-analysis is that signals from recruiters do in fact matter. It is also interesting to note the number of different signals that have been empirically assessed. While no study can address every signal, this study looks at two signals that have been discussed frequently in recruitment literature: timeliness and trustworthiness.

Timeliness of recruiters is characterized as responding and providing feedback in a prompt manner to applicants that depend on that information to make job choices (Becker et al., 2010; Rynes et al., 1991). Keeping with Spence's (1973) notion that signals are under the control of the alternative, timeliness "represents one of the few selection process variables that can be modified by organizations relatively easily" ( $\mathrm{p}$. 234, Becker et al., 2010). Applicants who experience delays during the recruitment process often infer they are not a favorite of the organization, that the organization is inefficient, or both (Rynes et al., 1991). Further, timely feedback may also be used by applicants to infer the level of procedural and interpersonal justice they can expect if they were to take a job at the organization (Gilliland, 1993). In fact, timeliness of recruiters may be one of the mechanisms driving the results of a more recent study that found the time lag between final interview and job offer was inversely related to likelihood of offer acceptance (Becker et al., 2010). Empirical results support this possibility, as delayed responses by organizations led to some applicants eliminating organizations from consideration of job choice; a result that was even more pronounced for sought after applicants (Rynes et al., 1991). Similarly, Boswell et al. (2003) found that one-third of their sample mentioned the lack of prompt follow-up or inability to 
keep the applicant informed was directly responsible for negative attitudes toward the organization. Finally, Chapman et al. (2005) found that timely response was highly predictive of attraction to an organization $(\rho=.46)$.

While timing of communications between applicants and recruiters has seen a bevy of research attention, empirical investigations concerning trustworthiness of recruiters have been sparse. This lack of attention is unfortunate given Rynes et al.'s (1991) explicit call for studies to investigate trust in recruiters, an element they recognized as critical following numerous interviews with applicants. Trust is defined as a psychological state of an individual's (i.e. applicant's) intention to accept vulnerability based on expectations of the intentions or behavior of another individual (i.e., recruiter; Rousseau, Sitkin, Burt, \& Camerer, 1998). Exchange relationships between applicants and recruiters that develop trust are expected to increase the level of confidence the applicants have that the recruiters, and subsequently the organization, can be relied upon to provide information and advice that serve the long-term interests of the applicants (Maurer, Howe, \& Lee, 1992). Also, honest two-way communication is expected to serve as a signal to applicants about the fairness and culture of justice in the organization (Gilliland, 1993). Empirical results indicate that trust in recruiters is used by applicants as a signal of broader organizational characteristics and violations of these role expectations may result in negative attitudes toward recruiters/organization (Dineen, Noe, \& Wang, 2004). In an interview setting, Schmitt and Coyle (1976) found the dimension of interviewer behavior that included trust positively correlated with all recruitment-focused dependent variables (i.e., acceptance intentions) used in the study. 
As would be expected, applicants who were suspicious of the motives and intentions of the recruiters were shown to reduce the amount of influence recruiters had on their job choices (Rynes et al., 1991).

While existing research on signals in the recruitment process have been supportive, few studies have investigated the dynamic impact they may have on applicant attitudes (Maurer et al., 1992). Signaling theory is dynamic (Spence, 1973), and studies investigating the effects of signals that serve, in part, as the grounds for taking or passing on a job offer must account for the process (Herriot, 2004). Even recent studies that have attempted to capture the effect of signals throughout the recruitment process have done so in simulated settings, where the researchers themselves question the generalizability of findings (Harold \& Ployhart, 2008). However, hypotheses are developed below concerning the expected changes in applicant perceptions of signals projected by recruiters during the recruitment process and how they will differentially function between organizations whose offer is passed and taken.

Recruiters are often the first, and possibly only, organization member the applicant meets. As such, recruiters transmit initial signals applicants use to make inferences about the organization (Cable \& Judge, 1996; Connerley, 1997; Goltz \& Giannantonion, 1995). As such, it would appear unlikely that during the applicant generation stage of the recruitment process, when interaction between applicant and formal organizational recruiters is unlikely (Barber, 1998), signals of timeliness or trustworthiness will meaningfully differ between taking and passing on a job offer from an organization. However, similar to the results of Russo et al. (1996) when individuals 
did not have access to information prior to the start of the decision-making process (no endowment condition), initial attitudes toward alternatives were not distorted but subsequent information was assessed based on the favorability of the first piece of information. That is, Russo et al. (1996) found when two alternatives did not have different starting points (i.e., no recruiter contact at the very start of the recruitment process), that PDID still occurred but that preference distortion occurred based on the favorability of the first piece of information (i.e., signal from recruiter). Boswell et al. (2003) address the point that while recruiter signals may not be predictive of job choice at the very start of recruiting, "recruiting experiences are likely to become more salient as individuals progress through the process and begin to make inferences about organizational characteristics based on their experiences" (p. 25). In this study, experiences during the recruitment process, such as delays or behaviors seen as untrustworthy, are expected to be perceived by applicants as objectionable and "spillover" to future attitudes and perceptions of the recruitment process (Schmit \& Ryan, 1997).

Yet, changes in applicant perceptions of recruiter signals are expected to exhibit a specific differential pattern for organizations whose offer is taken or passed. Specifically, while perceptions of timeliness and trustworthiness of recruiters are expected to remain relatively stable across the recruitment process for the preferred alternative, a negative trajectory over time is expected to develop for the two signals from organizations whose offer is passed on by applicants. The possibility of each of these expected trajectories is mentioned in two seminal works in signaling theory. 
Spence (1973) notes that attitudes (i.e., perceptions of signals) are expected to remain relatively stable or reach an equilibrium when "a set of beliefs is confirmed or at least not contradicted by the new data" (p. 368) whereas Rynes et al. (1991) comment that "core processing often sets in when organizations least desire it-that is, after a very negative recruitment experience" (p.515). Recruiter behaviors often become more salient and are weighed more heavily when violations or objectionable recruitment practices occur (Gilliland, 1993), and that after a certain level of incongruence is reached, applicants are expected to withdraw or pass on a job offer (Herriot, 2004). When external factors are the source of attributions, specifically organizational representativebased signals of timeliness or trustworthiness, evaluations are not likely to be internalized by individuals in order to maintain self-perceptions and therefore relied on to eliminate alternatives (Bauer, Maertz, Dolen, \& Campion, 1998; Montgomery, 1994; Ployhart, Ehrhart, \& Hayes, 2005; Weiner, 1985).

Making a similar argument, Boswell et al. (2003) argue and find support for the notion that recruiters "may play a greater role in decisions to reject an organization than in decisions to accept an organization" and that a "positive recruitment experience may be a necessary, but not sufficient, reason for job-offer acceptance" (p. 25). Support for this argument was found in a recent simulation, where timeliness of recruiter treatment influenced applicant attitudes in subsequent stages of the "process" and that delays were harder to recover from (i.e., required more instances of positive treatment; Saks \& Uggerslev, 2010). Therefore, applicants are expected to use signals of timeliness and trustworthiness throughout the duration of the recruitment process to discriminate 
between taking and passing on offers. However, spreading perceptions of signals about alternatives will occur by applicants focusing on negative (organizational-focused) attributes of the not chosen alternatives (Chapman \& Webster, 2006; Janis \& Mann, 1977). As applicants progress through the recruitment process, their perceptions of timeliness and trustworthiness are expected to become progressively more negative for organizations whose offers are passed on by applicants. Thus:

Hypothesis 1a: Applicant perceptions of recruiter timeliness whose offer they pass on will decrease over time.

Hypothesis 1b: Applicant perceptions of recruiter trustworthiness whose offer they pass on will decrease over time.

\section{IMAGE: REVIEW OF RESEARCH AND ITS INFLUENCE ON APPLICANT}

\section{ATTITUDES OVER TIME}

Over the last three decades, a stream of recruitment research has developed focusing on how applicant impressions of an organization influence their attraction to, and choice of, a given organization (Collins 2007; Dineen \& Soltis, 2010). The underlying idea of this research is applicants are expected to be more attracted to and likely to take a job from organizations they view positively (Turban, Campion, \& Eyring, 1995). Recent studies have broadened this general idea and incorporated marketing research concerning brand-equity to provide a more theoretical rational for why organizational image influences applicant reactions. Specifically, a favorable image held in customers' (i.e., applicants') minds about a product (i.e., a given organization) 
will increase the likelihood they will choose (i.e., take a job with) a given product (Collins \& Han, 2004; Collins \& Stevens, 2002).

Two seminal works on organizational image and recruiting serve as a baseline for most of the subsequent research. First, Belt and Paolillo (1982) investigated how corporate images of organizations influenced applicant attention, interest, desire, and intentions beyond applicant qualifications. While this study was the first to address image in a recruitment setting, it only addressed one type of recruitment practice (newspaper job advertisements), in one industry (fast-food), using lab participants. Over a decade later Gatewood, Gowan, and Lautenschlager (1993) built on Belt and Paolillo's study and noted that applicant evaluations of organizations may come from more than just one type of recruitment or information source. Also, they suggested that these organizational "general impressions", or images, were malleable and that organizations could actively change these applicant attitudes and affect responses to recruitment efforts.

While these early studies defined organizational image as applicant beliefs about a specific set of organizational attributes (Belt \& Paolillo, 1982) or general reaction towards organizations (Gatewood et al., 1993), more recent works have provided a more focused conceptualization of organizational image in the recruitment setting. In this manuscript, Collins and Stevens' (2002) definition of employer brand image, or simply image, of "potential applicants' attitudes and perceived attributes about the job or organization" (p. 1122) is used. It is also important to note that the terms image and reputation have been used interchangeably in recruitment research (Highhouse, 
Broadfoot, Yugo, \& Devenorf, 2009). In this study, the term image is used throughout the manuscript for two reasons. First, image appears to be term most frequently used to describe applicant attitudes and perceived attributes about an organization, as indicated by the use of “image" in Chapman et al.'s (2005) quantitative summary of the recruitment literature. Second, Highhouse et al. (2009) note that image is an "immediate and transparent impression" that "exists in people's minds" (p. 783). As decisions about employment (individual-level dependent variable) are the main focus of recruitment research, one should use individual-level constructs to measure mental associations about the organization (Brown, Dacin, Pratt, \& Whetten, 2006). Thus, the term image is used throughout the manuscript.

One of the first questions proposed in image research was how applicants form impressions of organizational image (Gatewood et al., 1993; Turban, Forret, \& Hendrickson, 1998). Results of these early studies indicate that one of the most prominent predictors of image perceptions is applicant familiarity with the organization. Even Gatewood et al.'s (1993) seminal work noted that image ratings were most strongly related to applicant exposure to the organization. This process is consistent with early psychology research (Zajonc, 1968) which indicates that repeated interaction, or “mere exposure", with an object should increase individuals' positive evaluations of the given object. This finding has repeatedly been shown in recruitment research, as applicants that are more familiar with an organization generally perceive that organization to have a more positive image (Cable \& Graham, 2000; Turban, 2000; Turban, Lau, Ngo, Chow, \& Si, 2001). When Highhouse and colleagues (Highhouse, 
Zicker, Thorsteinson, Stierwalt, \& Salughter, 1999) conducted a study that identified a variety of different factors that applicants used to discriminate between organizations and predict image, they were only able to use organizations that were "well-known" by all participants. Even when familiarity with an organization was shown to increase applicant knowledge about both positive and negative attributes about organizations, familiarity was still shown to results in a net positive effect on image perceptions (Brooks, Highhouse, Russell, \& Mohr, 2003). However, other elements of the organization have also been used to predict positive image perceptions including their diversity initiatives, progressive labor practices, environmental policies, and social performance (Aiman-Smith, Bauer, \& Cable, 2001; Albinger \& Freeman, 2000; Avery \& McKay, 2006; Richey, Bernardin, Tyler, \& McKinner, 2001).

Another series of questions involves why organizational image is expected to influence applicants and subsequent recruiting outcomes. From a practical sense, image is developed early in the recruitment process, or before recruiting even starts (Collins \& Han, 2004). Given that recruitment decisions made by both organizations and applicants are sequential, initial attitudes about the organization will be influential, at a minimum, to the extent initial attitudes affect the pruning of alternatives (Collins \& Stevens, 2002; Turban, 2001). That is, the sequential dependence of staffing an organization leads to early information and attitudes being influential for the remainder of the process, if only because of applicants initial decisions to select-out were made due to factors such as image (Carlson \& Connerley, 2003). From a theoretical standpoint, and related to the prior discussion about awareness, the image applicants hold about a given organization 
allow applicants to link information and knowledge gained through the rest of the recruitment process to the organization and influence how applicants respond to various other recruitment tactics (Collins \& Stevens, 2002). For instance, recruiters may ask the same questions to applicants (i.e., about qualifications for a job) with applicants perceiving organizations with positive images are being selective while firms with negative images are seen as invasive (Turban et al., 1998). Explanations for this process have centered around two theories (Aiman-Smith et al., 2001; Turban, 2001; Turban et al., 1995): social identity theory and signaling theory.

Social identity theory (Ashforth \& Mael, 1989; Dutton, Dukerich, \& Harquail, 1994) argues that individuals' self-concept and -worth are derived and influenced, in part, by the characteristics of groups in which they are members. In the recruitment setting, organizations with positive images are perceived by applicants to allow for more positive, or maintenance of, self-concepts if they were to take a job with that organization (Turban et al., 1995). Inversely, identification with organizations that have negative images, perhaps due to reports of poor social performance or layoffs (Kammeyer-Mueller \& Liao, 2006; Turban \& Greening, 1997), may be seen by potential future employees as a threat to their self-image. These effects are expected to be particularly strong in the recruitment process, as the choice to identify with a group is volitional for applicants (Cable \& Graham, 2000). By accepting employment, applicants are accepting the attributes of the job as well as the attributes of, and identifying with, the organization (Lemmink, Schuijf, \& Streukens, 2003). That is, applicants will be able to garner positive self-worth perceptions by choosing to work for an employer with a 
positive image (Turban, 2001). The possible positive self-worth derived from taking a job with an organization with a positive image may be one reason why Chapman et al. (2005) found stronger effects for image relative to job characteristics, as images are seen by outsiders as well as insiders (Brown et al., 2006) whereas job characteristics might not.

Applicant perceptions of organizational image may also be used as a signal regarding organizational characteristics. According to signaling theory, organizational image may serve as an indicator to applicants about the quality of the employment opportunity (Cable \& Turban, 2003). Specifically, image may be used as a source of information, especially early in the recruiting process when information is scarce, about the working conditions and culture of the organization. Furthermore, applicants have been shown to make trait inferences, stemming from organizational image, about both the organization and job (Lievens \& Highhouse, 2003). That is, applicants may use organizational image to make inferences and predictions about their future self-worth as well as the working conditions and culture within the organization if they take the job.

As with any business practice, researchers have investigated the effects of image in recruiting on the bottom line. First, image affects applicant pool characteristics in such a way that positive images attract higher quality applicants because applicants will infer that those organizations are highly selective and higher quality applicants are more likely to invest their limited time and resources in perusing the job (Turban \& Cable, 2003; Turban et al., 1995). As a result, organizations with more positive images not only attract more applicants to select from (Turban et al., 1995) but also higher quality 
applicants. Furthermore, job seekers have been shown to be more willing to take lower salaries, or "pay a premium", to work for organizations they perceive to have positive images (Cable \& Turban, 2003). Conversely, having a negative image may result in organizations being less efficient, less effective, or both when recruiting applicants. Negative images may increase the likelihood that quality applicants will pass on the offer, and thereby increase costs of recruiting and wages need to entice applicants to take an offer (Kammeyer-Mueller \& Liao, 2006).

Given the possible rewards and consequences faced by organizations with positive and negative images, understanding how organizations can foster a positive image in applicant minds is critical. Research has shown that organizations can, and do, influence applicant perceptions of image by tailoring aspects of their recruitment materials, or the variety of materials, to raise awareness and emphasize positive attributes such as industry prestige, development opportunities, or favorability as an employer (Cable \& Graham, 2000). Relatedly, a sub-group of studies has addressed how organizations can manage their image in such a way that they attract under-represented minority groups to increase the diversity of their workforce (Avery \& McKay, 2006; Perkins, Thomas, \& Taylor, 2000). However, organizations will want to be judicious in their attempts to influence applicant perceptions of image. Favorable, yet inaccurate, perceptions of image stemming from organizational attempts to positively influence applicant image perceptions may lead to reduced satisfaction and increased turnover in applicants shortly after starting employment (Cable, Aiman-Smith, Mulvey, \& Edwards, 2000). 
Beyond highlighting certain practices or aspects of the organization, there are a number of recruitment strategies or methods by which organizations can affect, both positively and negatively, the image perceptions applicants have towards the organization. One set of activities that has been thoroughly investigated by Collins and colleagues (Collins 2007; Collins \& Han, 2004; Collins \& Stevens, 2002) and broadly referred to as "early recruitment-related activities" include advertisements, sponsorships, word-of-mouth endorsements, and publicity. While they found that higher levels of each of these tactics improved applicants perceived image of the organization, they also discovered that many of these tactics work in conjunction with one another to further increase applicant attitudes toward the organization. Also, Collins and Han (2004) found that use of these early recruitment activities interacted with later recruitment activities, resulting in higher applicant pool quantity and quality.

While numerous studies have coalesced around the importance of image to applicants, objective measures of image are often used instead of actually assessing applicant attitudes. Fortune, Business Week, Working Mother, and The 100 Best Companies to Work for in America have all been coded and used to "objectively" measure the image of organizations (Cable \& Graham, 2000; Gatewood et al., 1993; Turban \& Cable, 2003). However, the use of objective measures implies that image perceptions are consistent across all individuals, ignoring the diverse group of possible stakeholders and their possibly divergent attitudes towards the organization (Cable \& Graham, 2000). Applicants evaluating an organization's image are expected to focus on (or be unaware of) other aspects of the organization than investors and therefore are 
likely to hold different perceptions of image (Lemmink et al., 2003). For instance, Fortune ratings are primarily influenced by financial performance rankings, while ratings focused on recruitment are influenced by other aspects of organizational performance (i.e., products produced; Highhouse et al., 2009). That is not to say that these "objective" ratings of image do not influence applicants, because research suggests they do. Cable and Graham (2000) used Fortune ratings and found that financial performance aspect of image was a strong image-based predictor of applicant job choice. Also, it is not surprising that "objective" measures of image have been shown to converge with image ratings made by actual applicants (Cable \& Turban, 2003; Gatewood et al., 1993). Yet, as mentioned above, applicant decisions about employment are the main focus of this study, making individual-based measurements of image most appropriate (Brown et al., 2006). In summation, while applicant perceptions of organizational image are used in this study, research findings indicate that efforts to attain high positions on lists of "best places to work" can be worth the effort (Allen, Mahto, \& Otondo, 2007).

Chapman et al. (2005) summarized the overall effect of organization image on recruiting outcomes, reporting correlations between image and recruitment outcomes of organization attraction $(\rho=.48)$ and acceptance intentions $(\rho=.41)$ that were substantial. Further, the effects of image have been repeatedly shown to predict outcomes such as attractiveness and intentions beyond job information and may be more instrumental for recruiting outcomes than job characteristics (Allen et al., 2007; Belt \& 
Paolillo, 1982; Cable \& Turban 2003; Collins, 2007; Lievens \& Highhouse, 2003). Yet, given these unequivocal results, questions concerning organization image still persist. Existing research has primarily used between-applicant study designs, as few studies investigate situations where applicants have to make image evaluations about more than one organization (Collins \& Stevens, 2002). Also, these studies are frequently static in design. Sparse longitudinal research limits the conclusions one can draw about the dynamic influence of image (Lemmink et al., 2003). Thus, researchers still need a better understanding of the psychological processes underlying how applicants construct judgments and perceptions of organizational image (Brooks et al., 2003). To date, researchers have been unable to match the complexities of how image influences the decision making process of recruitment (Collins, 2007) without using policy capturing designs or lab settings (e.g., Kanar, Collins, \& Bell, 2010; Saks \& Uggerslev, 2010). Below, arguments and subsequent hypotheses are developed that begin to address questions of how image influences applicants throughout the recruitment process.

Organizational image has been shown to be positively related to attraction to the organization (Turban et al., 1998). Existing studies on image (e.g., Collins \& Stevens, 2002) often look at initial image perceptions and results indicate that image perceptions at the start of the recruitment process predict applicant decisions to take or pass on an offer. In PDID terminology, applicant initial image perceptions may function as an endowment, with positive images influencing preferences before recruiting information is reviewed. Russo et al. (1996) indicated that choice between alternatives was influenced not only by information provided (that was shown to be distorted), but also 
the alternative that had a more positive attribute (i.e., image) than other options at the start of information gathering. Further, Simon et al. (2004) found that individuals shifted attribute values initially as well as prior to making the decision. Positive perceptions of organizational image have been shown to develop independent of recruitment-specific activities (Turban et al., 1998; Zajonc, 1968) and are therefore expected to meaningfully initially differ between offers applicants pass on and those they take. Thus:

Hypothesis 2: Applicant initial image perceptions of the organization they take an offer from will be higher than initial image perceptions of organizations whose offer they pass.

Applicant perceptions of organizational image are not only expected to meaningfully differ between takers and passers initial, but also over the course of the recruitment process. Original perceptions of image are expected to be the basis through which applicants seek out, encode, and interpret future indicators of image (Collins \& Han, 2004). Yet, image perceptions are expected to increase over time for the organization applicants take a job with while image perceptions are expected to decrease over time for the organization whose offers were passed on by applicants. This spreading in opposite directions of applicant perceptions of image is expected as image has been shown to affect applicants though both self-focused (social identity) and organizationfocused (signaling characteristics) attributions (Cable \& Turban, 2003; Lievens \& Highhouse, 2003; Turban et al., 1995). Information gathered over time about an initial favorite should be used to bolster applicant perceptions of that organization's image to maximize the self-worth perceptions that can be generated when they take the job. 
Inversely, information gathered about initially lesser alternatives will be perceived to confirm early impressions that those organizations provide less desirable work settings. Indirect support for this was shown in Saks and Uggerslev's (2010) simulation study, where new information, both positive and negative, influenced applicant perceptions of image over the duration of the "simulated" recruitment process. Over the course of the recruitment process, the changes in applicant perceptions of organizational images are expected to be "largely about confirming and rationalizing those early judgments" (p. 1700; Allen et al., 2007), both positive and negative. Therefore:

Hypothesis 3a: Applicant image perceptions of the organization they take an offer from will increase over time.

Hypothesis 3b: Applicant image perceptions of the organizations whose offer applicants pass will decrease over time.

\section{PO FIT: ROLE IN RECRUITMENT AND INFLUENCE ON APPLICANT}

\section{ATTITUDES OVER TIME}

Over the last two decades, researchers have feverishly studied the antecedents, dimensionality, and outcomes of individuals' fit across various work contexts (Edwards, 2008). While scholars have theorized about the role of congruence between individuals and the environment for nearly 100 years (Kristof-Brown, Zimmerman, \& Johnson, 2005; Parsons, 1909), fit remained an "elusive" construct for the better part of a century (Judge \& Ferris, 1992). Generally speaking, person-environment (PE) fit is the (in)compatibility between individuals and their work environment when their characteristics are (mis)matched (Edwards, 2008; Kristof, 1996; Kristof-Brown et al., 
2005). Early theorizing by Lewin (1935) put forth the notion that behavior in a given setting was the function of the person and the environment. More recently, researchers have begun to break PE fit down into smaller, distinguishable dimensions. Specifically, the person element of fit remains consistent while the congruent "environment" has varied. Researchers have argued and found empirical support for multiple levels of the environment in which individuals can be congruent with, including the organization, job, vocation, supervisor, and work group (Cable \& DeRue, 2002; Kristof-Brown, 2000; Kristof-Brown et al., 2005). In this study, the focus is specifically on personorganization (PO) fit (justification for this decision is given below).

PO fit is defined by Kristof (1996) as "the compatibility between people and organizations that occurs when (a) at least one entity provides what the other needs, or (b) they share similar fundamental characteristics, or (c) both" (p. 4-5). Much of the PO fit literature, especially research focused on recruitment (Edwards, 2008), is grounded in Schneider's (1987) attraction-selection-attrition (ASA) model. The ASA model contends that people are attracted to, selected by, and remain with organizations that hold similar values or goals. Thus, applicants are expected to be more attracted to organizations they believe have the same values and behavioral norms they feel are important (Bretz \& Judge, 1994; Chatman, 1989; O’Reilly, Chatman, \& Caldwell, 1991). Once hired, individuals in work environments that are more similar or congruent with their values, goals, or norms are expected to behave in a manner that ensures they are able to remain in the environment (Edward, 2008). Therefore, individuals that have high levels of PO fit are expected to be more productive, satisfied, committed, and remain at the 
organization for extended periods of time (Cable \& Judge, 1996; Kristof, 1996; KristofBrown et al., 2005).

Recently, a number of meta-analyses (Arthur, Bell, Doverspike, \& Villade, 2006; Kristof-Brown et al., 2005; Verquer, Beehr, \& Wagner, 2003) have investigated the extent to which PO fit influences work outcomes. Given that results between these three studies differ somewhat, findings from Kristof-Brown et al. (2005) are reported as it provides the most expansive, extensive, and detailed quantitative summarization of PO fit studies. Results support early hypotheses that positive short- and long-term outcomes for both employees and organizations result from high levels of PO fit (Bretz et al., 1993; Muchinsky \& Monahan, 1987). PO fit predicts a number of employee attitudes including organization satisfaction $(\rho=.65)$, organizational commitment $(\rho=.51)$, and job satisfaction $(\rho=.44)$. Behaviorally, results from Kristof-Brown et al. (2005) indicate that PO fit predicted employee task $(\rho=.13)$ and contextual performance $(\rho=.27)$, and these relationships are expected to generalize across all settings. As for withdrawal attitudes and behaviors, perceived PO fit significantly predicted intentions to quit ( $\rho=$ $.52)$, strain $(\rho=.34)$, and actual turnover $(\rho=-.16)$ across all settings.

Prior to discussing the role of PO fit in the context of recruiting, it is necessary to discuss the choice of PO fit as the focal fit construct in this manuscript. As stated above, researchers have begun highlighting a number of different types of fit including personsupervisor (PS), person-group (PG), and person-job (PJ) fit (Kristof-Brown, 2000). While all three alternative types of fit are critical to organizational research, they are less applicable in the recruitment setting than PO fit. Given that applicants are often 
interacting with recruiters, they may not have enough information about future supervisors (Kristof-Brown, 2000). Furthermore, applicants and possibly hiring organizations are unsure of which supervisor or group applicants would be assigned to if given the job, leaving both parties unable to make judgments of PS or PG fit during the recruitment process. PJ fit, while important for recruiting outcomes (Kristof-Brown et al., 2005), may be of less relevance in this study given that all applicants are applying for the same job (accounting intern) in a variety of different organizations. Also, existing research indicates that applicants put more emphasis on PO, rather than PJ fit, when making job choice decisions (Cable \& Judge, 1996).

Just as it is critical to identify the focal "type" of fit in a study, it is necessary to identify and justify the type of PO fit used in this study. Specifically, this study will investigate the perceived supplementary PO fit of applicants during the duration of the dynamic recruitment process. Two parts of this construct require further discussion. First, the term perceived fit is used when a single individual makes a direct or holistic assessment of one's compatibility between P and O jointly (Cable \& DeRue, 2002; Kristof, 1996). This is distinguished from subjective and objective fit, where $\mathrm{P}$ and $\mathrm{O}$ would be rated independently, by either one source or different sources, respectively (Kristof-Brown et al., 2005). Perceived fit was chosen for this study because it allows individuals the greatest level of cognitive manipulation to determine the importance of various dimensions when making ratings; something that is critical when fit perceptions are based on limited information (Kristof, 1996; Kristof-Brown et al., 2005). While perceived, or molar, assessments of PO fit may be more affect laden then alternative 
operationalizations of PO fit, it appears to be the most proximal predictor of outcomes in recent models of fit (Edwards, Cable, Williamson, Lambert, \& Shipp, 2006). That is not to say that subjective or objective PO fit are trivial in the recruitment settings. Research indicates that applicant PO fit perceptions may develop from objective PO fit, but that the effect of objective PO fit is mediated by applicants perceived PO fit (Cable \& Judge, 1996; Dineen, Ash, \& Noe, 2002; Judge \& Cable, 1997). Simply put, research indicates that PO fit exists and influence job choice to the extent that applicants perceive it to exist (Kristof, 1996).

The second part of the perceived supplementary PO fit construct that requires further discussion is supplementary fit. Supplementary PO fit assess the similarity between the individual and organization whereas complementary PO fit is a mutually offsetting pattern of characteristics between the individual and organization (KristofBrown et al., 2005; Muchinsky \& Monahan, 1987). Also important to supplementary PO fit is the distinction of what type of overlap between individual and organization is being assessed. Studies have looked at cultural, personality, ethnic, or even age-based similarity between individuals and organizations and its practices to operationalize supplementary PO fit (Lievens, Decaesteker, Coetsier, \& Geirnaert, 2001; Ng \& Burke, 2005; Rau \& Adams, 2005; Turban et al., 2001). However, in this study, the congruence between individual and organizational values is the focus, as this is the most commonly studied form of supplementary fit and is expected to influence both applicant and recruiter behaviors (Chatman, 1989; Kristof-Brown, 2000). 
The recruitment process is expected to be heavily influence by PO fit as applicants are expected to be more attracted to, and subsequently more likely to take a job with, organizations whose values match their own personal values (Kristof, 1996; Schneider, 1987; Tom, 1971). During recruitment, applicants will seek out, and if given the opportunity, select into organizations that maximize their affect while avoiding those organizations where applicant values are not commiserate with organizational environments (Judge \& Bretz, 1992). Critical to this process is that applicants actually have some amount of information about the organization. Information about the organizational culture, either gathered independently by the applicant or provided by the organization via recruitment efforts, will help increase the accuracy and utility of applicant PO fit perceptions when making job choices (Judge \& Bretz, 1992; Kristof, 1996). Edwards (2008) discusses this specific point when noting the ASA model that expects applicants to be more attracted and more likely to take an offer from an organization requires applicants to first perceive or become aware of the organization. It would be difficult for an applicant to establish, and be influenced by, PO fit perceptions if they were oblivious to the organization or "O".

The information used to make PO fit perceptions comes from two sources: applicants seeking out information or organizations providing information. Applicants, or soon to be applicants, can gather this information through various methods of job search activities as well as career planning (Saks \& Ashforth, 2002). Saks and Ashforth (1997) found that applicants sought out recruitment advertisements, used college placement offices, or questioned a friend or relative that did not work at the organization 
to gather information necessary to make PO fit assessments. Rynes et al. (1991) found that applicants were able to identify organizations they had good and poor fit with based, in part, on the information they collected about organizational characteristics. A handful of studies have also highlighted a relatively new source of information available to applicants to aid in making PO fit assessment: organization websites. Specifically, applicants have been shown to use organization websites to gather information and get feedback about organizations in order to develop PO fit perceptions (Cober et al., 2004; Dineen et al., 2002; Dineen \& Noe, 2009).

Organizations are also active in providing applicants with information about their values to allow applicants to develop PO fit perceptions. For instance, organization choices about job advertisements, including the level of information specificity, have been shown to influence applicant PO fit perceptions (Roberson et al., 2005). Also, organizations can provide applicants with various types of realistic job previews to facilitate PO fit perceptions based on accurate information (Kristof-Brown, 2000; Phillips, 1998). Recruiters and interviewers may also attempt to provide applicants with information about organizational culture, as they are familiar with the culture. However, applicants do not usually have as detailed an understanding of organizational norms and values, and may question recruiters and interviewers to gather this information (Van Vianen, 2000). Not surprisingly, organizations also use this time to assess applicant fit, which has been shown to be highly predictive of hiring outcomes. Specifically, interviewer and recruiter perceived PO fit has been shown to be strongly correlated with 
intentions to hire $(\rho=.70)$ as well as extension of job offers $(\rho=.50$; Kristof-Brown et al., 2005).

That is not to say researchers have only focused on how organizational characteristics have influenced PO fit perceptions. A number of studies have investigated how applicants, the "P" in PO fit, influence PO fit perceptions and recruiting outcomes. Researchers have shown that applicant dispositions, specifically personality, influence their organizational cultural preference and their attraction to organizations that possess those cultures (Burke \& Deszca, 1982; Judge \& Cable, 1997). Further, applicant values of fairness, concern for others, and achievement have all been shown to influence the types of organizations they develop high PO fit perceptions towards, resulting in higher attraction (Bretz, Ash, \& Dreher, 1989; Judge \& Bretz, 1992). Finally, Kristof-Brown (2000) notes that applicants may be well served to do some form of self-analysis prior to the recruitment process to ensure they hold accurate self-focused information prior to assessing PO fit.

Included in the results of the meta-analysis conducted by Kristof-Brown et al. (2005) was a summarization of the relationship between PO fit and recruitment outcomes. Interestingly, a meta-analysis focused on recruitment, published the same year, also investigated these relationships (Chapman et al., 2005). Overall, both metaanalyses arrived at the same magnitude of relationship for PO fit and organizational attraction $(\rho=.46)$. However, only Kristof-Brown et al. broke these studies down by type of PO fit (as that was the focus of the meta-analysis) and results indicated that perceived PO fit-organizational attraction relationship was actually significantly stronger 
for perceived fit compared to indirect measures of PO fit $(\rho=.62$ to $\rho=.22$, respectively). Also, both meta-analyses discovered and analyzed studies that addressed the PO fit-job choice relationship. However, Kristof-Brown et al. uncovered more studies $(\mathrm{k}=4$ to $\mathrm{k}=3)$, with more participants $(\mathrm{n}=1829$ to $\mathrm{n}=118)$, and found a larger relationship ( $\rho=.24$ to $\rho=.18$ ) than Chapman et al., and reported credibility intervals that excluded zero, indicating generalizability of this relationship across all settings. It is important to note that the magnitude of the relationships between PO fit and job choice was the largest observed relationship between a predictor and job choice found by Chapman et al. (2005). Kristof-Brown et al. (2005) provides a succinct summary of these findings when they note "even during relatively brief preentry encounters, attitudes and decisions are strongly influenced by various types of fit" (p. 316). Given these results and those reported earlier, it appears the organizations that recruit effectively and identify applicants that perceive they are a good fit with the organization should not only be more successful when recruiting, but also increase employee attitudes, performance, and retention (Cable \& Judge, 1996; Kristof-Brown et al., 2005; McCulloch \& Turban, 2007).

It is clear from these results that applicant PO fit perceptions are critical aspects of the recruitment process. While these meta-analytic estimates of PO fit-recruitment outcome relationships are useful, they should serve as a starting point for new research rather than an impediment. To start, the PO fit-recruitment outcome relationships have not received nearly as much attention as other applicant attitudes or perceptions, evident by Chapman et al. (2005) identifying only 11 effect sizes across four outcomes. 
However, the need for more research on applicant PO fit perceptions stems from more than just the small number of replications of these effects. Specifically, fit perceptions are dynamic and to fully understand the impact they have on applicant job choice, they must be traced throughout the various stages of the recruitment process (Higgins $\&$ Judge, 2004). As such, longitudinal investigations that focus on the changes in applicant PO fit perceptions throughout the duration of the recruitment process and their effects on job decisions are needed (Harold \& Ployhart, 2008; Kristof-Brown et al., 2005).

Similar to the brand argument made above, applicants may have perceptions about organizations based solely on exposure to the organization before the recruitment process starts. Yet, perceptions of PO fit are distinguishable from organizational image, as image is an average, consistent perception across applicants whereas PO fit is the similarity between the values of a single applicant and the organization (Judge \& Cable, 1997; Slaughter \& Greguras, 2009). Research findings indicate that organizational characteristics visible in the applicant generation phase, such as those included in business press, corporate reports, organization websites, and job positing, influence applicant early PO fit perceptions (Braddy, Meade, Kroustalis, 2006; Dineen et al., 2002; Lievens et al., 2001). Providing support that PO fit will influence both positive and negative initial preferences, 100 percent of Rynes et al. (1991) sample indicated organizational characteristics were influential in developing initial good fit perceptions and 95 percent indicated organizational characteristics were influential in developing initial poor fit perceptions. That is, pre-recruitment information can be used to establish “early favorites" based on higher perceived levels of PO, thereby serving as an 
endowment (Russo et al., 1996). Recent research supports the notion that early PO fit perceptions may be meaningfully distinguished by ultimate job choice. Harold and Ployhart (2008) found that at the start of their simulated recruitment study, applicant PO fit perceptions significantly predicted recruiting outcome later in the study. Therefore, initial perceptions of PO fit are expected to be higher for the organization that applicants take an offer from relative to the offer they pass. Thus:

Hypothesis 4: Applicant initial PO fit perceptions of the organization they take an offer from will be higher than initial PO fit perceptions of organizations whose offer they pass.

Applicant initial PO fit perceptions should also influence how they subsequently evaluate information gathered throughout the recruitment process. Roberson et al. (2005) echo this argument, noting that initial fit perceptions generated from information found in a recruitment advertisement may serve as a starting point, or endowment, for future fit perceptions. Harold and Ployhart's (2008) study also support this assertion, as applicant fit perceptions influence attraction over the course of the recruitment process. These findings confirm prior research findings that PO fit became more predictive over time (Adkins, Russell, \& Werbel, 1994; Kristof, 1996; Resick, Baltes, \& Shantz, 2007) and arguments from PDID literature of spreading of alternatives as one progresses and collects more information in the decision making process (Svenson, 1992). However, as fit perceptions incorporate both self- and organization-focused evaluations, the trajectory of PO fit perceptions is expected to be positive for organizations whose job offers are taken and negative for organizations whose job offers are passed. Information gathering 
about the existing favorite should be distorted in such a way that applicants believe they are the source of fit or congruence, increasing the likelihood they will reinforce their self-concept upon selecting into the organization (Saks \& Ashforth, 1997; 2002). Conversely, information about less-preferred organizations should be distorted in the negative direction, as negative fit perceptions have been shown to be driven by “violations" that are organization-based (Dineen et al., 2002; Rynes et al., 1991).

Supporting evidence for this argument can be found in a recent study by Dineen and colleagues (2002). Controlling for objective fit, Dineen et al. (2002) found that information about fit in the form of feedback differentially functioned for high vs. low PO fit, such that individuals who were given positive PO fit feedback information became more attracted (positive trajectory) while those who received negative PO fit feedback information became less attracted (negative trajectory). These processes are expected to be the same when individuals go out and collect information to generate their own feedback about their PO fit. Specifically, applicants should continue to positively distort information about PO fit throughout the recruitment process for the organization they end up taking an offer with, while negatively distorting information about organization whose jobs offer they pass. Thus:

Hypothesis 5a: Applicant PO fit perceptions of the organization they take an offer from will increase over time.

Hypothesis 5b: Applicant PO fit perceptions of the organizations whose offer they pass will decrease over time. 


\section{ATTRACTION AND ACCEPTANCE INTENTIONS: DISTINGUISHING}

\section{ATTITUDES}

Theories seeking to explain individual behavior are almost as diverse and intricate as the behaviors they seek to explain. However, a select number of factors have been identified in a host of behavioral theories and have proven to be especially powerful predictors of individual behavior. Specifically, individual attitudes and behavioral intentions have been repeatedly shown to be strong predictors of actual performance of behaviors (Kim \& Hunter, 1993; Sheppard, Hartwick, \& Warshaw, 1988). In fact, attitudes and behavioral intentions serve as cornerstones for the dominant framework of attitude-behavior research (Olson \& Zanna, 1993), the theory of reasoned action (Ajzen \& Fishbein, 1980; Fishbein \& Ajzen, 1975). According to the theory of reasoned action, performance of a given behavior is determined, in part, by individual attitudes toward and intentions to perform a given behavior. As such, attitudes and intentions commonly serve as independent variables in studies looking to predict a given behavior or set of behaviors.

While broad in scope, attitudes towards a behavior according to the theory of reasoned action are defined as the degree to which an individual holds a positive or negative evaluation of performing a given behavior (Ajzen, 1991; Fishbein \& Ajzen, 1975). The extensive study of attitudinal influences on human behavior has highlighted a number of important outcomes of attitudes including biased interpretation and assimilation of attitude-relevant information as well as prediction of behavior (Olson \& Zanna, 1993). Yet, for any one given behavior, individuals may hold a number of 
different attitudes towards that behavior and it is the job of the researcher to identify the conceptually relevant, or thematically corresponding, attitude that best matches the behavior (Kim \& Hunter, 1993). Not surprisingly, research indicates that the level of correspondence between the attitude and behavior in question affects the strength of the relationship (Sheppard et al., 1988). That is, the higher the attitudinal relevance, or bandwidth, with the behavior, the stronger the relationship between the measured attitude and behavior observed. While the overall mean correlation for the attitudebehavior relationship has been shown to be large, $r=.79$, it a ranged from $r=.40$ for low-match situations to $r=.86$ for high-match situations, underscoring the importance of correspondence between the attitude and behavior in question (Kim \& Hunter, 1993).

However, according to the theory of reasoned action, the influence of attitudes on behaviors is not expected to be entirely direct. Most attitude-behavior theories, including the theory of reasoned action, posit that intentions mediate the attitude-behavior relationship (Bagozzi, 1981; Fishbein \& Ajzen, 1975). Behavioral intentions, or simply intentions, are assumed to capture the effort level an individual plans to exert to perform a given behavior (Ajzen, 1991). Assuming that the behavior is under the control of the individual, intentions to perform a certain behavior are the primary and immediate determinate of action (Sheppard et al., 1988). Identical to the results found for attitudebehavior relationships, the overall mean correlation between intentions and performing a behavior large $(r=.82)$. As would be expected by the theory of reasoned action (Ajzen \& Fishbein, 1980; Fishbein \& Ajzen, 1975), this proximal predictor was more strongly related to behavior than attitudes towards the behavior. However, this relationship also 
increased as the conceptual match between intentions and behavior type assessed increased, from $r=.62$ for low-match situations to $r=.94$ for high-match situations (Kim \& Hunter, 1993).

Studies addressing the relationship between attitudes and behavioral intentions have also been conducted, as it is a critical tenet of the theory of reasoned action (Ajzen \& Fishbein, 1980). Generally speaking, the more positive (negative) individual attitudes towards a behavior are, the stronger (weaker) their intentions to perform the behavior become (Ajzen, 1991). Meta-analytic evidence supports this idea, as the true-score correlation between attitudes and behavioral intentions was estimated to be .87 . This was the highest observed true-score correlation included in the study (Kim \& Hunter, 1993). This finding was expected, as the relationship between individual attitudes and behavioral intentions are less susceptible to uncontrollable external forces because they are both purely internal cognitions. As with the other two relationships discussed above, the attitude-intention relationship increased in strength as the conceptual match increased, from $r=.70$ for low-match situations to $r=.91$ for high-match situations.

Yet, bandwidth has not been the only factor shown to attenuate the relationships between attitudes, intentions, and observed behaviors. An increase in the length of time between measurement of attitudes or intentions and behavioral performance has been shown to reduce the correlations observed (Ajzen \& Fishbein, 1980). To maximize the accuracy of predicting behaviors with attitudes or intentions, these two cognitive factors must remain stable between the time they are assessed and when behaviors are observed (Ajzen, 1991). Without accounting for the temporal spacing of measurement and 
observation, the direction and magnitude of these relationships will be left somewhat in question (McBroom \& Reed, 1992). This is not lost on the developers of the theory of reasoned action. The fact that attitudes and intentions towards behaviors are often assessed when it is not possible for individuals to have the full information necessary to be completely confident in their attitudes and intentions is a noted limitation to the theory of reasoned action (Ajzen, 1985; Sheppard et al., 1988).

In the recruitment context, researchers have highlighted one attitude, attraction to the organization, and one intention, offer acceptance intention, that are expected to have the highest correspondence with, and be the most proximal predictors of, applicant job choice (Chapman et al., 2005). Organizational attractiveness is applicant attitudinal and affective evaluations of a given organization as a place of employment and is considered a critical cognition in recruitment (Highhouse, Lievens, \& Sinar, 2003; Roberson et al., 2005). Acceptance intentions assess applicant cognitions about pursuing and taking a job offer with a given organization (Highhouse et al., 2003). While related, these two are conceptually distinct as acceptance intentions have a more active connotation and imply future action rather than just thoughts about a given organization (Schreurs, Derous, De Witte, Proost, Andriessen, \& Glabeke, 2005). Furthermore, research in the recruitment setting support the theory of reasoned action, as attraction has been shown to influence applicant job choice and much of this effect is indirect through applicant intentions to take a job offer (Highhouse et al., 2003).

Results from Chapman et al. (2005) parallel a number of findings in Kim and Hunter's (1993) meta-analysis that addresses the interrelationships between attitudes, 
behavioral intentions, and performance of behaviors across a wide variety of settings. First, the high correlation between organizational attraction and acceptance intentions persisted in the recruitment setting $(\rho=.78)$ and was the largest observed correlation in the study. Second, the theoretically more proximal predictor of behavior, acceptance intentions, had a larger relationship with job choice $(\rho=.33)$ than organizational attraction-job choice relationship $(\rho=.19)$. Finally, meta-analytic path models supported the mediated relationships expected according to the theory of reasoned action. Thus, it appears that tenets of the theory of reasoned action are supported in the recruitment setting.

Given empirical data indicating high correlations between both attitudes and intentions with behavior in other settings (Kim \& Hunter, 1993), recruitment studies often assess organizational attraction and acceptance intentions rather than the more difficult to obtain behavioral outcome of job choice. That is, measures of applicant attraction to organizations and acceptance intentions are often used as surrogate assessments of job choice (Highhouse et al., 2003). While findings indicate that these attitudinal outcomes can result in large monetary differences between organizations recruiting from similar applicant pools (Connerley, Carlson, \& Mecham, 2003), attraction and acceptance intentions are costless exercises for applicants and are quite different than actual job choice (Rynes, 1991). Furthermore, organizational attraction and acceptance intentions must remain stable between the time they are assessed and when applicants make job choices to maximize the accuracy of predicting these behaviors (Ajzen, 1991). Yet, information is constantly gathered and processed by 
applicants throughout the recruitment process (Barber, 1998). Information gained by applicants in between assessments of attraction and acceptance intentions should affect applicant job choice decisions. As organizational attraction and acceptance intention measurements become more temporally separated from job choice, the less predictive they are expected to be (Powell \& Goulet, 1996). Thus, studies with real applicants that better capture the time-dependent processes of attitude-intention-behavior models are needed to better understand their interrelationships in the recruitment setting (Chapman \& Webster, 2006).

However, even in other settings, behavior could be modestly predicted by attitudes and intentions measured substantially earlier than the behaviors (Harrison, Newman, \& Roth, 2006; Schwartz, 1978). Given that organizational attraction and acceptance intentions have been predicted by information gathered before formal recruitment efforts begins (Gatewood et al., 1993; Roberson et al., 2005; Taylor \& Bergman, 1987), it is likely that applicants develop favorites at the start of recruitment (resulting in higher levels of attraction and acceptance intentions) whose offers they are more likely to take. In one of the few studies that addresses the development of organizational attraction and intentions over time, Chapman and Webster (2006) found early ratings of attraction and intentions, made prior to job interviews, influenced postinterview cognitions and subsequent job choices. In a study conducted a decade prior that focused on acceptance intentions, Powell and Goulet (1996) speculate that this may be the case as their "findings collectively suggest that applicants may form early impressions about jobs that are largely sustained as they proceed through campus 
interviews and make their eventual job choices" (p. 1634). Therefore, initial attitudes of organizational attraction and acceptance intentions should be higher for the organization that applicants take an offer from relative to the attraction and acceptance intentions for the organizations whose offer they pass.

Hypothesis 6a: Applicant initial attraction to the organization they take an offer from will be higher than initial attraction to organizations whose offer they pass. Hypothesis 6b: Applicant initial intentions to accept an offer from the organization they take an offer from will be higher than initial intentions to accept an offer from the organizations whose offer they pass.

Once formed, applicant attitudes and intentions are expected to distort subsequent evaluative responses and information processing when applicants encounter the object of the attitudes or intentions (i.e., the organization; Ajzen, 1985; Olson \& Zanna, 1993). Congruent with PDID research (Montgomery, 1983; Russo et al., 2006), applicant attraction and acceptance intentions should be influenced by earlier information in such a way that attraction and acceptance intentions of the favorite (lesser alternative) will increase (decrease) resulting in a dominant alternative to be chosen. So, as applicants gather and distort more information over the duration of the recruitment process (Barber, 1998; Ma \& Allen, 2008), they are expected to have increased confidence in their behavioral choices (i.e., take or pass on an offer) which should be reflected in assessments of their attraction and acceptance intentions (Soelberg, 1967). Furthermore, the closer applicants get to actually making job choice decisions, the less likely it is that external influences (that have been found to attenuate these relationships; 
Kim \& Hunter, 1993) will affect the expected relationship between both attraction and acceptance intentions and job choice. That is, measures of attraction and acceptance intentions are expected to better predict taking an offer as well as passing on an offer if they are assessed later in the recruitment period (Ajzen, 1991), closer to job choice decisions.

Yet, perceptions of attraction and acceptance intentions are expected to have positive and negative trajectories, for the favorite and lesser alternatives, respectively. Applicants have been shown to use information about themselves and the organization when determining their level of attraction or acceptance intentions during the recruitment process (Chapman \& Webster, 2006). Therefore, applicants might have increasing levels of attraction and acceptance intentions towards their initial favorite as their attention should focus on the positive aspects of their own attraction and believe intent to join the organization is under their control (Ajzen, 1991; Chapman \& Webster, 2006; Montgomery \& Willen, 1999; Soelberg, 1967). Conversely, applicants that assimilate information about lesser alternatives will be more likely to focus on attributes of the organization that are less attractive and reduce intentions to join an organization that is perceived as less desirable (Vroom, 1966). Indirect support for this pattern of divergence of applicant attraction and acceptance intentions was recently found, as intentions were positively related to subsequent job choice when positive initial information was provided by the organization whereas this relationship was negative when negative information was provided (Schreurs et al., 2009). Thus: 
Hypothesis 7a: Applicant attraction to the organization they take an offer from will increase over time.

Hypothesis 7b: Applicant attraction to the organizations whose offer they pass will decrease over time.

Hypothesis 8a: Applicant intentions to accept an offer from the organization they take an offer from will increase over time.

Hypothesis 8b: Applicant intentions to accept an offer from the organizations whose offer they pass will decrease over time. 


\section{CHAPTER III}

\section{RESEARCH METHODOLOGY}

\section{PARTICIPANTS AND PROCEDURES}

Participants in this study were undergraduate students enrolled in the Program for Professional Accountants (PPA). As a requirement for completing their degree program, all students must obtain an internship. The recruitment period began during the spring semester and concluded a month after the end of the spring semester. Recruiting of PPA students was rigorously controlled by the accounting department and thus provided a number of desirable characteristics for this study of recruiting over time. First, all students were provided an opportunity to be recruited and interviewed by each of the “Big 4” accounting firms (Ernst \& Young, Deloitte Touche Tohmatsu, KPMG, and PricewaterhouseCoopers). A previous study using an earlier cohort of PPA students found that all, or nearly all, PPA students interview with every Big 4 firms (Barrick, Swider, \& Stewart, 2010), which allowed for the assessment intra- and inter-applicant attitudes and perceptions towards the same set of organizations. Second, all interactions between Big 4 firms and recruits took place during specified time periods, thereby allowing for a standardized time frame in which to assess applicant attitudes. Finally, all Big 4 job offers were extended on the exact same day, 7 days after the final attitude survey was released, so concerns about recruits self-selecting out are greatly attenuated. Thus, when reporting their attitudes about a focal firm, applicants did not know whether they were eventually going to be given the opportunity to take a job with that firm. 
While this setting provides a number of benefits, it also presented a number of limitations. First, every applicant applied for similar jobs. While this fact decreases concerns about the confounding effect of job characteristics on the results, it may inflate the influence organizational-based factors, relative to job-based factors (e.g., PJ fit), had on job choices compared to samples with more heterogeneous sets of job and applicants. Second, all applicants applied for internships, not full-time positions. While recruiting studies have used internship-based samples in the past and 90 percent of internships for PPA students resulted in full-time offers in previous years, applicants in this setting were still making temporary job choices (e.g., Resick et al., 2007). Third, every applicant in this sample had to make job choices by a set deadline. While this time constraint is not unusual for recruitment studies using college job seekers (Barber, 1998), other applicant samples (i.e., unemployed job seekers) may not have as clearly defined deadlines for making their job choice but rather more general constraints on job choice timing (i.e., financial need). Finally, the sample included attitudes and perceptions about four large, prominent organizations in one industry. As prior studies have shown recruitment processes differ by industry and organization size (Barber et al., 1999), the results of this study may not generalize to other industries or smaller organizations.

The survey methodology was as follows. Each PPA student was required to enroll in a one credit hour course the spring semester of this study. The course is designed to provide PPA students with "practical" knowledge about the field of accounting. Students were surveyed on 6 separate occasions at the conclusion of class beginning mid-January until the conclusion of the semester. Two additional surveys 
were distributed online following the conclusion of the course but prior to the end of the recruitment process. This resulted in 8 waves of data collection. To encourage participation in the final two surveys, applicants that completed online surveys were entered into a raffle for one of five Apple iPad2s. Completion of each survey earned applicants one raffle entry, with competition of both online surveys earning a bonus entry, resulting in the maximum applicant entries of three.

Each of these surveys included a set of items (described below) to measure applicant attitudes about each of the Big 4 accounting firms. That is, while the items used were consistent across measures for each of the Big 4 firms, the referent was changed (i.e., "My personal values match KPMG's values and culture” was changed to “My personal values match Ernst \& Young’s values and culture”). Put simply, applicant attitudes about all 4 of the Big 4 accounting firms were assessed roughly every 3 weeks. The 3-week separation between observations was done for two reasons. Firstly, it did not force the participant to complete a lengthy survey on a weekly basis, which would have likely increased attrition rates. Secondly, giving 3 weeks between ratings of attitudes toward firms allows for changes in applicant attitudes, or the organization and the tactics used, to be distinguishable across observations (allowing variance at Level-1 to increase). Data on job offers made by Big 4 firms and job choices made by applicants were provided by the PPA program that objectively collects this data from Big 4 firms. Also, while demand and memory effects are a concern in any longitudinal study with numerous assessments (Mitchell \& James, 2001), concerns about the influence of these effects are substantially attenuated given the survey methodology. Length of time 
between measurements and the counter-balanced order of firm-specific survey items across assessments make recall of prior responses or pattered responding unlikely. Furthermore, as all assessments were collected prior to applicants receiving offers, it was not possible for applicants to distort responses based on their ultimate job choice decisions.

The total size of the sample used in this study was 207 as all 207 students enrolled in the PPA completed at least 1 survey. Complete job offer and decision data were collected by PPA administrators for 190 of the 207 applicants sampled (92\% response rate). Of the 190 students with complete job offer data, 178 received offers from at least one Big 4 firm and were thus included in the analyses. The final sample consisted of 426 Big 4 offers generated by the 178 applicants (average of 2.39 offers). The distribution of the number of offers per applicant was somewhat normal, with 20 applicants receiving offers from all four Big 4 firms, 71 receiving three offers, 46 receiving two offers, and 41 receiving one offer. Finally, a total of 3007 responses were collected at Level-1 for these 178 applicants. That is, for the 426 offers made by Big 4 firms, applicants reported their attitudes about each of these firms, on average, 7.06 times out of 8 possible opportunities ( $88 \%$ response rate).

\section{MEASURES}

Table A1 provides a detailed listing of the timing of measures used for this study. Note that motivation check, demographics, and qualifications are not firm specific so they were only assessed one time, at the start of the first wave of data collection 
Motivation Check. Applicant motivation was assessed with 3 items $(\alpha=.87)$. Items included "It is critical for me to obtain an internship this recruiting period," "I am motivated to get an internship this recruiting period," and "I am taking the recruitment process seriously". Response choices will range from 1 (strongly disagree) to 5 (strongly agree).

Preference Check. During the first wave of data collection, applicants were presented with a scenario that assesses the extent to which they held initial favorites at the start of the recruitment process. Each applicant was told they had 100 points to distribute among the Big 4 accounting firms and that the number of points allocated to each firm indicated their current preference for that firm as a future employer. Therefore, firms that were given more points were currently more preferred than firms given less points with possible point values for a firm ranging from 0 to 100 . Using this data, a measure of disparity, Gini coefficients were then calculated to assess the initial dominance of one or more Big 4 accounting firms over the others (Harrison \& Klein, 2007). Minimum disparity, indicating no initial preference, occurred when each firm was awarded 25 points while maximum disparity, indicating one dominate alternative, occurred when one firm was given all 100 points.

Demographics. Age, gender, and ethnicity were assessed with single items.

Qualifications. Applicant qualifications were assessed using GPA reported on applicant resumes.

The following scales were included on each of the 8 surveys. Each item was repeated 4 times, once for each Big 4 firm. However, all items for each organization 
appeared on a separate sheet of paper (or webpage for online surveys) to reduce the likelihood that participants would make errors when reporting their attitudes about a Big 4 firm.

Timeliness. Timeliness of formal recruiter responses to applicants was assessed using a 4-item measure developed to measure responsiveness in service industries ( $\alpha$ s between .90 and .98; Lam, 1997). Items included "Recruiters at the organization tell me when they will contact me," "I am given information promptly by recruiters at the organization," "Recruiters at the organization are always willing to help," and "At the organization, recruiters are never too busy to respond to my requests". Response choices ranged from 1 (strongly disagree) to 5 (strongly agree).

Trustworthiness. Trustworthiness of formal recruiters was measured using a 3item scale previously used to assess trustworthiness of recruiters ( $\alpha$ s between .73 and .97; Fisher, Ilgen, \& Hoyer, 1979). Interestingly, lower alphas occurred for later waves of data collection relative to initial measurements of trustworthiness. Items included "I feel recruiters at the organization are extremely trustworthy," "I believe the recruiters at the organization are telling me the truth as they see it," and "I feel the recruiters at the organization are not being honest with me (r)". Response choices ranged from 1 (strongly disagree) to 5 (strongly agree).

Organizational Image. Organizational image was measured using a 4-item scale ( $\alpha$ s between .93 and .98) from Collins (2007). Items included "I believe that other students in the school think highly of this company," "My friends have high regard for this company as an employer," "I believe that my friends hold a favorable impression of 
this company as a good employer," and "Other students in my school hold a favorable impression of this company as an employer". Response choices ranged from 1 (strongly disagree) to 5 (strongly agree).

PO Fit. PO fit was measured using 3-items ( $\alpha$ s between .96 and .99) from Cable and DeRue (2002). Items included "The things that I value in life are very similar to the things that the organization values," "My personal values match the organization's values and culture," and "The organization's values and culture provide a good fit with the things that I value in life." Response choices ranged from 1 (strongly disagree) to 5 (strongly agree).

Organizational Attraction. Attraction to the organization was assessed using a 4item scale ( $\alpha$ s between .90 and .98; Turban et al., 2001). Items included "I would exert a great deal of effort to work for this company," "I would like to work for this company," "I would choose this company as a top choice for an employer," and "I would find a job with this company attractive". Response choices ranged from 1 (strongly disagree) to 5 (strongly agree).

Acceptance Intentions. Acceptance intentions were measured using three items ( $\alpha$ s between .71 and .91) previously used to assess the likelihood applicants would accept a job offer if one was given (Harris \& Fink, 1987). Items included "If I was offered a job by the organization, I would accept it," "If I was offered a job at the organization, I would accept it immediately," and "I think it is likely that the organization will offer me a job”. Response choices ranged from 1 (strongly disagree) to 5 (strongly agree). 


\section{ANALYSIS STRATEGY}

As described above, this study addresses change in attitudes over time, which requires a growth modeling framework to be used for analyses. Growth modeling involves "looking at how individuals (or units, groups, organizations, etc.) change over time and whether there are differences in patterns of change" (p. 363; Bliese \& Ployhart, 2002). Data was analyzed using Hierarchical Linear Modeling (HLM; Raudenbush, Bryk, \& Congdon, 2000) for a number of reasons. First, the nested nature of the observations of attitudes towards the organization nested within organizations and organizations nested within applicants requires the use of multi-level modeling. Responses made by the same individual are expected to be correlated, which if unaccounted for, would violate assumptions of regression based statistical techniques (Kenny \& Judd, 1986). If one were not to use multi-level modeling, then the nonindependence of observations would inflate Type I error rates, thereby increasing the likelihood of finding spurious significant relationships (Bliese \& Hanges, 2004; Raudenbush \& Bryk, 2002).

Second, the random coefficient model (RCM) specification in HLM is superior at handling missing data relative to other growth modeling procedures such as latent growth curve models (Ployhart \& Vandenberg, 2010). "Missing data are almost always a problem in longitudinal research" (p. 219; Wothke, 2000) and this research study was no different, given the number of waves of data that were collected. Slightly more than 12 percent of all observations were missing due to PPA students missing classes, failing to fill out scales/items, and other reasons for missingness. While latent growth modeling, 
using programs such as LISREL, has benefits (i.e., correction for measurement error), it is not appropriate when missing data is expected. Thus, the use of HLM substantially reduces concerns that missing 1 or more of the 8 waves of surveys would exclude a participant from analyses.

The final reason to use HLM in this study's data analysis is RCM allows for the specification of the error variance-covariance matrix structure when testing models (Ployhart \& Vandenberg, 2010). While not considered necessary in "group"-based multi-level models where within-group errors are expected to be independent after controlling for group membership (Bryk \& Raudenbush, 1992), the systematic and sequential structure of time must be accounted for when using RCM to predict growth. The relationship between within-individual errors may be affected by autocorrelation (stronger relationships between errors of measures made closer, rather than father apart, temporally) as well as heteroscedasticity may change over time (Willett \& Sayer, 1994). However, ex-ante decisions about including autoregressive error variance-covariance structures or attempts to account for heteroscedasticity stemming from error dependencies of within-individual measures is not suggested. Rather, Bliese and Ployhart (2002) recommend examining residuals for possible evidence of autocorrelation or heteroscedasticity and then adjusting the model to account for these possible errors (formally tested by comparing log-likelihood differences between models with and without corrections). Thus, these corrections will be tested iteratively as suggested by Bliese and Ployhart (2002), to ensure the appropriateness of the model and conclusions drawn from it. 
When using HLM, a critical decision to be made is whether to center Level-1 predictor variables (Hofmann \& Gavin, 1998). For this study, predictors at Level-1 were not centered. This decision was made to ensure the Level-1 effects remain in their original metric, as the intercept without centering reflect applicant initial attitudes towards firms, which are interpretable and hypothesized to differ in the study (Hofmann \& Gavin, 1998). Also, it is important to note that all hypotheses in this study argue for linear changes in slopes depending on the applicant passing or taking an offer. Thus, time was kept in a linear function for hypothesis testing. However, ex-post tests of quadratic or other higher-order growth functions can be tested using HLM, providing more justification for the use of HLM in this study (Ployhart \& Vandenberg, 2010).

Model specifications for the study are included in Figure B2. At Level-1, the variable Time in the metric of days (coded 0 for the initial wave of data collection) was used to predict each of the 6 applicant attitudes assessed in this study. At Level-2, the variable Take represents whether the applicant passes (coded 0$)$ or takes (coded 1$)$ a job offer from an organization. Finally, Level-3 represents the applicant. As this study does not make any predictions concerning time-invariant applicant variables influencing job attitudes (i.e., personality traits) with the exception of the control for GPA, no other Level-3 predictors are included in the model. Also included in Figure B2 is the breakdown of the entire model equation into fixed and random effects. In this study, the coefficients of interests are in the fixed-effects model. In the fixed-effects portion of the model, $\gamma_{000}$ represents the mean applicant attitude (e.g., initial PO fit) at Time 0 towards an organization they receive an offer from but pass while $\gamma_{010}$ represents the intercept 
difference of applicant attitudes about organizations whose offer they take. Furthermore, $\gamma_{100}$ represents the mean rate of change in applicant attitude (e.g., slope of PO fit) towards an organization they receive an offer from but pass while $\gamma_{110}$ represents the slope difference of applicant attitudes about organizations whose offer they take.

Significance in $\gamma_{010}$ and $\gamma_{110}$ would indicate that intercept and slope values, respectively, of attitudes towards recruiting organizations differed depending on whether the applicant takes or passes on a job offer. 


\section{CHAPTER IV}

\section{RESULTS}

\section{MOTIVATION AND PREFERENCE CHECK}

Results from the 3-item scale assessing applicant motivation indicate PPA students were highly motivated to secure a job offer during the recruitment period assessed in this study. Specifically, applicants reported a mean score of $4.82(1=$

strongly disagree to $5=$ strongly agree), indicating they took the recruitment process seriously and felt it was critical they obtained an internship during the recruitment period.

As described above, prior to modeling growth, applicant general preferences toward Big 4 firms were assessed by asking applicants to distribute 100 points among the 4 firms to indicate current preferences. Applicants with Gini coefficients of 0 indicate no disparity or initial preference among Big 4 firms at the start of the recruitment process while a Gini coefficient of .75 indicates preference for 1 firm dominates all other firms (Harrison \& Klein, 2007). Results indicate that the average Gini coefficient for the sample was .127 and was significantly different from $0(t=$ $10.31 ; d f=197 ; S E=.012 ; 95 \%$ CI $[.103, .151])$. Examining the frequencies of Gini coefficients indicated that slightly less than 40 percent of applicants (39.4 percent) reported no initial preferences among Big 4 firms. Said differently, over 60 percent of all applicants included in this sample indicated they held some level of initial preferences toward Big 4 firms at the start of the recruitment process. 


\section{MODELING PROCEDURE}

The RCM developed in the manuscript were based on the 5-step sequence developed by Bliese and Ployhart (2002) for building growth models. When testing the effect of theory-based predictors of intercept and slope variability in longitudinal research, Bliese and Ployhart advocate first estimating interclass correlation coefficients (ICCs) for outcomes, then determining fixed function for time (e.g., linear, quadratic), followed by assessing and accounting for significant growth parameter variability, and finally establishing the appropriate error structure. Following these four steps, Level-2 moderators of intercepts and slopes (i.e., Take) can be added to the RCM and subsequent results should be interpreted in hypothesis testing (Bliese \& Ployhart, 2002; Bliese, Chan, \& Ployhart, 2007). It is important to note that these steps are appropriate for growth models with 3 levels like the ones used in this study, where applicant attitudes at various times during the recruitment process (Level-1) are nested within Big 4 firms (Level-2), which are nested within applicants (Level-3).

ICCs assess the level of nonindependence between observations at a given level of a multilevel model (Bliese, 1998). Stated differently, ICCs indicate the percentage of total variance in an outcome that can be explained by factors at a given level (Bliese, 2000; Bryk \& Raudenbush, 1992). ICCs were calculated at Level-1, -2, and-3 for all six attitudes measured in this study. Results indicated that 81.9 percent of the variance in recruiter timeliness was explained by within-organizations over time factors (Level-1), 0.1 percent of the variance was explained by between-organization within-applicant factors (Level-2), and 18.0 percent of the variance was explained by between-applicant 
factors (Level-3). For recruiter trustworthiness, 82.0 percent of the variance was explained by within-organizations over time factors (Level-1), 0.1 percent of the variance was explained by between-organization within-applicant factors (Level-2), and 17.9 percent of the variance was explained by between-applicant factors (Level-3). For image, 63.2 percent of the variance was explained by within-organizations over time factors (Level-1), 7.7 percent of the variance was explained by between-organization within-applicant factors (Level-2), and 29.1 percent of the variance was explained by between-applicant factors (Level-3). For PO fit, 73.6 percent of the variance was explained by within-organizations over time factors (Level-1), 5.9 percent of the variance was explained by between-organization within-applicant factors (Level-2), and 20.5 percent of the variance was explained by between-applicant factors (Level-3). For organizational attraction, 66.0 percent of the variance was explained by withinorganizations over time factors (Level-1), 11.1 percent of the variance was explained by between-organization within-applicant factors (Level-2), and 22.9 percent of the variance was explained by between-applicant factors (Level-3). For acceptance intentions, 62.4 percent of the variance was explained by within-organizations over time factors (Level-1), 14.0 percent of the variance was explained by between-organization within-applicant factors (Level-2), and 23.6 percent of the variance was explained by between-applicant factors (Level-3). While several ICCs were found to be small $(<1.0$ percent), very small ICCs for dependent variables can still significantly impact model results and standard errors resulting in the inflation of Type I error rates (Barcikowski, 1981; Bliese, 2000). Thus, accounting for all 3 levels of the growth model is not only 
appropriate, but also necessary, in this study. However, it is important to note that across all models within-organizations over time factors (Level-1) and between-applicant factors (Level-3) accounted for more variance in the dependent variable than betweenorganization within-applicant factors (Level-2) indicating the importance of both time and applicants in the recruiting process.

To test for changes in attitudes over time, a time variable was created based on the number of days from the initial survey (which was coded as day $=0$ ) to properly model growth and account for "measurement creep" (phenomenon in which intervals between measurement in longitudinal research naturally increase over time; Singer $\&$ Willett, 2003). When entered as predictors at Level-1, the fixed effect for time was a significant predictor of all 6 attitudes assessed in the study. Specifically, time was significant and positively related to perceptions of recruiter timeliness $(b=.011 ; p<$ $.01)$, recruiter trustworthiness $(b=.010 ; p<.01)$, image $(b=.004 ; p<.01)$, PO fit $(b=$ $.009 ; p<.01)$, organizational attraction $(b=.005 ; p<.01)$, and acceptance intentions $(b$ $=.004 ; p<.01)$. That is, on average, applicant attitudes toward organizations they received offers from increased over the duration of the recruitment process. According to Bliese and Ployhart (2002), when linear effects of time are shown to be significant, a non-hypothesized higher-order term (i.e., quadratic) for rate of change should also be examined. A quadratic term for time was created by squaring the original time metric, and results indicated the presence of a significant quadratic change pattern for recruiter timeliness $(b=-.0001 ; p<.05)$, recruiter trustworthiness $(b=-.0001 ; p<.01)$, image $(b$ $=.0002 ; p<.01)$, and PO fit $(b=-.0001 ; p<.01)$. The shape of the quadratic change 
pattern for applicant perceptions of recruiter timeliness, recruiter trustworthiness, and PO fit are similar, with applicant attitudes increasing at a slightly decreasing rate over time. Conversely, the shape of the quadratic change pattern for applicant perceptions of image is increasing at an increasing rate, yet values become uninterpretable and out of range prior to the conclusion of the recruitment process. Implications and possible future studies based on these unexpected, yet significant, non-linear growth terms are discussed below.

After determining that variance in attitudes could be explained by Level-2 and Level-3 factors (Step 1) and fixed effects for time were significant (Step 2), the next step is to examine whether attitude trajectories vary between-organization yet withinapplicant as well as between-applicant (Bliese \& Ployhart, 2002). To test for random variability in growth of attitudes over time at Level-2 and Level-3, log-likelihood ratios are compared between models with and without random effects for time (Pinheiro \& Bates, 2000). The results of these tests indicated that accounting for random variability in growth between-organization yet within-applicant significantly improved the model for recruiter timeliness $\left(\chi^{2}(2)=165.37 ; p<.01\right)$, recruiter trustworthiness $\left(\chi^{2}(2)=\right.$ 197.98; $p<.01)$, image $\left(\chi^{2}(2)=44.98 ; p<.01\right)$, PO fit $\left(\chi^{2}(2)=229.92 ; p<.01\right)$, organizational attraction $\left(\chi^{2}(2)=150.41 ; p<.01\right)$, and acceptance intentions $\left(\chi^{2}(2)=\right.$ $311.31 ; p<.01)$. Thus, random effects at Level-2 were included in all 6 growth models. Tests for Level-3 random effects for between-applicant growth were run by comparing log-likelihood ratios of models with just random effects at Level-2 and those with random effects at both Level-2 and Level-3. The results of tests for random variability in 
between-applicant growth indicated that models significantly improved for recruiter timeliness $\left(\chi^{2}(2)=125.56 ; p<.01\right)$, recruiter trustworthiness $\left(\chi^{2}(2)=119.48 ; p<.01\right)$, image $\left(\chi^{2}(2)=95.04 ; p<.01\right)$, PO fit $\left(\chi^{2}(2)=77.86 ; p<.01\right)$, organizational attraction $\left(\chi^{2}(2)=48.97 ; p<.01\right)$, and acceptance intentions $\left(\chi^{2}(2)=36.38 ; p<.01\right)$ when random effects were included at Level-3. Thus, Level-2 and Level-3 random effects were included in all 6 models.

The fourth step when modeling growth using RCM, before adding predictors of intercept and slope variability, is to test if alternative error structures improve the model (Bliese \& Ployhart, 2002). More common multi-level models, such as those used to explain relationships in team- or group-settings, assume errors at Level-1 are uncorrelated after accounting for grouping. However multi-level models based on longitudinal data are unique as errors from closer assessments, temporally, are expected to be more related than assessments that are more temporally separated (Ployhart \& Vandenberg, 2010; Singer \& Willett, 2003). To assess if correlation of errors is present in this data, models were run with two alternative error structures, an autoregressive structure and a heterogeneous and correlated structure, in addition to a homogeneous and uncorrelated error structure. Similar to the tests for random effect discussed above, loglikelihood ratios are compared between models with and without alternative error structures (Pinheiro \& Bates, 2000). Relative to baseline models with homogeneous and uncorrelated error structures, the addition of an autoregressive error structure improved model fit for recruiter timeliness $\left(\chi^{2}(1)=144.54 ; p<.01\right)$, recruiter trustworthiness $\left(\chi^{2}(1)=153.52 ; p<.01\right)$, image $\left(\chi^{2}(1)=201.81 ; p<.01\right)$, PO fit $\left(\chi^{2}(1)=120.72 ; p<\right.$ 
$.01)$, organizational attraction $\left(\chi^{2}(1)=150.22 ; p<.01\right)$, and acceptance intentions $\left(\chi^{2}(1)\right.$ $=109.00 ; p<.01)$. While the heterogeneous and correlated error structure also improved model fit for recruiter timeliness $\left(\chi^{2}(7)=265.52 ; p<.01\right)$, recruiter trustworthiness $\left(\chi^{2}(7)=166.67 ; p<.01\right)$, image $\left(\chi^{2}(7)=40.80 ; p<.01\right)$, PO fit $\left(\chi^{2}(7)=73.77 ; p<.01\right)$, organizational attraction $\left(\chi^{2}(7)=34.21 ; p<.01\right)$, and acceptance intentions $\left(\chi^{2}(7)=\right.$ 124.24; $p<.01$ ), the autoregressive error structure was retained for all 6 models, given it resulted in greater reductions in the log-likelihood ratio per degree of freedom. Following these steps, hypothesized predictors of intercept and slope variability are added at higher levels in the model (Bliese \& Ployhart, 2002). Finally, prior to testing all hypotheses, GPA was entered as a control variable at Level-3 to account for differences in applicant qualifications as GPA was identified as a critical indicator of applicant quality by HR managers at Big 4 firms (Barrick et al., 2010).

In summary, the above 4 steps test the assumptions and correctly specify growth models for longitudinal data. Specifically, estimating the percentage of total variance in each outcome that can be explained by factors at a given level (ICCs) and determining the presence and shape of growth meet the assumptions of within-individual change over time while assessing the variability of the growth parameters and determining the appropriate error structure ensures the baseline model for within-individual change is correctly specified (Bliese \& Ployhart, 2002). After determining the appropriateness of given assumptions and inclusion of necessary features of the model (e.g., random effects for time at Level-2 and Level-3), the final step of the sequence (Step 5), is to test hypotheses seeking to explain intra-individual changes in attitudes. 


\section{HYPOTHESIS TESTING}

First, descriptive statistics, reliabilities, and zero-order correlations among the variables are reported in Table A2 and have been collapsed across-companies, withinapplicants. Relationships between applicant attitudes and job choice appear to confirm prior studies and follow a similar pattern. Specifically, the relationships between applicant attitudes and job choice (again, coded pass $=0$ and take $=1$ ) become more positive the closer, temporally, the assessment is to ultimate job choice decisions.

Hypothesis 1a stated that applicant perceptions of recruiter timeliness whose offer they pass on were expected to decrease over time. Results reported in Table A3 indicate that the interaction between time and applicant perceptions of recruiter timeliness was significant $(b=.002 ; p<.01)$. However, graphs of this interaction (Figure B3) indicate that the resulting trajectories are not in the hypothesized direction.

Specifically, applicant perceptions of recruiter timeliness increased for all organizations that extended offers. However, while not hypothesized, attitude bolstering was greater for organizations applicants took an offer from compared to organizations whose offer they passed. Simple-slopes analyses for two-way interactions (Preacher, Curran, \& Bauer, 2006) confirm that slopes were significantly positive for organizations that applicants took offers from $(b=.012 ; p<.01)$ and those they passed on $(b=.009 ; p<$ .01 ), but applicant perceptions of recruiter timeliness were significantly more positive for organizations that had their offers taken early in the process (by the 12th day of recruitment). Thus, while applicant perceptions of recruiter timeliness become more 
positive over time for organizations whose offer they took compared to those whose offer they passed, Hypothesis 1a was not supported.

Similar to Hypothesis 1a, Hypothesis $1 \mathrm{~b}$ argued that applicant perceptions of trustworthiness of recruiters whose offer they pass on were expected to decrease over time. Results reported in Table A4 indicate that the interaction between time and applicant perceptions of recruiter trustworthiness was significant $(b=.002 ; p<.01)$. However, Figure B4, which is a graph of this interaction, indicates that the resulting trajectories are again not in the hypothesized direction. Specifically, applicant perceptions of recruiter trustworthiness increased for all organizations they received offers from, but the increase was greater for organizations they took an offer from compared to organizations whose offer they passed. Simple-slopes analyses for two-way interactions confirm that slopes were significantly positive for organizations that applicants took offers from $(b=.011 ; p<.01)$ as well as those they passed on $(b=.009$; $p<.01)$ and that perceptions of recruiter trustworthiness were significantly different and more positive for organizations that had their offers taken by the 8th day of recruitment. Thus, while applicant perceptions of recruiter trustworthiness become more positive over time for organizations whose offer they took compared to those whose offer they passed, Hypothesis $1 \mathrm{~b}$ was not supported.

Hypothesis 2 stated that applicant initial image perceptions of the organization they take an offer from would be higher than initial image perceptions of organizations whose offer they pass. Table A5 reports the results of the RCM for applicant image perceptions over time and indicates that applicant perceptions of organization image is 
significantly higher $(b=.11 ; p<.01)$ for organizations they took an offer from compared to organizations whose offers they passed. Thus, Hypothesis 2 was supported. Two distinct trajectories were hypothesized for applicant image perceptions over time, with Hypothesis 3a arguing that applicant image perceptions of the organization they take an offer from will increase over time and Hypothesis $3 \mathrm{~b}$ arguing that applicant image perceptions of the organizations whose offer applicants pass will decrease over time. Results reported in Table A5 indicate that the interaction between time and applicant perceptions of organization image was significant $(b=.002 ; p<.01)$. A graphical depiction of applicant image perceptions over time appears in Figure B5. This graph provides support for Hypotheses 2 and 3a, as applicant image perceptions of the organization they take an offer from are significantly higher initially, and according to simple-slopes analysis, become significantly more positive $(b=.004 ; p<.01)$ over the recruitment process. However, Figure B5 does not support Hypothesis 3b, as applicant image perceptions of the organizations whose offer they pass on do increase, rather than decrease, over time but at a significantly less positive rate $(b=.002 ; p<.01)$ than for the organization they take an offer from throughout the recruitment process. Therefore, Hypothesis 3a was supported but Hypothesis $3 \mathrm{~b}$ was not supported.

According to Hypothesis 4, applicant initial PO fit perceptions of the organization they take an offer from were expected to be higher than initial PO fit perceptions of organizations whose offers they pass. However, results reported in Table A6 indicate that initial applicant perceptions of PO fit did not significantly differ between the organizations whose offers they passed on and the organization whose offer 
they took $(b=-.04 ; p>.10)$. Therefore, Hypothesis 4 was not supported. Slopes were expected to diverge based on taking or passing on an offer such that Hypothesis 5a argued that applicant PO fit perceptions of the organization they take an offer from would increase over time while Hypothesis $5 \mathrm{~b}$ argued that the slope for PO fit perceptions of the organizations whose offer they pass on would be negative. Results of the RCM for applicant PO fit perceptions over time (reported in Table A6), indicate the presence of a significant interaction $(b=.005 ; p<.01)$ between time and applicant perceptions of PO fit. To formally test Hypotheses 5a and 5b, simple-slopes analysis was employed (Preacher et al., 2006). Consistent with Hypothesis 5a, the slope of PO fit perceptions was significantly positive $(b=.011 ; p<.01)$ for organizations whose offers applicants took. However, counter to Hypothesis 5b, the slope of PO fit perceptions was significantly positive $(b=.005 ; p<.01)$ for organizations that had their offers passed on by applicants and did not significantly differ from PO fit perceptions for the organization that applicants took an offer from until the 22nd day of the recruitment process. A graphical depiction of applicant image perceptions over time appears in Figure B6 and is consistent with Hypothesis 5a and inconsistent with Hypotheses 4 and $5 \mathrm{~b}$ as applicant image PO fit perceptions of the organizations whose offer they pass on do not significantly differ initially and increase, rather than decrease, over time positive rate ( $b$ $=.002 ; p<.01)$ than for the organization they take an offer from throughout the recruitment process. Thus, Hypothesis 5a was supported while Hypotheses 4 and $5 \mathrm{~b}$ did not receive support for the predicted relationships. 
Hypothesis 6a stated that applicant initial attraction to the organization they take an offer from will be higher than initial attraction to the organizations whose offers they pass. Table A7 reports the results of the RCM for applicant perceptions of organizational attraction over time and indicates that applicant perceptions of organizational attraction is not significantly higher $(b=-.01 ; p<.01)$ for organizations they take an offer from compared to organizations whose offers they passed. Thus, Hypothesis 6a was not supported. Hypotheses $7 \mathrm{a}$ and $7 \mathrm{~b}$ suppose that two distinct trajectories for applicant attraction to organizations over time are expected such that Hypothesis $7 \mathrm{a}$ argues that applicant attraction to the organization they take an offer from will increase over time and Hypothesis 7 argues that applicant attraction to the organizations whose offers they pass on will decrease over time. Results reported in Table A7 indicate that the interaction between time and applicant organizational attraction was significant $(b=$ $.006 ; p<.01)$. A graphical depiction of applicant attraction to organizations over time appears in Figure B7. This graph provides support for Hypothesis 7a, as applicant attraction to the organization they take an offer from becomes more positive over the recruitment process. Simple-slopes analysis indicates that the positive slope for attraction to the organization applicants take an offer from is significant $(b=.007 ; p<$ .01). However, Figure B7 does not support Hypothesis 7b, as applicant attraction to the organizations whose offer they pass on does not significantly change $(b=.001 ; p>.10)$, rather than decrease, over time. Applicant attraction to organizations they take an offer from and pass on an offer are significantly different after 13 days of the start of the 
recruitment process. Therefore, Hypothesis $7 \mathrm{a}$ was supported but Hypothesis $7 \mathrm{~b}$ was not supported.

According to Hypothesis 6b, applicant initial intentions to accept an offer from the organization they take an offer from was expected to be higher than intentions to accept an offer from organizations whose offers they pass. Yet counter to Hypothesis 6b, results reported in Table A8 indicate that initial intentions to accept an offer from organizations whose offer they take was significantly less $(b=-.09 ; p<.05)$ than initial intentions to accept an offer from organizations whose offers they pass. Therefore, Hypothesis $6 \mathrm{~b}$ was not supported. Slopes were expected to diverge based on taking or passing on an offer such that applicant intentions to accept an offer from the organization they take an offer from would increase over time (Hypothesis 8a) while the slope for intentions to accept an offer from the organizations whose offer they pass would be negative (Hypothesis $8 \mathrm{~b}$ ). Results of the RCM for applicant acceptance intention over time (reported in Table A8) indicate the presence of a significant interaction $(b=.008 ; p<.01)$ between time and applicant acceptance intentions. To formally test Hypotheses $8 \mathrm{a}$ and 8b, simple-slopes analysis was employed (Preacher et al., 2006). Consistent with Hypothesis 8a, the slope of acceptance intentions was significantly positive $(b=.009 ; p<.01)$ for organizations from which applicants took an offer. However, the slope of intentions to accept an offer was not significant $(b=.0003$; $p>.10$ ) for organizations that had their offers passed on by applicants, providing no support for Hypothesis $8 \mathrm{~b}$. Intentions to accept an offer from the organization applicants took an offer from were significantly more positive than their intentions to accept an 
offer they ultimately passed on by the 19th day of the recruitment process. A graphical depiction of applicant image perceptions over time appears in Figure B8 and is consistent with Hypothesis $8 \mathrm{a}$ and inconsistent with Hypotheses $6 \mathrm{~b}$ and 8b. Specifically, applicant acceptance intentions toward the organizations whose offer they pass on were significantly higher initially but did not significantly change over time. However, applicant acceptance intentions toward the organization they take an offer from became significantly more positive over the course of the recruitment process.

To summarize the results of Step 5 from the Bliese and Ployhart (2002) growth model building sequence, a significant initial difference in applicant attitudes favoring the ultimately taken alternative was found for organization image but not for PO fit, attraction to the organization, and acceptance intentions. Thus, Hypothesis 2 was supported but Hypotheses 4, 6a, and 6b (respectively) were not. Also, applicant perceptions of organizational image, PO fit, organizational attraction, and acceptance intentions for the ultimately taken alternative were found to increase over time. Thus, Hypotheses 3a, 5a, 7a, and 8a (respectively) were supported. However, applicant perceptions of recruiter timeliness, recruiter trustworthiness, organizational image, PO fit, organizational attraction, and acceptance intentions for alternatives that were ultimately passed on were not found to decrease over time. Thus, Hypotheses 1a, 1b, 3b, $5 \mathrm{~b}, 7 \mathrm{~b}$ and $8 \mathrm{~b}$ (respectively) were not supported. 


\section{CHAPTER V}

\section{DISCUSSION AND CONCLUSION}

Existing recruiting frameworks often focus on describing why applicant attitudes would influence job choice yet often fail to address how and when applicant attitudes develop and affect job choice decisions. In this study, hypotheses consistent with PDID research were proposed and tested to determine how as well as when applicant perceptions of recruiter timeliness and trustworthiness, organizational image, PO fit, attraction to organizations, and offer acceptance intentions discriminate whether applicants ultimately take or pass on job offers. Findings indicate that over the course of the recruitment process, applicant attitudes about organizations become more consistent; applicants are overly positive toward their early-developed preferred alternative compared to other alternatives that also extended offers. Specifically, all 6 applicant attitudes measured in this study distinguished between ultimately taken and passed alternatives within three weeks of a five month recruitment process. Thus, while prior research has shown each of these attitudes to predict recruiting outcomes (Chapman et al., 2005), this study indicates that these attitudes rapidly develop and are reinforced as more information is assimilated such that a clear preferred alternative is developed quickly and chosen at the end of the recruitment process. More importantly, the preferred alternative was strongly developed even before the actual employment interview occurred, roughly three months into the recruiting process. Results of this study contribute to researchers' current theoretical and practical understanding of employee recruitment. 


\section{THEORETICAL CONTRIBUTIONS}

While seminal works on the process of employee recruitment agree that recruiting is a process of change (e.g., Rynes et al., 1991), nearly all of this change process has been studied from an organization's perspective (e.g., Breaugh \& Starke, 2000). Relatively little is known about how applicant perceptions of the organization or its agents change during recruiting. Specifically, studies on how and when organizations choose which actions and efforts to engage in to influence applicant job choice decisions are plentiful while a dearth of studies exist explaining how and when applicant attitudes change throughout the recruitment process and influence their job choice decisions. In fact, Dineen and Soltis (2010) comment in their recent review on the "unbalanced state of the recruitment literature" (p. 61) and that a shift in focus away from organizational efforts to generate applicants while simultaneously treating applicants as passive is warranted. Adding to more recent studies of recruitment focused on the development of applicant attitudes over time (Harold \& Ployhart, 2008; Saks \& Uggerslev, 2010), this study attempts to describe the change process of recruiting by assessing applicant attitudes from existing recruiting frameworks and theories and identifying the various times they begin to distinguish between actual job choice decisions. The findings of this study extend the two existing studies mentioned above by using job seekers making actual job choice decisions, examining six different applicant attitudes, and simultaneously addressing the separate processes of taking and passing on job offers.

Results of this study indicate that recruiting, from an applicant perspective, is a dynamic decision-making process where applicants gather and assimilate information in 
distinct patterns prior to making job choice decisions. Yet, consistent with findings in consumer behavior research (e.g., Carlson \& Russo, 2001; Russo et al., 1996; 1998) and legal settings (e.g., Simon, Snow, \& Read, 2004) where sequential information gathering also occurs, results indicate that applicants information gathering process is not rational but rather path-dependent, and perhaps biased. Specifically, across six applicant attitudes that have previously been shown to predict recruiting outcomes such as job choice ( $\rho$ s ranging from .19 to .48; Chapman et al., 2005), applicant attitudes toward the organization they take an offer from increase, and at a faster rate, over time relative to organizations whose offers they pass. These attitudes significantly differ between taking and passing on an offer as early as the start of the recruitment process (i.e. image) or as "late" as slightly more than three weeks (i.e. PO fit) into a 5 month recruitment process. That is, following this initial period of the recruitment process, the remaining information collected and assimilated by applicants about organizations results in bolstering of attitudes of the preferred alternative to proactively avoid dissonance following job choice decisions.

Yet, it is important to note that while results are consistent with PDID research as applicants develop and eventually choose to take a "dominant alternative", the expected negative trajectories for lesser alternatives were not found in any of the 6 attitudes assessed in this study. Instead, attitudes for lesser alternatives did not decrease but rather increased over time for 4 of the attitudes assessed. These results may be driven by the fact that decision makers in the recruiting setting, applicants, do not always have the ability to choose an alternative. Specifically, organizations must give an offer in order 
for applicants to have the opportunity to decide whether to take or pass on the offer. The contingent nature of decision makers' alternatives for a decision in the recruiting setting is not frequently assessed in prior PDID research, where decision makers might be asked to assimilate information about two "white tablecloth restaurants" at which they will be able to dine (Russo et al., 1996). This type of choice exercise would mirror the recruitment setting only if participants were told prior to starting the task that they would not know until all information is presented whether they can get a reservation. Thus, applicants appear to still bolster attitudes about initial favorites, but do not diminish lesser alternatives, as they might need to take offers from initial lesser alternatives if the favorite does not extend an offer. The findings of this study are similar to a prior study of PDID when benefits of alternatives are contingent on something other than simply the decision maker's choice. Brownstein, Read, and Simon (2004) looked at PDID when individuals were placing bets on simulated horse races (when payouts were contingent on selecting the winning horse) and found that while initial favorites were bolstered by individuals as more information was provided, other betting options were not diminished over time as "there are no sure bets at the racetrack and so were unwilling to claim maximal confidence in any horse" (p. 901). The effects of the contingency of available alternatives must be further investigated in both PDID and recruiting research to better explain the possible lack of negative trajectories found in this study.

For almost a half-century (Behling et al., 1968) researchers have been focused on how the behavior of organizational representatives, or recruiters, influence applicants. While early research findings were equivocal (Rynes, 1991), more recent research has 
argued that the modest results were a function of recruiter behavior signaling to applicants that an organization was not suitable or professional rather than signaling positive characteristics of the organization to applicants (Boswell et al., 2003; Dineen et al., 2004). Yet, results of this study indicate that applicant perceptions of recruiter timeliness and trustworthiness, which are organization-focused information, increase for organizations that gave offers, whether they were taken or not. These findings call into question the notion that recruiter behavior is most salient, as well as influential, when violations such as untimely responses or dishonest interactions occur and result in negative changes in applicant attitudes (Gilliland, 1993; Herriot, 2004). However, consistent with prior research, results do indicate that perceptions of recruiter behaviors, both timeliness and trustworthiness, discriminate between offers taken and passed on and these differences in applicant perceptions become more severe and discriminant as the recruitment process progresses (Boswell et al., 2003). Thus, applicant perceptions of recruiter timeliness and trustworthiness do not appear to simply be necessary and sufficient for organizations to effectively recruit, but rather, they are a meaningful and significant source of differentiation that predict applicant job choice decisions, with more positive perceptions of recruiters' behaviors developing for organizations that have their offers taken rather than passed.

The perceived attributes of an organization as an employer, or the image they have conveyed has been shown to be one of the strongest predictors of recruiting outcomes (Chapman et al., 2005). These applicant attitudes about the organization, while expected to influence the entire recruitment process and be positively related to 
recruiting outcomes, have often been the focus of studies describing early or initial stages of recruiting (e.g., Brooks et al., 2003; Collins \& Han, 2004; Collins \& Stevens, 2002). Results of this study are consistent with prior findings, as applicant perceptions of organizational image significantly differed between organizations they take offers from and organizations whose offers they ultimately pass on at the start of the recruitment process. That is, applicant attitudes about an organization as an employer significantly distinguish between the job choice decisions they make 5 months later. However, the influence of image perceptions was not shown to be isolated to the initial stages of recruitment, as these initial perceptions of organizational image appear to be influencing future perception of image. That is, initial differences in applicant image perceptions were hypothesized, and shown to meaningfully increase over the duration of the recruitment process. For organizations whose offers were taken, applicant perceptions of image not only were significantly higher initially than organizational image perceptions whose offers were passed, but these difference also increase over time allowing applicants to have one organizational image increasingly dominate image perceptions over other alternatives. These results indicate that applicants become significantly more positive about their initial "favorite" relative to lesser alternatives throughout the process of recruiting. These findings also help underscore the criticality of assessing applicant perceptions of organizational image rather than relying solely on objective lists or ratings (e.g., Fortune reputation ratings; Turban \& Cable, 2003). While objective lists do converge somewhat with applicant perceptions and predict recruiting outcomes (Cable \& Graham, 2000), they fail to account for the changes in applicant perceptions of image, 
which were shown in this study to occur, that become progressively stronger over time and meaningfully distinguish between job choice decisions.

Applicants often use the recruitment process to assess the level of congruence, or fit, between themselves and the recruiting organization (Bretz \& Judge, 1994), and that these perceptions of fit can develop prior to the start of the formal recruitment process (Braddy et al., 2006; Dineen et al., 2002; Lievens et al., 2001). While early initial differences were hypothesized in this study, results indicate that initial perceptions of PO fit did not discriminate between organizations that had their offers taken and those that had their offers passed on at the end of the recruitment process. Thus, while mere exposure to organizations' image resulted in significant differences between offers taken and passed, applicants did not make similar distinctions about their fit with the organization, or have enough information to do so at the start of the recruitment process. It should be noted that extant research indicates that fit perceptions based on information gathered during the applicant generation phase were only based on simulated recruitment settings (e.g., Braddy et al., 2006; Dineen et al., 2002; Lievens et al., 2001) and PO fit perceptions when making actual job choice decisions may take time to develop before they discriminate between organizations' offers being taken or passed.

However, results indicate that applicant perceived similarity with the organization they take an offer from increases over time and becomes significantly higher than organizations whose offers they pass. Therefore, it appears that applicants quickly develop PO fit perceptions toward the organization they ultimately take offers from, and then assimilate information gathered about the organization to bolster their PO 
fit with their preferred alternative overtime. PO fit exists and influences job choice decisions to the extent to which applicants perceive it to exist (Kristof, 1996), and this study indicates that applicants perceive PO fit to exist with the organization they take an offer from relatively early and increases in consistency as the recruitment process unfolds. Thus, it is critical for researchers focusing on PO fit and recruitment to specify, when, not just why, PO fit (along with other types of fit) perceptions are used by applicants to discriminate and decide which job offers to pass on and which offer to take.

Studies of recruitment often use organizational attraction and acceptance intentions as dependent variables, as they are expected to mediate attitude-job choice decision relationships and are easier to obtain (Highhouse et al., 2003). In this study, both attitudes were assessed across the recruitment process, and counter to hypotheses, applicant attraction to organizations whose offer they take were not significantly higher than their attraction to organizations whose offers they passed. However, intentions to accept were actually significantly higher for organizations whose offers were eventually passed on compared to organizations that had their offers taken. This unexpected finding actually provides some support for Chapman and colleagues' (2005) results supporting both an "attitude mediated model" and an "intentions mediated mode" for recruitment outcomes. Consistent with the results of this study, they found that organizational characteristics (including image) were directly, while also indirectly linked through organizational attraction, related to acceptance intentions which was the sole link to job choice. So, while initial differences in image described above were found, the inverse finding for acceptance intentions may be reconciled by the possible pattern of direct and 
indirect effects between image, organizational attraction, and acceptance intentions found in the Chapman et al., (2005) meta-analysis. These unexpected initial differences aside, organizational attraction and acceptance intentions quickly began to diverge with significant positive changes for the organization whose offer was ultimately taken while no significant change was found for either attraction or acceptance intentions for the organizations whose offers were passed. These findings are consistent with prior metaanalytic research (e.g., Kim \& Hunter, 1993) that indicate reports of attitudes and intentions are better predictors of actual behavior the temporally closer they are measured to actual behavior. Results of this study indicate that in a recruiting setting applicants do create a dominate alternative early, that choice becomes even more dominate over time and increasingly differentiates between decisions to take and pass on offers compared to earlier measures.

This study also contributes to the recruitment literature by moving away from previous operationalizations of job choice as one decision making process to instead investigating the processes of taking as well as passing on job offers as two distinct decisions made by applicants. By routinely grouping these distinct processes into one outcome variable, recruitment researchers potentially obscure critical findings or reach conclusions that are based on possibly contaminated dependent variables (KammeyerMueller et al., 2005). Failing to account for these divergent trajectories of attitudes about organizations serve to explain, in part, why corrected correlations between applicant attitudes and job choice have previously been found to be modest at best (Chapman et al., 2005). For example, simply using applicant organizational attraction to predict a 
binary job choice dependent variable would indicate a significant but modest positive relationship. However, the results of analyses of organizational attraction in this study indicate that patterns of applicant information gathering and assimilation as well as subsequent attitudes differ between organizations applicants are initially, or at least very quickly, more positive toward relative to other alternatives. The paltry results found in previous studies are even further explained by the findings of this study that slopes for passed on alternatives were usually positive but significantly less so than the attitudes that developed for the chosen alternative. That is, while not as strong, the modest increases in applicant attitudes toward organizations they choose to remain in the applicant pool, but ultimately pass on the offer from, attenuates observed relationships when taking and passing on offers are treated as one variable. For example, an applicant's image perceptions about two alternatives (one firm ultimately has their offer taken, the other offer is passed) would not as clearly distinguish which offer would be taken in the future if they both increased over time compared to if perceptions of one alternative increased and one decreased over time as originally hypothesized.

This study underscores what research in other decision-making settings has shown for decades; processes underlying choosing an alternative differ from processes underlying rejecting alternatives (Shafir, 1993). As such, recruitment theories must begin to describe not only how applicants attitudes influence and result in taking a given offer, but also explicitly distinguish and discuss the processes by which applicant attitudes influence their decision to pass on offers. This type of theoretical development would parallel developments in other literatures such as turnover, whereby some models focus 
on explaining when and why people leave a job (e.g. unfolding model of voluntary turnover; Lee, Mitchell, Wise, \& Fireman, 1996) and others focus on explaining when and why people stay (e.g. job embeddedness model; Mitchell, Holtom, Lee, Sablynski, \& Erez, 2001). More studies that give a complete treatment of job choice decisions would help fill this existing gap in the recruitment literature and possibly contribute to explaining why extant research findings on applicant perceptions (i.e., recruiter behavior) have frequently been inconclusive or pedestrian.

\section{PRACTICAL IMPLICATIONS}

Like any type of business activity, properly and effectively allocating recruiting expenses and investments is critical to organizations' success at attracting and ultimately hiring employees. Recruiting is a significant expenditure, with estimates of total costs of \$73 billion in 2012 for US organizations (Research and Markets, 2008), but strategic and efficient recruiting efforts can increase the utility of organizations' selection systems and serve as a sustainable competitive advantage (Murphy, 1986; Taylor \& Collins, 2000). Given that every applicant attitude assessed in this study was significantly higher for organizations applicants took offers from compared to those they passed on within 4 weeks of a 5 month recruiting process, organizations looking to use recruiting as a source of competitive advantage should work quickly, perhaps even before formal recruitment begins, in an effort to establish themselves as applicants' initial favorites and capitalize on the benefits of overly positive information assimilation processes. These results are consistent with the work of Collins and colleagues (Collins, 2007; Collins \& Han, 2004; Collins \& Stevens, 2002) that indicate that early-recruitment activities such 
as sponsorships, advertisements, and word-of-mouth endorsements can affect applicant pool quality, quantity, and recruiting outcomes. The possible benefits of being an early mover may be even greater in a college setting when there are a large number of possible applicants, as well as competition for those applicants, but with more established recruitment cycles (Schwab, Rynes, \& Aldag, 1987). Rather than wait for recruitment opportunities such as career fairs or informational sessions, organizations should proactively try to generate and maintain applicant interests and allow for applicants to formally apply before possible rival alternatives. This proactive approach should push up the timing of when offers are extended relative to recruiting organizations that start later, which has also been shown to result in a greater likelihood of offer acceptance (Becker et al., 2010). Thus results of this study indicate that organizations should act quickly to establish the position as a preferred alternative, relative to other alternatives for applicants, in order to increase the favorability in which future information is assimilated, likelihood applicants will take an offer if given one, and overall recruiting effectiveness.

Related to the above point, assuming organizations are able to identify when they are the "favorite" of applicants, early in the recruiting process they should focus resources (e.g., time and money) on maintaining this position with these applicants rather than trying to change applicant perceptions that hold early attitudes that are less positive, or more positive for other organizations. Theoretical arguments and empirical findings in this study indicate that applicants do not optimally gather and assimilate information but rather are influenced by earlier attitudes, and thus even when 
organizations provide accurate information that they are the more "correct" alternative for the applicant, applicants that view them as lesser alternatives might not assimilate that information to the extent they objectively should. However, the level of organizations' recruiting focus on applicants that are more likely to take an offer given initial attitudes must be made with caution. Careful consideration must be paid to the quality of the applicant as well as their attitudes toward the organization, as the recruitment and selection of unqualified or less suitable applicants that hold an organization as a favorite may result in a substantial drop in the utility of the selection system even though very few offers are passed (Murphy, 1986). Along with the notion of establishing relationships via word-of-mouth or broadly advertising with universities or placement centers in an effort to become initial favorites for possible applicants, organizations that are unable to effectively do this at one university but want to generate applicant pools of similarly high quality should look to establish ties to other universities that have commensurate academic standards and profiles.

The results of this study also have implications for recruiters and organizations that actively try to assess applicant attitudes toward their organization in an effort to maximize recruiting efficiency (Taylor \& Collins, 2000). Recruiters that simply track applicant attitudes about the organization they represent may be misled by a trend of positive changes in applicant attitudes when it appears applicant attitudes are becoming more favorable and positive toward all organizations as the recruitment process progresses. While applicant attitudes may be shown to increase, this rate of change may be significantly less positive than increases in applicant attitudes toward another 
alternative. If this were the case, then recruiting organizations would expect an applicant to accept an offer, even though the applicant favored another alternative throughout the entire recruitment process. This scenario could have occurred in this sample if organizations that had their offer passed on had assessed applicant perceptions of image from the start of the recruitment process, as applicant perceptions of these organizations' images did increase over time but at a significantly lower rate than for the organization that had their offer taken. Thus, recruiting organizations that monitor applicants should not only assess applicant attitudes toward their organization but also applicant attitudes toward other alternatives they are pursuing.

The results of this study can also provide insight on effective behavior for recruiters. Applicant perceptions of recruiter timeliness and trustworthiness distinguished whether applicants took or passed on an offer from the recruiter's organization. Thus, when interacting with applicants, recruiters should be most effective at maintaining applicant interest in the represented organization, and ultimately influencing job choice decisions, by being prompt and honest when contacting and responding to applicants. In fact, results indicate that applicant attitudes about recruiter timeliness and trustworthiness were more pronounced later in the recruitment process. Therefore, recruiters should not only dutifully and truthfully provide information to applicants but may also use initial interactions to gather information about applicant attitudes that were shown to quickly differentiate between taken and passed on offers (i.e., organizational image). That is, even if applicant initial perceptions of recruiters do not significantly differentiate between ultimate job choice decisions, recruiters can still 
gather useful information for their organizations to use to help focus future recruiting efforts. Related to the point above, recruiters would be wise to assess applicant attitudes, either using standardized metrics or informally, about not only the company they represent but also applicant attitudes about other alternatives early in the recruitment process while being more focused on disseminating timely and truthful, or realistic, information later in the recruitment process (Philips, 1998).

Finally, applicants would be wise to recognize and try to minimize the extent to which they engage in PDID prior to the conclusion of the recruitment process. Job choice decisions reached following a recruitment process rife with PDID can be expected to result in the "correct" decision for the wrong reasons at best, or suboptimal choices at worst (Murphy \& Tam, 2004). Unfortunately, applicants that engage in pathdependent assimilations of information in the positive direction for their existing favorite may be unaware of this process. Research in other decision making settings indicates that decision makers do not recognize the extent to which PDID influences their decision as correlations between decision makers' actual distortion and perceptions that distortion actually occurred has been found to be near zero (Russo et al., 2006). Yet, PDID researchers have also outlined a number of behaviors or actions decision makers can use to minimize the effects of PDID on assimilation of sequentially gathered information. Applicants may look to make evaluations of organizations public to family or friends, allow themselves more time to make job choice decisions, evaluate recruiting information in less aroused states, or expect to provide justification for their final decisions (Brownstein, 2003). In doing so, applicants may be able to avoid, or at least 
attenuate, the processes repeatedly shown to occur in this study where they gather and assimilate information about initial or early favorites in increasingly positive ways throughout the recruitment process. Furthermore, and contrary to much of the extant PDID research, applicant attitudes about organizations they receive offers from but reject were found to become more positive or not change over the course of the recruitment process. While some evidence in PDID research indicates that in situations when there is less certainty about alternatives (e.g., choosing horses to win a race; Brownstein et al., 2004), decision makers may not diminish lesser alternatives, 4 of 6 applicant attitudes in this study exhibited positive slopes. These differences may reflect applicants recognizing that unlike other situations where there was less guaranteed payout from selecting an alternative (e.g., a horse race), applicants may not get the option to take the initial favorite as well as be "forced" to take a less preferred alternative.

Also, this study provides insight for decision-making researchers seeking to not only identify biases in decision making but also how these biases operate in different decision-making situations. Specifically, the results of this study contribute to extant and equivocal findings on the effects of consequences and the longevity of these consequences on the directionality of PDID (Brownstein, 2003). Taking and passing on job offers have significant consequences, both positive and negative, for applicants and those consequences often remain throughout the duration of the employment relationship (Murphy \& Tam, 2004). The pattern of biases in this study, where applicant attitudes about the ultimately chosen alternative were bolstered relative to other alternatives, is 
different than the traditional PDID study. Whereas the traditional study relies on a decision that the experiment participant "controls" and when the consequences are either just positive or just negative outcomes. In this case, the decision occurs in a setting where the applicant may not even get receive an offer to take, and even if an offer is extended decisions of taking or passing on a job offer possibly has both positive and negative consequences (e.g., Mills \& Ford, 1995; Tyszka, 1998). More research is needed to untangle the possible multiplicative effects of positive and negative consequences tied to decisions and how patterns of PDID are affected. Furthermore, the importance of the consequences from these decisions are quite different than prior PDID studies, where the choice often involves which decisions among two restaurants or hotels (Russo et al., 1996). Again, the decisions made in this study are significant for the applicant career trajectories. Thus, this study focuses on decisions that have prolonged consequences, as applicants are reminded of their decision to take a job offer every day they go to work. Researchers have recently questioned how the presence of consequences that linger for decision makers, such as attitudes toward a car that would be used daily, affect how they distort information prior to making decisions (Simon et al., 2008). Clearly, more research is needed to determine if these hold in similar decision-making contexts, but results indicate that both valence of decision consequences and the longevity of these consequences in this study resulted in a pattern of information assimilation that was overly positive to initial or quickly developed favorite and less positive (or non-significant) for eventually passed on alternatives. 


\section{LIMITATIONS AND FUTURE RESEARCH DIRECTIONS}

Using a sample of applicants being recruited by a small set of fairly homogenous organizations confers a number of benefits, including being able to assess intra- and inter- applicant perceptions about organizations and excluding possible differences caused by industry or organizational size factors (Barber et al., 1999), but also presents some drawbacks. Specifically, job-based factors such as PJ fit or job tasks that have been shown to influence recruiting outcomes (Chapman et al., 2005) are held constant by the study sampling strategy. While job-specific recruiting is not uncommon (Barber, 1998), the attitudes assessed in this study were exclusively about organizations offering virtually identical jobs in very large organization in the same industry and, the effect of these attitudes on job choice decisions may have been artificially inflated. To the extent to which the focus on applicant attitudes of Big 4 firms and subsequent job choice decisions were affected by increased variance in organization-related attitudes at the expense of reduced variance in job-related attitudes, then the study results may be overstated due to range enhancement (Hunter \& Schmidt, 2004). Yet, it should also be noted that to the extent to which Big 4 firms use a more homogenous set of recruitment practices relative to smaller firms, the results of this study may actually be conservative estimates of the effects of organization-related attitudes on recruitment outcomes. Future research should focus on applicants applying to a wide variety of jobs with organizations of various sizes and in various industries to assess whether similar path-dependent information gathering and assimilation processes occurs with information concerning attitudes about organization industry or size. For instance, perhaps applicant preferences 
for working at a small organization are much higher than working for a large organization at the start of the recruitment process, and these attitudes become increasingly consistent and more positive for the small organization over time. Future research should look to address this, and similar, recruiting situations.

While applicants in this study were seeking full-time employment with large multinational organizations, these full-time jobs were temporary (internships) and applicants may approach these types of recruitment processes differently. However, both anecdotal and empirical evidence indicates that applicants in this study treated the recruitment process as a serious step toward securing permanent jobs with Big 4 firms. PPA administrators noted that at the conclusion of the internship process in prior years, upwards of 95 percent of all interns are extended full-time job offers. The concern that internships were approached differently by applicants in this study relative to permanent job searches was further attenuated by applicant mean responses to three items assessing the extent to which they expected their internships to result in a full-time job offer ( $M=$ 4.68 out of 5.00). Thus, both organizations and applicants should be expected to value the internship recruitment process and treat it as they would a search for permanent employment as organizations anticipated the majority of applicants would be extended permanent job offers and applicants also appeared to recognize this high likelihood. However, future studies should look at samples of applicants that are applying for permanent work exclusively as their job choice decisions may be differently influenced by impending financial needs or family demands (Boswell, Zimmerman, \& Swider, 2012). 
This study was also unable to account for possible differences in the specifics of the actual job offers. Research indicates that characteristics of a given offer/job such as pay, type of work, and location all have significant effects on recruiting outcomes (Chapman et al., 2005). However, concerns about drastic differences in these potential confounds are somewhat limited in this sample. Specifically, applicants in this sample were applying for similar jobs at the same level in each of the 4 homogeneous organizations. Also, PPA administrators noted that within a given recruiting year, very little variance in the actual offers exists across applicants and between organizations. Another potential confound, location of job, was also not expected to have a large influence on findings of this study. Each of the Big 4 accounting firms had multiple offices $(M=5)$ within 200 miles of the university in which these applicants were recruited from and greater than 90 percent of offers accepted were for positions within that distance.

While this study addressed a number of existing gaps in the recruitment literature, the results also prompt additional research questions that may help contribute to both the theories and practice of recruiting. More research is needed that tracks applicants not only during the recruitment process but also the first few months (and even years) of actual employment. Research on PDID, which was used to drive the hypotheses in this study, is based in part on Svenson's (1992) differentiationconsolidation theory that notes that both before-decision differentiation of alternatives (PDID) as well after-decision confirmation about the chosen alternative will occur. However, the overly favorable information distortion for the ultimately chosen 
alternative has been shown to be temporary. Simon and colleagues $(2004 ; 2008)$ found evidence that information distortion occurred both before and immediately after decisions were made, but that the overly positive evaluations of the chosen alternative quickly attenuated. While this study indicates that PDID does occur for the initial favorite in the recruitment setting, it cannot address after-decision distortion and eventual reductions over time. However, the after-decision patterns found in the Simon et al. studies coincide with recent research indicating that new employees experience the "honeymoon-hangover" effect (Boswell et al., 2005; Boswell et al., 2009). Specifically, new entrants might continue the overly positive information assimilation processes that occurred during recruitment in the initial few months of employment, the "honeymoon", but eventually attitudes become based on more objective information assimilation and return to accurate levels, the "hangover". Research that tracks applicant attitudes throughout the entire recruitment process and the start of actual employment would help determine if these two established patterns of attitude development are actually one longer form of attitude development driven by path-dependent information assimilation. Applicant attitudes, as evident by results of this and other studies, are highly influential on job choice decisions. However, external pressures have also been shown to affect applicant attitudes and subsequent decisions. Family members or friends' attitudes and experience with organizations can significantly affect recruiting outcomes (Fisher et al., 1979; Williamson, Cable, \& Aldrich, 2002). The influence of these external pressures on applicant decisions may increase drastically if numerous members of the applicant's social circle hold similar, either positive or negative, attitudes toward an 
organization. Research indicates applicants faced with the decision of which organization to work for often use their network of friends to determine which organizations to pursue (Kilduff, 1990; 1992), and their social network might also influence their initial attitudes, and subsequent development, toward a given organization throughout the recruitment process. Thus, the attitudes and behaviors of friends who are also being recruited may drive applicants to be overly positive (negative) toward an organization and ultimately take (pass) their offer. Future studies may look to use referents other than "students" or "friends" in the organizational image items developed in prior research (Collins, 2007) and used in this study to assess these effects. For instance, asking applicants about the attitudes or perceptions that "family members", "mentors", or "professors" have of a given organization as an employer may help clarify the influence family or esteemed others may have of external pressures on applicant job choice decisions.

Conversely, future studies may also look at how perceived competition for a job would influence applicant initial attitudes and subsequent information assimilation during recruitment. Competition for job offers in this sample was low given each firm extended between 103 and 113 job offers, yet applicant attitudes about organizations that are expected to extend few if any offers might start lower and remain low relative to attitudes about organizations expected to extend many offers. Hiring expectancy have been shown to be positively related to recruitment outcomes (Chapman et al., 2005) and competition can affect other types of employment decisions (i.e., turnover; Dreher \& Dougherty, 1980), so researchers looking to investigate applicant attitude development 
in the recruiting setting may benefit from the inclusion of competition-related attitudes in their study design.

The focus of this study was tracking the pattern of development for 6 applicant attitudes that had previously been shown to influence recruiting outcomes. However, this is not to say that these attitudes are unrelated to one another or exert independent influence on job choice decisions. In fact, the inclusion of organizational attraction and acceptance intentions was driven by prior research that concluded these attitudes mediate and are therefore related to distal attitudes and job choice decisions (Chapman et al., 2005). Researchers may wish to examine all of the applicant attitudes assessed in this study, as well as others, to identify when each attitude is most important or predictive relative to other attitudes. Yet, predicting behavior with a set of correlated predictors can lead to unstable results and possibly inaccurate conclusions about the importance of a given predictor (Johnson \& LeBreton, 2004). Recognizing this problem, researchers have begun developing methodologies to help tease apart the amount of explainable variance in a dependent variable (e.g. job choice) accounted for by a single predictor even when it is highly correlated with other predictors. Relative weight analysis, for instance, estimates the independent contribution of each predictor to variance accountable in an outcome by creating a set of orthogonal predictors that are maximally related to the original variables (LeBreton, Binning, Adorno, \& Melcher, 2004). Employing relative weight analysis to applicant attitudes overtime would allow researchers to compare the relative importance of each attitude at various points throughout the recruitment process. Results from this type of study could give 
organizations information about not only which applicant attitudes they should try to influence, but also when those attitudes are most influential on ultimate job choice decisions.

While all Big 4 firms were instructed not to extend offers until a certain day, there was no way to definitively rule out the possibility that firms made early offers. However, both circumstantial arguments and additional data analysis indicate early offers did not occur, or at least were very infrequent. First, PPA administrators noted that there were possible sanctions that could be leveled against Big 4 firms that violated the policy barring early offers. The PPA administrators also indicated that it would be unlikely that a firm could make a number of early offers without other applicants and the administrators themselves hearing about the violations. Second, if early offers were common, then it would be unlikely that the 20 applicants the market indicated were the most desirable (given they received offers from all 4 firms) and therefore probably the most likely to get early offers, would remain in the applicant pool for all of the Big 4 firms through the duration of the recruitment process. One would suspect that even the most risk-adverse yet desirable applicant, if given an early offer from their preferred alternative, would only continue with one other alternative. Finally, when data from the final survey that was launched one week prior to offers being extended were excluded from analyses, 4 of 6 interactions and the initial difference in image perceptions remain consistent with results using the full data. Given how quickly these attitudes begin to distinguish between the ultimately taken and passed on offers, coupled with the 
circumstantial arguments above, it appears the effects of any possible early offers are minimal.

Additionally, not only were all offers extended on the same day, but this study also exclusively focused on applicant attitudes about organizations that extended offers to the applicants. However, similar to the differences found between taking and passing on offers, questions remain as to how applicant attitudes can affect whether they receive offers and or not. For instance, it is possible that organizational representatives are not the only actors providing signals in the recruitment process, as positive applicant attitudes (which were shown to develop over the recruitment process) might signal to firms that applicants would be likely to accept an offer, making firms more likely to extend an offer (Bangerter, Roulin, \& König, in press). However, additional analyses indicate that if applicants are signaling to firms which result in offer extension, then it is not occurring early in the recruitment process. A one-way ANOVA for all 6 attitudes towards each Big 4 accounting firm, using offer status as the grouping variable, were run to determine if applicant attitudes meaningfully predicted where they received an offer at the end of the recruitment process. Results indicated that for only 9 of 24 ANOVAs using applicant attitudes reported in Wave 1 were there significant mean difference based on whether an offer was generated 5 months later. So, for 15 of 24 attitudes, initial attitudes did not determine whether offers ultimately came. Another set of one-way ANOVAs was run with applicant attitudes reported for Wave 5, nearly two months after the start of recruiting, and only 12 of 24 attitudes exhibited mean differences. However, and as expected, by Wave 7 and 8 all mean differences were significant as applicants 
began self-selecting out of some Big 4 firms' selection process as they pruned down their alternatives. While all attitudes in this study are reported prior to offers being given, as well as analyses based only on those organizations applicants were able to "elicit" offers from, future research should address how applicant attitudes may entice or eschew offers from organizations. Also, while it was not collected in this study, information about why applicants did not receive offers from given Big 4 firms, either because applicants failed to been seen as hirable by a firm or applicants self-selected out of the selection process with a firm because they do not think they are a desirable employer, may help clarify why the results of this study did not align with prior PDID research.

While not possible to assess in this study, as mentioned above, unexpected or "shock" job offers have been shown to have a large impact on employment decisions (Lee et al., 1996). Results of prior studies indicate that shocks jar individuals from deliberate or existing judgment patterns and force new information to be integrated with current attitudes (Holtom, Mitchell, Lee, \& Iderrieden, 2005). In a recruiting setting, offers extended to applicants from organizations they consider to be lesser alternatives that are unexpected, perhaps because they arrive earlier than applicants anticipated, may disrupt applicants from assimilating existing biased information that bolsters current favorites and drives applicants to bolster attitudes about the organization that extended an unexpectedly early offer. These types of "shock" offers may be especially influential when they were unsolicited (Lee, Gerhart, Weller, \& Trevor, 2008), whereby applicants were given offers or the promise of an offer before formally applying to the 
organization. Researchers looking to extend and build on the findings of this study might look at the timing of offers as well as when applicants were expecting the offer to arrive to assess the extent to which "shock" offers affect applicant attitude development and subsequent job choice decisions.

\section{CONCLUSION}

Understanding the process of how individuals end up employed at organizations is critical for both the individuals and organizations, and still requires extensive development (Ployhart, 2006). One of the first steps in the employment process deals with organizations' efforts to change the attitudes of potential employees and affect their job choice decisions, known as recruitment. However, applicants are not passive actors and their own prior attitudes about organizations also influence how they respond to information presented by recruiting organizations. Applicant perceptions of recruiter timeliness, recruiter trustworthiness, image, PO fit, organizational attraction, and acceptance intentions significantly differed for the organization they took offers from and those they passed on more than four months prior to actually making decisions. Results of this study are consistent with prior conceptualizations of recruitment from seminal works (e.g., Rynes et al., 1991); recruitment is not an event, but rather a process that needs to be studied as such. Yet this process was shown to be potentially biased in favor of applicants initial or early favorite alternative, making potentially diagnostic information gathered (but improperly valued either positively or negatively) later in the recruitment process less useful. Applicants looking to make the "correct" job choice should look to avoid this suboptimal decision-making process while organizations 
looking to maximize the effectiveness of their recruiting efforts should try to exploit it. Research going forward must continue to address these seemingly conflicting goals, perhaps in the same study, in order to discern ways that both applicants and organizations can accomplish short- and long-term employment goals. 


\section{REFERENCES}

Adams, G., \& Rau, B (2004). Job seeking among retirees seeking bridge employment. Personnel Psychology, 57, 719-744.

Adkins, C. L., Russell, C. R., \& Werbel, J. D. (1994). Judgments of fit in the selection process: The role of work value congruence. Personnel Psychology, 47, 605623.

Aiman-Smith, L., Bauer, T., \& Cable, D. (2001). Are you attracted? Do you intend to pursue? A recruiting policy-capturing study. Journal of Business and Psychology, 16, 219-237.

Albinger, H. S., \& Freeman, S. J. (2000). Corporate social performance and attractiveness as an employer to different job seeking populations. Journal of Business Ethics, 28, 243-253.

Allen, D. G., Mahto, R. V., \& Otondo, R. F. (2007). Web-based recruitment: Effects of information, organizational brand, and attitudes toward a web site on applicant attraction. Journal of Applied Psychology, 92, 1696-1708.

Arthur, W., Jr., Bell, S. T., Doverspike, D., \& Villado, A. J. (2006). The use of personorganization fit in employment decision making: An assessment of its criterionrelated validity. Journal of Applied Psychology, 91, 786-801.

Arthur, W., Bennett, W., Edens, P. S., \& Bell, S. T. (2003). Effectiveness of training in organizations: A meta-analysis of design and evaluation features. Journal of Applied Psychology, 88, 234-245. 
Ashforth, B. E., \& Mael, E. (1989). Social identity theory and the organization. Academy of Management Review, 14, 20-39.

Avery, D. R., \& McKay, P. F. (2006). Target practice: An organizational impression management approach to attracting minority and female job applicants. Personnel Psychology, 59, 157-187.

Ajzen, I. (1985). From intentions to action: A theory of planned behavior. In J. Kuhl \& J. Beckman (Eds.), Action control: From cognitions to behaviors (pp. 11-39). New York: Springer.

Ajzen, I. (1991). The theory of planned behavior. Organizational Behavior and Human Decision Processes, 50, 179-211.

Ajzen, I., \& Fishbein, M. (1980). Understanding attitudes and predicting social behavior. Englewood Cliffs, NJ: Prentice Hall.

Bagozzi, R. P. (1981). Attitudes, intentions, and behavior: A test of some key hypotheses. Journal of Personality \& Social Psychology, 41, 607-627.

Bangerter A., Roulin N. \& König C.J. (in press). Personnel selection as a signaling game. Journal of Applied Psychology.

Barber, A. E. (1998). Recruiting employees: Individual and organizational perspectives. Thousand Oaks, CA: Sage.

Barber, A. E., \& Roehling, M. V. (1993). Job postings and the decision to interview: A verbal protocol analysis. Journal of Applied Psychology, 78, 845-856. 
Barber, A. E., Wesson, M. J., Roberson, Q. M., \& Taylor, M. S. (1999). A tale of two job markets: Organizational size and its effects on hiring practices and job search behavior. Personnel Psychology, 52, 841-868.

Barcikowski, R. S. (1981). Statistical power with group mean as the unit of analysis. Journal of Educational Statistics, 6, 267-285.

Baron, R. M., \& Kenny, D. A. (1986). The moderator-mediator variable distinction in social psychological research: Conceptual, strategic, and statistical considerations. Journal of Personality and Social Psychology, 51, 1173-1182.

Barrick, M. R., Swider, B. W., \& Stewart, G. L. (2010). Initial evaluations in the interview: Relationships with subsequent interviewer evaluations and employment offers. Journal of Applied Psychology, 95, 1163-1172.

Bauer, T. N., Maertz, C. P., Dolen, M. R., \& Campion, M. A. (1998). Longitudinal assessment of applicant reactions to employment testing and test outcome feedback. Journal of Applied Psychology, 83, 892-903.

Bazerman, M. H., Schroth, H. A., Shah, P. P., Diekmann, K. A., \& Tenbrunsel, A. (1994). The inconsistent role of comparison others and procedural justice in reactions to hypothetical job descriptions: Implications for job acceptance decisions. Organizational Behavior \& Human Decision Processes, 60, 326-352.

Becker, W. J., Connolly, T., \& Slaughter, J. E. (2010). The effect of job offer timing on offer acceptance, performance, and turnover. Personnel Psychology, 63, 223241. 
Behling, O., Labovitz, G., \& Gainer, M. (1968). College recruiting: A theoretical basis. Personnel Journal, 47, 13-19.

Belt, J. A., \& Paolillo, J. G. P. (1982). The influence of corporate image and specificity of candidate qualifications on response to recruitment advertising. Journal of Management, 8, 105-112.

Bliese, P. D. (1998). Group size, ICC values, and group-level correlations: A simulation. Organizational Research Methods, 1, 355-373.

Bliese, P. D. (2000). Within-group agreement, non-independence, and reliability: Implications for data aggregation and analysis. In K. J. Klein \& S. W. Kozlowski (Eds.), Multilevel Theory, Research, and Methods in Organizations (pp. 349381). San Francisco, CA: Jossey-Bass, Inc.

Bliese, P. D., Chan, D., \& Ployhart, R. E. (2007). Multilevel methods: Future directions in measurement, longitudinal analyses, and non-normal outcomes. Organizational Research Methods, 10, 551-563.

Bliese, P. D., \& Hanges, P. (2004). Being both too liberal and too conservative: The perils of treating grouped data as though they were independent. Organizational Research Methods, 7, 400-417.

Bliese, P. D., \& Ployhart, R. E. (2002). Growth modeling using random coefficient models: Model building, testing, and illustrations. Organizational Research Methods, 5, 362-387. 
Bond, S. D., Carlson, K. A., Meloy, M. G., Russo, J. E., \& Tanner, R. J. (2007).

Precommitment bias in the evaluation of single options. Organizational Behavior and Human Decision Processes, 102, 240-254.

Boswell, W. R. (2006). Job search. In S.G. Rogelberg, Encyclopedia of Industrial/Organizational Psychology (pp. 414-416), Sage Publications.

Boswell, W. R., Boudreau, J. W., \& Tichy, J. (2005). The relationship between employee job change and job satisfaction: The honeymoon-hangover effect. Journal of Applied Psychology, 90, 882-892.

Boswell, W. R., Roehling, M. V., LePine, M. A., \& Moynihan, L. M. (2003). Individual job-choice decisions and the impact of job attributes and recruitment practices: A longitudinal field study. Human Resource Management, 42, 23-37.

Boswell, W. R., Shipp, A. J., Payne, S. C., \& Culbertson, S. S. (2009). Changes in newcomer job satisfaction over time: Examining the pattern of honeymoons and hangovers. Journal of Applied Psychology, 94, 844-858.

Boswell, W.R., Zimmerman, R.D., \& Swider, B.W. (2012). Toward an understanding of search context and search objectives. Journal of Management, 38, 129-163.

Braddy, P.W., Meade, A.W., \& Kroustalis, C.M. (2006). Organizational recruitment website effects on viewers' perceptions of organizational culture. Journal of Business and Psychology, 20, 525-543.

Breaugh, J. A. (2008). Employee recruitment: Current knowledge and important areas for future research. Human Resource Management Review, 18, 103-118. 
Breaugh, J. A., Macan, T. H., \& Grambow, D.M. (2008). Employee recruitment: Current knowledge and directions for future research. In Hodgkinson, G. P. \& Ford, J.K. (Eds.) International Review of Industrial and Organizational Psychology, Volume 23 (pp. 45-82). Hoboken, NJ: John Wiley \& Sons Ltd.

Breaugh, J. A., \& Starke, M. (2000). Research on employee recruitment: So many studies, so many remaining questions. Journal of Management, 26, 405-434.

Bretz, R. D., Ash, R. A., \& Dreher, G. F. (1989). Do people make the place? An examination of the attraction-selection-attrition hypothesis. Personnel Psychology. 42, 561-581.

Bretz, R. D., \& Judge, T. A. (1994). Person- organization fit and the theory of work adjustment: Implications for satisfaction, tenure, and career success. Journal of Vocational Behavior, 44, 32-54.

Bretz, R. D., \& Judge, T. A. (1998). Realistic job previews: A test of the adverse selfselection hypothesis. Journal of Applied Psychology, 83, 330-337.

Bretz, R. D., Rynes, S. L., \& Gerhart, B. (1993). Recruiter perceptions of applicant fit: Implications for individual career preparation and job search behavior. Journal of Vocational Behavior, 43, 310-327.

Brooks, M., Highhouse, S., Russell, S., \& Mohr, D. (2003). Familiarity, ambivalence, and firm reputation: Is corporate fame a double-edged sword? Journal of Applied Psychology, 88, 904-914. 
Brown, B., \& Campion, M. A. (1994). Biodata phenomenology: Recruiters' perceptions and use of biographical information in resume screening. Journal of Applied Psychology, 79, 897-908.

Brown, T. J., Dacin, P. A., Pratt, M. G. \& Whetten, D. A. (2006). Identity, intended image, construed image, and reputation: An interdisciplinary framework and suggested terminology. Journal of the Academy of Marketing Science, 34, 99106.

Brownstein, A. L. (2003). Biased predecision processing. Psychological Bulletin, 129, $545-568$.

Brownstein, A. L., Read, S. J., \& Simon, D. (2004). Bias at the racetrack: Effects of individual expertise and task importance on predecision reevaluation of alternatives. Personality and Social Psychology Bulletin, 30, 891-904.

Bryk, A. S., \& Raudenbush, S. W. (1992). Hierarchical linear models: Applications and data analysis methods. Newbury Park, CA: Sage.

Burke, R. J., \& Deszka, E. (1982). Preferred organizational climates of type A individuals. Journal of Vocational Behavior, 21, 50-59.

Cable, D. M., Aiman-Smith, L., Mulvey, P., \& Edwards, J. (2000). The sources and accuracy of job applicants' beliefs about organizational culture. Academy of Management Journal, 43, 1076-1085.

Cable, D. M., \& DeRue, D. S. (2002). The convergent and discriminant validity of subjective fit perceptions. Journal of Applied Psychology, 87, 875-884. 
Cable, D. M., \& Graham, M. E. (2001). The determinants of job seekers' reputation perceptions. Journal of Organizational Behavior, 21, 929-947.

Cable, D. M., \& Judge, T. (1996). Person-organization fit, job choice decisions, and organizational entry. Organizational Behavior and Human Decision Processes, 67, 294-311.

Cable, D. M., \& Turban, D. (2003). The value of organizational reputation in the recruitment context: A brand equity perspective. Journal of Applied Social Psychology, 33, 2244-2266.

Carless, S. A. (2005). Person-job fit versus person-organization fit as predictors of organizational attraction and job acceptance intentions: A longitudinal study. Journal of Occupational and Organizational Psychology, 78, 411-429.

Carlson, K. A., \& Russo, J. E. (2001). Biased interpretation of evidence by mock jurors. Journal of Experimental Psychology: Applied, 7, 91-103.

Chapman, D. S., \& Rowe, P. M. (2002). The influence of videoconference technology and interview structure on the recruiting function of the employment interview: A field experiment. International Journal of Selection and Assessment, 10, 185197.

Chapman, D. S., Uggerslev, K. L., Carroll, S. A., Piasentin, K. A., \& Jones, D. A. (2005). Applicant attraction to organizations and job choice: A meta-analytic review of the correlates of recruiting outcomes. Journal of Applied Psychology, 90, 928-944. 
Chapman, D. S., Uggerslev, K. L., \& Webster, J. (2003). Applicant reactions to face-toface and technology-mediated interviews: A field investigation. Journal of Applied Psychology, 88, 944-953.

Chapman, D. S., \& Webster, J. (2006). Toward an integrated model of applicant reactions and job choice. International Journal of Human Resource Management, 17, 1032-1057.

Chapman, D. S. \& Zweig, D. I. (2005). Developing a nomological network for interview structure: Antecedents and consequences of the structured selection interview. Personnel Psychology, 58, 673-702.

Chatman, J. A. (1989). Improving interactional organizational research: A model of person-organization fit. Academy of Management Review, 14, 333-349.

Cober, R. T., Brown, D. J., Keeping, L. M., \& Levy, P. E. (2004). Recruitment on the net: How do organizational web site characteristics influence applicant attraction? Journal of Management, 30, 623-646.

Collins, C. J. (2007). The interactive effects of recruitment practices and product awareness in job seekers' employer knowledge and applicant behaviors. Journal of Applied Psychology, 92, 180-190.

Collins, C. J., \& Han, J. (2004). Exploring applicant pool quantity and quality: The effects of early recruitment practices, corporate advertising, and firm reputation. Personnel Psychology, 57, 685-717.

Collins, C. J., \& Stevens, C. K. (2002). The relationship between early recruitmentrelated activities and the application decisions of new labor-market entrants: A 
brand equity approach to recruitment. Journal of Applied Psychology, 87, 11211133.

Connerley, M. L. (1997). The influence of training on perceptions of recruiters' interpersonal skills and effectiveness. Journal of Occupational and Organizational Psychology, 70, 259-272.

Connerley, M. L., Carlson, K. D., \& Mecham, R. L. (2003). Evidence of differences in applicant pool quality. Personnel Review, 32, 22-39.

Connerley, M. L. \& Rynes, S. L. (1997). The influence of recruiter characteristics and organizational recruitment support on perceived recruiter effectiveness: Views from applicants and recruiters. Human Relations, 50, 1563-1586.

Dineen, B. R., Ash, S. R., \& Noe, R. A. (2002). A web of applicant attraction: Personorganization fit in the context of Web-based recruitment. Journal of Applied Psychology, 87, 723-734.

Dineen, B. R., \& Noe, R. A. (2009). Effects of customization on application decisions and applicant pool characteristics in a Web-based recruitment context. Journal of Applied Psychology, 94, 224-234.

Dineen, B. R., Noe, R. A., \& Wang, C. (2004). Perceived fairness of web-based applicant screening procedures: Weighing the rules of justice and the role of individual differences. Human Resource Management, 43, 127-45.

Dineen, B. R., \& Soltis, S. M. (2010). Recruitment: A review of research and emerging directions. In S.Zedeck (Ed.), APA Handbook of Industrial and Organizational 
Psychology (Vol. 2: Selecting and developing members for the organization; pp. 43-66). Washington: American Psychological Association.

Dreher, G. F, \& Dougherty, T. W. (1980). Turnover and competition for expected job openings: An exploratory analysis. Academy of Management Journal, 23, 766772.

Dutton, J. E., Dukerich, J. M., \& Harquail, C. V. (1994). Organizational images and member identification. Administrative Science Quarterly, 39, 239-263.

Edwards, J. R. (2008). Person-environment fit in organizations: An assessment of theoretical progress. Academy of Management Annals, 2, 167-230.

Edwards, J. R., Cable, D. M., Williamson, I. O., Lambert, L. S., \& Shipp, A. J. (2006). The phenomenology of fit: Linking the person and environment to the subjective experience of person-environment fit. Journal of Applied Psychology, 91, 802827.

Ehrhart, K. H., \& Ziegert, J. C. (2005). Why are individuals attracted to organizations? Journal of Management, 31, 901-919.

Elliot, A. J., \& Devine, P. G. (1994). On the motivational nature of cognitive dissonance: Dissonance as psychological discomfort. Journal of Personality and Social Psychology, 67, 382-394.

Festinger, L. (1957). A theory of cognitive dissonance. Stanford, CA: Stanford University Press.

Fishbein, M., \& Ajzen, I. (1975). Belief, attitude, intention and behavior: An introduction to theory and research. Reading, MA: Addison-Wesley. 
Fisher, C. D., Ilgen, D. R., \& Hoyer, W. D. (1979). Source credibility, information favorability, and job offer acceptance. Academy of Management Journal, 22, 94103.

Gatewood, R. D., Gowan, M. A., \& Lautenschlager, G. J. (1993). Corporate image, recruitment image, and initial job choice decisions. Academy of Management Journal, 36, 414-427.

George, J. M., \& Jones, G. R. 2000. The role of time in theory and theory building. Journal of Management, 26, 657-684.

Gilliland, S. W. (1993). The perceived fairness of selection systems: An organizational justice perspective. Academy of Management Review, 18, 694-734.

Goltz, S. M., \& Giannantonio, C. M. (1995). Recruiter friendliness and attraction to the job: The mediating role of inferences about the organization. Journal of Vocational Behavior, 46, 109-118.

Harris, M. M., \& Fink, L. S. (1987). A field study of employment opportunities: Does the recruiter make a difference? Personnel Psychology, 40, 765-784.

Harn, T. J., \& Thornton, G. C. (1985). Recruiter counseling behaviors and applicant impressions. Journal of Occupational Psychology, 58, 57-65.

Harrison, D. A., \& Klein, K. J. (2007). What's the difference? Diversity constructs as separation, variety, or disparity in organizations. Academy of Management Review, 32, 1199-1228. 
Harrison, D. A., Newman, D. A., \& Roth, P. L. (2006). How important are job attitudes? Meta-analytic comparisons of integrative behavioral outcomes and time sequences. Academy of Management Journal, 49, 305-325.

Harold, C. M., \& Ployhart, R. E. (2008). What do applicants want? Examining changes in attribute judgments over time. Journal of Occupational and Organizational Psychology, 81, 191-218.

Hastie, R. (2001). Problems for judgment and decision making. Annual Review of Psychology, 52, 653-683.

Hausknecht, J. P., Day, D. V., \& Thomas, S. C. (2004). Applicant reactions to selection procedures: An updated model and meta-analysis. Personnel Psychology, 57, 639-683.

Herriot, P. (2004). Social identities and applicant reactions. International Journal of Selection and Assessment, 12, 75-83.

Higgins, C. A., \& Judge, T. A. (2004). The effect of applicant influence tactics on recruiter perceptions of fit and hiring recommendations: A field study. Journal of Applied Psychology, 89, 622-632.

Highhouse, S., Broadfoot, A., Yugo, J. E., \& Devendorf, S. A. (2009). Examining corporate reputation judgments with generalizability theory. Journal of Applied Psychology, 782-789.

Highhouse, S., \& Hoffman, J. R. (2001). Organizational attraction and job choice. In C.L. Cooper \& I.T. Robertson (Eds.), International review of industrial and organizational psychology (pp. 37-64). Chichester: Wiley. 
Highhouse, S., Lievens, F., \& Sinar, E. F. (2003). Measuring attraction to organizations. Educational and Psychological Measurement, 63, 986-1001.

Highhouse, S., Zickar, M. J., Thorsteinson, T. J., Stierwalt, S. L., \& Slaughter, J. (1999). Assessing company employment image: An example in the fast food industry. Personnel Psychology, 52, 151-172.

Hofmann, D., \& Gavin, M. (1998). Centering decisions in hierarchical linear models: Implications for research in organizations. Journal of Management, 24, 623-641.

Holtom, B. C., Mitchell, T. R., Lee, T. W., \& Interrieden, E. J. (2005). Shocks as causes of turnover: What they are and how organizations can manage them. Human Resource Management, 44, 337-352.

Hunter, J. E., \& Schmidt, F. L. (2004). Methods of meta-analysis: Correcting error and bias in research findings. Thousand Oaks: Sage Publications.

Janis, I. L., \& Mann, L. (1977). Decision making: A psychological analysis of conflict, choice, and commitment. New York: Free Press.

Johnson, J. \& LeBreton, J. M. (2004). History and use of relative importance indices in organizational research. Organizational Research Methods, 7, 238-257.

Judge, T. A., \& Bretz, R. D. (1992). Effects of work values on job choice decisions. Journal of Applied Psychology, 77, 261-271.

Judge, T. A., \& Cable, D. M. (1997). Applicant personality, organizational culture, and organization attraction. Personnel Psychology, 50, 359-394. 
Kanar, A. M., Collins, C., \& Bell, B. (2006). A comparison of the effects of positive and negative information on job seekers' organizational attraction and attribute recall. Human Performance, 23, 193-212.

Kanfer, R., Wanberg, C. R., \& Kantrowitz, T. M. (2001). Job search and employment: A personality-motivational analysis and meta-analytic review. Journal of Applied Psychology, 86, 837-855.

Kammeyer-Mueller, J. D., \& Liao, H. (2006). Workforce reduction and job-seeker attraction: Examining job seekers' reactions to firm workforce reduction policies. Human Resource Management, 45, 585-603.

Kammeyer-Mueller, J. D., Wanberg, C. R., Glomb, T. M., \& Ahlburg, D. (2005). The role of temporal shifts in turnover processes: It's about time. Journal of Applied Psychology, 90, 644-658.

Kenny, D. A., \& Judd, C. M. (1986). Consequences of violating the independence assumption in analysis of variance. Psychological Bulletin, 99, 422-431.

Kilduff, M. (1990). The interpersonal structure of decision making: A social comparison approach to organizational choice. Organizational Behavior and Human Decision Processes, 47, 270-288.

Kilduff. M. (1992). The friendship network as a decision-making resource: Dispositional moderators of social influences on organizational choice. Journal of Personality and Social Psychology. 62, 168-180.

Kim, M., \& Hunter, J. (1993). Relationships among attitudes, intentions and behavior. Communication Research, 20, 331-364. 
Kristof, A. L. (1996). Person-organization fit: An integrative review of its conceptualizations, measurement, and implications. Personnel Psychology, 49, $1-49$.

Kristof-Brown, A. L. (2000). Perceived applicant fit: Distinguishing between recruiters' perceptions of person-job and person-organization fit. Personnel Psychology, 53, $643-671$.

Kristof-Brown, A. L., Zimmerman, R. D., \& Johnson, E. C. (2005). Consequences of individuals' fit at work: A meta-analysis of person-job, person-organization, person-group, and person-supervisor fit. Personnel Psychology, 58, 281-342.

Lam, S. K. (1997). SERVQUAL: A tool for measuring patients' opinions of hospital service quality in Hong Kong. Total Quality Management, 8, 145-152.

Larsen, D. A., \& Phillips, J. I. (2002). Effect of recruiter on attraction to the firm: Implications of the elaboration likelihood model. Journal of Business and Psychology, 16, 347-364.

LeBreton, J. M., Binning, J. F., Adorno, A. J., \& Melcher, K. M. (2004). Importance of personality and job-specific affect for predicting job attitudes and withdrawal behavior. Organizational Research Methods, 7, 300-325.

Lee, T. W., Gerhart, B., Weller, I., \& Trevor, C. O. (2008). Understanding voluntary turnover: Path-specific job satisfaction effects and the importance of unsolicited job offers. Academy of Management Journal, 51, 651-671.

Lee, T. W., Mitchell, T. R., Wise, L., \& Fireman, S. (1996). An unfolding model of voluntary employee turnover. Academy of Management Journal,39, 5-36. 
Lemmink, J., Schuijf, A., \& Streukens, S. (2003). The role of corporate image and company employment image in explaining application intentions. Journal of Economic Psychology, 24, 1-15.

Lewin, K. (1935). Dynamic theory of personality. New York: McGraw-Hill.

Lievens, F., Decaesteker, C., Coetsier, P., \& Geirnaert, J. (2001). Organizational attractiveness for prospective applicants: A person-organization fit perspective. Applied Psychology: An International Review, 50, 30-51.

Lievens, F., \& Highhouse, S. (2003). The relation of instrumental and symbolic attributes to a company's attractiveness as an employer. Personnel Psychology, 56, 75-102.

Ma, R., \& Allen, D. G. (2009). Recruiting across cultures: A value-based model of recruitment. Human Resource Management Review, 19, 334-346.

MacKinnon, D. P. (2008). Introduction to statistical mediation analysis. Mahwah, NJ: Lawrence Erlbaum.

Maurer, S., Howe, V., \& Lee, T. (1992). Organizational recruiting as marketing management: An interdisciplinary study of engineering graduates. Personnel Psychology, 45, 807-833.

McBroom, W. H., \& Reed, F.W. (1992). Toward a reconceptualization of attitudebehavior consistency. Social Psychological Quarterly, 55, 205-216.

McCulloch, M. C. \& Turban, D. B. (2007). Using person-organization fit to select employees for high-turnover jobs. International Journal of Selection and Assessment, 15, 63-71. 
McKay, P. F., \& Avery, D. R. (2006). What has race got to do with it? Unraveling the role of racioethnicity in job seekers' reactions to site visits. Personnel Psychology, 59, 395-429.

Mellers, B. A., Schwartz, A., \& Cooke, A. D. J. (1998). Judgment and decision making. Annual Review of Psychology, 49, 447-477.

Mills, J., \& Ford, T. E. (1995). Effects of importance of a prospective choice on private and public evaluations of the alternatives. Personality and Social Psychology Bulletin, 21, 256-266.

Mitchell, T. R. (1974). Expectancy models of job satisfaction, occupational preference, and effort: A theoretical, methodological, and empirical appraisal. Psychological Bulletin, 81, 1053-1077.

Mitchell, T. R., Holtom, B. C., Lee, T. W., Sablynski, C. J., \& Erez, M. (2001). Why people stay: Using job embeddedness to predict voluntary turnover. Academy of Management Journal, 44, 1102-1121.

Mitchell, T. R., \& James, L. R. (2001). Building better theory: Time and the specification of when things happen. Academy of Management Review, 26, 530547.

Montgomery, H. (1983). Decision rules and the search for a dominance structure:

Towards a process model of decision making. In P. C. Humphreys, O. Svenson, \& A. Vari (Eds.), Analysing and aiding decision processes (pp. 343-369). Amsterdam: North-Holland and Budapest: Akademiai Kiado. 
Montgomery, H. (1994). Towards a perspective theory of decision making and judgment. Acta Psychologica, 87, 155-178.

Montgomery, H., Selart, M., Garling, T., \& Lindberg, E. (1994). The judgment-choice discrepancy: Noncompatibility or restructuring? Journal of Behavioral Decision Making, 7, 145-155.

Montgomery, H., \& Willen, H. (1999). Decision making and action: The search for a good structure. In P. Jusslin \& H. Montgomery (Eds.), Judgment and decision making: Neo-Brunswikian and process-tracing approaches (pp. 147-173). Mahwah, NJ: Erlbaum.

Moore, D. A., \& Flynn, F. J. (2008). The case of behavioral decision research in organizational behavior. Academy of Management Annals, 2, 399-431.

Moynihan, L. M., Roehling, M. V., LePine, M. A., Boswell, W. R. (2003). A longitudinal study of the relationships among job search self-efficacy, job interviews, and employment outcomes. Journal of Business and Psychology, 18, 207-233.

Muchinsky. P. M., \& Monahan, C. J. (1987). What is person-environment congruence? Supplementary versus complementary models of fit. Journal of Vocational Behavior, 31, 268-277.

Murphy, K. R. (1986). When your top choice turns you down: Effect of rejected job offers on utility of selection tests. Psychological Bulletin, 99, 128-133. 
Murphy, K. R., \& Tam, A. P. (2004). The decisions job applicants must make: Insights from a Bayesian perspective. International Journal of Selection and Assessment, $12,66-74$.

Ng, E. W. S., \& Burke, R. (2005). Person-organization fit and the war for talent: Does diversity management make a difference? International Journal of Human Resource Management, 16, 1195-1210.

Nickerson, R. S. (1998). Confirmation bias: A ubiquitous phenomenon in many guises. Review of General Psychology, 2, 175-220.

O'Reilly, C. A., Chatman, J., \& Caldwell, D. F. (1991). People and organizational culture: A profile comparison approach to assessing person- organization fit. Academy of Management Journal, 34, 487-516.

Olson, J. M., \& Zanna, M. P. (1993). Attitudes and attitude change. Annual Review of Psychology, 44, 117-154.

Osborn, D. P. (1990). A reexamination of the organizational choice process. Journal of Vocational Behavior, 36, 45-60.

Parsons, F. (1909). Choosing a vocation. Boston: Houghton-Mifflin.

Perkins, L. A., Thomas, K. M., \& Taylor, G. A. (2000). Advertising and recruitment: Marketing to minorities. Psychology and Marketing, 17, 235-255.

Phillips, J. M. (1998). Effects of realistic job previews on multiple organizational outcomes: A meta-analysis. Academy of Management Journal, 41, 673-690.

Pinheiro, J. C., \& Bates, D. M. 2000. Mixed-effects models in S and S-PLUS. New York: Springer. 
Ployhart, R. E. (2006). Staffing in the $21^{\text {st }}$ century: New challenges and strategic opportunities. Journal of Management, 32, 868-897.

Ployhart, R. E., Ehrhart, K. H., \& Hayes, S. C. (2005). Using attributions to understand the effects of explanations on applicant reactions: Are reactions consistent with the covariation principle? Journal of Applied Social Psychology, 35, 259-296.

Ployhart, R. E., \& Vandenberg, R. J. (2010). Longitudinal research: The theory, design, and analysis of change. Journal of Management, 36, 94-120.

Powell, G. N. (1984). Effects of job attributes and recruiting practices on applicant decisions: A comparison. Personnel Psychology, 37, 721-732.

Powell, G. N., \& Goulet, L. R. (1996). Recruiters' and applicants' reactions to campus interviews and employment decisions. Academy of Management Journal, 39, 1619-1640.

Preacher, K. J., Curran, P. J., \& Bauer, D. J. (2006). Computational tools for probing interaction effects in multiple linear regression, multilevel modeling, and latent curve analysis. Journal of Educational and Behavioral Statistics, 31, 437-448.

Rao, H., \& Drazin, R. (2002). Overcoming resource constraints on product innovation by recruiting talent from rivals: A study of the mutual fund industry, 1986-94. Academy of Management Journal, 45, 491-507.

Rau, B. L., \& Adams, G. A. (2005). Attracting retirees to apply: Desired organizational characteristics of bridge employment. Journal of Organizational Behavior, 26, 649-660. 
Raudenbush, S. W., \& Bryk, A. S. (2002). Hierarchical linear models: Applications and data analysis methods. Thousand Oaks, CA: Sage.

Resick, C.J., Baltes, B.B. \& Shantz, C.W. (2007). Person-organization fit and workrelated attitudes and decisions: Examining interactive effects with job fit and conscientiousness. Journal of Applied Psychology, 92, 1446-1455.

Richey, B., Bernardin, H. J., Tyler, C. L., \& McKinney, N. (2001). The effects of arbitration program characteristics on applicants' intentions toward potential employers. Journal of Applied Psychology, 86, 1006-1013.

Roberson, Q. M., Collins, C. J., \& Oreg, S. (2005). The effects of recruitment message specificity on applicant attraction to organizations. Journal of Business and Psychology, 19, 319-339.

Rousseau, D. M., Sitkin, S. B., Burt, R. S., \& Camerer, C. (1998). Not so different after all: A cross-discipline view of trust. Academy of Management Review, 23, 393404.

Russo, J. E., Carlson, K. A., \& Meloy, M. G. (2006). Choosing an inferior alternative. Psychological Science, 17, 899-904.

Russo, J. E., Medvec, V. H., \& Meloy, M. G. (1996). The distortion of information during decisions. Organizational Behavior and Human Decision Processes, 66, $102-110$.

Russo, J. E., Meloy, M. G., \& Medvec, V. H. (1998). Predecisional distortion of product information. Journal of Marketing Research, 35, 438-452. 
Russo, J. E., Meloy, M. G., \& Wilks, T. J. (2000). Predecisional distortion of information by auditors and salespersons. Management Science, 46, 13-27.

Ryan, A. M., \& Huth, M. (2008). Not much more than platitudes? A critical look at the utility of applicant reactions research. Human Resource Management Review, 18, $119-132$.

Rynes, S. (1991). Recruitment, job choice, and post-hire consequences: A call for new research directions. In M. Dunnette \& L. Hough (eds.), Handbook of industrial and organizational psychology (2nd ed., Vol. 2, pp. 399-444). Palo Alto, CA: Consulting Psychologists.

Rynes, S. L., Bretz, R. D. Jr., \& Gerhart, B. (1991). The importance of recruitment in job choice: A different way of looking. Personnel Psychology, 44, 487-521.

Rynes, S. L., \& Cable, D. M. (2003). Recruitment research in the twenty-first century. In W. C. Borman, D. R. Ilgen, \& R. J. Klimoski (eds), Handbook of Psychology: Industrial and Organizational Psychology, Volume 12 (pp. 55-76). Hoboken, NJ: Wiley \& Sons Ltd.

Rynes, S. L., \& Miller, H. E. (1983). Recruiter and job influences on candidates for employment. Journal of Applied Psychology, 68, 147-154.

Saks, A. M. (2005). Job search success: A review and integration of the predictors, behaviors, and outcomes. In S. D. Brown \& R. W. Lent (Eds.), Career development and counseling: Putting theory and research to work (pp. 155-179). Hoboken, NJ: Wiley. 
Saks, A. M., \& Ashforth, B. E. (1997). A longitudinal investigation of the relationships between job information sources, applicant perceptions of fit, and work outcomes. Personnel Psychology, 50, 395-426.

Saks, A. M., \& Ashforth, B. E. (2002). Is job search related to employment quality? It all depends on the fit. Journal of Applied Psychology, 87, 646-654.

Saks, A. M., \& Uggerslev, K. L. (2010). Sequential and combined effects of recruitment information on applicant reactions. Journal of Business and Psychology, 25, $351-365$.

Schmit, M. J., \& Ryan, A. M. (1997). Applicant withdrawal: The role of test-taking attitudes and racial differences. Personnel Psychology, 50, 855-876.

Schmitt, N., \& Coyle, B. W. (1976). Applicant decisions in the employment interview. Journal of Applied Psychology, 61, 184-192.

Schneider, B. (1987). The people make the place. Personnel Psychology, 40, 437-453.

Schreurs, B., Derous, E., De Witte, K., Proost, K., Andriessen, M., \& Glabeke, K. (2005). Attracting potential applicants to the military: The effects of initial faceto-face contacts. Human Performance, 18, 105-122.

Schwab, D. P., Rynes, S. L., \& Aldag, R. J. (1987). Theories and research on job search and choice. In K. M. Rowland \& G. R. Ferris (Eds.), Research in personnel and human resources management (Vol. 5, pp. 129-166). Greenwich, CT: JAI Press.

Schwartz, S. H. (1978). Temporal instability as a moderator of the attitude-behavior relationship. Journal of Personality and Social Psychology, 36, 715-724. 
Shafir, E. (1993). Choosing versus rejecting: Why some options are better and worse than others. Memory \& Cognition, 21, 546-556.

Shah, A. K., \& Oppenheimer, D. M. (2008). Heuristics made easy: An effort reduction framework. Psychological Bulletin, 134, 207-222.

Sheppard, B. H., Hartwick, J., \& Warshaw, P. R. (1988). The theory of reasoned action: A meta-analysis of past research with recommendations for modifications and future research. Journal of Consumer Research, 15, 325-343.

Simon, D., Krawczyk, D. C., Bleicher, A., \& Holyoak, K. J. (2008). The transience of constructed preferences. Journal of Behavioral Decision Making, 21, 1-14.

Simon, D., Krawczyk, D. C., \& Holyoak, K. J. (2004). Construction of preferences by constraint satisfaction. Psychological Science, 15, 331-336.

Simon, D., Snow, C. J., \& Read, S .J. (2004). The redux of cognitive consistency theories: Evidence judgments by constraint satisfaction. Journal of Personality and Social Psychology, 86, 814-837.

Singer, J. D., \& Willett, J. B. 2003. Applied longitudinal data analysis. New York: Oxford University Press

Slaughter, J. E. \& Greguras, G. J. (2009). Organizations: The influence of trait inferences International Journal of Selection and Assessment, 17, 1-18.

Slaughter, J. E., Zickar, M. J., Highhouse, S., \& Mohr, D. C. (2004). Personality trait inferences about organizations: Development of a measure and assessment of construct validity. Journal of Applied Psychology, 89, 85-103. 
Soelberg, P. (1967). Unprogrammed decision making. Industrial Management Review, $8,19-29$.

Spence, M. (1973). Job market signaling. Quarterly Journal of Economics, 87, 255-274.

Svenson, O. (1992). Differentiation and consolidation theory of human decision making: A frame of reference for the study of pre- and postdecision processes. Acta Psychologica, 80, 143-168.

Svenson, O. (1999). Differentiation and consolidation theory: Decision making processes before and after a choice. In P. Jusslin \& H. Montgomery (Eds.), Judgment and decision making: Neo-Brunswikian and process-tracing approaches (pp. 175-197). Mahwah, NJ: Erlbaum.

Taylor, M., \& Bergmann, T. (1987). Organizational recruitment activities and applicants' reactions at different stages of the recruitment process. Personnel Psychology, 40, 261-285.

Taylor, M. S., \& Collins, C. J. (2000). Organizational recruitment: Enhancing the intersection of theory and practice. In C. L. Cooper \& E. A. Locke (eds.), Industrial and organizational psychology: Linking theory and practice (pp. 304334). Oxford, UK: Basil Blackwell.

Taylor, M. S., \& Giannantonio, C. M. (1993). Forming, adapting, and terminating the employment relationship: A review of the literature from individual, organizational, and interactionist perspectives. Journal of Management, 19, 461515. 
Thompson, L. F., Braddy, P. W., \& Wuensch, K. L. (2008) E-recruitment and the benefits of organizational web appeal. Computers in Human Behavior, 24, 23842398.

Tom, V. R. (1971). The role of personality and organizational images in the recruiting process. Organizational Behavior and Human Performance, 6, 573-592.

Turban, D. B. (2001). Organizational attractiveness as an employer on college campuses: An examination of the applicant population. Journal of Vocational Behavior, 58, $293-312$.

Turban, D. B., \& Cable, D. M. (2003). Firm reputation and applicant pool characteristics. Journal of Organizational Behavior, 24, 733-751.

Turban, D. B., Campion, J. E., \& Eyring, A. R. (1995). Factors related to job acceptance decisions of college recruits. Journal of Vocational Behavior, 47, 193-213.

Turban, D. B., Forret, M. L., \& Hendrickson, C. L. (1998). Applicant attraction to firms: Influences of organizational reputation, job and organizational attributes and recruiter behaviors. Journal of Vocational Behavior, 52, 24-44.

Turban, D. B., \& Greening, D. W. (1997). Corporate social performance and organizational attractiveness to prospective employees. Academy of Management Journal, 40, 658-672.

Turban, D. B., Lau, C., Ngo, H., Chow, I. H., \& Si, S. X. (2001). Organizational attractiveness of firms in the People's Republic of China: A person-organization fit perspective. Journal of Applied Psychology, 86, 194-206. 
Tyszka, T. (1998). Two pairs of conflicting motives in decision making. Organizational Behavior and Human Decision Processes, 74, 189-211.

Van Vianen, A. E. M. (2000). Person-organization fit: The match between newcomers' and recruiters' preferences for organizational cultures. Personnel Psychology, 53, $113-149$.

Verquer, M. L., Beehr, T. A., \& Wagner, S. H. (2003). A meta-analysis of relations between person-organization fit and work attitudes. Journal of Vocational Behavior, 63, 473-489.

Vroom, V. H. (1966). Organizational choice: A study of pre- and postdecision processes. Organizational Behavior and Human Performance, 1, 212-225.

Walker, H. J., Feild, H. S., Giles, W. F., \& Bernerth, J. B. (2008). The interactive effects of job advertisement characteristics and applicant experience on reactions to recruitment messages. Journal of Occupational and Organizational Psychology, $81,619-638$.

Wanous, J. P., Keon, T. L., \& Latack, J. C. (1983). Expectancy theory and occupational/organizational choices: A review and test. Organizational Behavior and Human Performance, 32, 66-86.

Weber, E. U., \& Johnson, E. J. (2009). Mindful judgment and decision making. Annual Review of Psychology, 60, 53-85.

Weiner, B. (1985). An attributional theory of achievement, motivation, and emotion. Psychological Review, 92, 548-573. 
Willett, J. B., \& Sayer, A. G. (1994). Using covariance structure analysis to detect correlates and predictors of individual change over time. Psychological Bulletin, 116, 363-381.

Williamson, I. O., Cable, D. M., \& Aldrich, H. E. (2002). Smaller but not necessarily weaker: How small businesses can overcome barriers to recruitment. In J. Katz, \& T. M. Welbourne (Eds.), Managing people in entrepreneurial organizations: Learning from the merger of entrepreneurship and human resource management (pp. 83-106). Amsterdam: JAI Press.

Wothke, W. (2000). Longitudinal and multi-group modeling with missing data. In T. D. Little, K. U. Schnabel, \& J. Baumert (Eds.), Modeling longitudinal and multiple group data: Practical issues, applied approaches, and specific examples (pp. 219-240). Hillsdale, NJ: Erlbaum.

Zajonc, R. B. (1968). Attitudinal effects of mere exposure. Journal of Personality and Social Psychology, 9, 1-27.

Zuckerman, M. (1979). Attribution of success and failure revisited, or: The motivational bias is alive and well in attribution theory. Journal of Personality, 47, 245-287. 
APPENDIX A

TABLES 
Table A1: Measurement Timing

\begin{tabular}{|c|c|c|c|c|}
\hline & Wave 1 & Wave 2 & Wave 3 & Wave 4 \\
\hline \multirow[t]{15}{*}{ Constructs to be assessed } & Timeliness & Timeliness & Timeliness & Timeliness \\
\hline & Trustworthiness & Trustworthiness & Trustworthiness & Trustworthiness \\
\hline & Image & Image & Image & Image \\
\hline & PO Fit & PO Fit & PO Fit & PO Fit \\
\hline & Attraction to Org & Attraction to Org & Attraction to Org & Attraction to Org \\
\hline & $\begin{array}{l}\text { Acceptance Intentions } \\
\text { Motivation Check } \\
\text { Demographics } \\
\text { Qualifications }\end{array}$ & Acceptance Intentions & Acceptance Intentions & Acceptance Intentions \\
\hline & 90 Items Assessed & 84 Items Assessed & 84 Items Assessed & 84 Items Assessed \\
\hline & Wave 5 & Wave 6 & Wave 7 & Wave 8 \\
\hline & Org Brand Image & Org Brand Image & Org Brand Image & Org Brand Image \\
\hline & PO Fit & PO Fit & PO Fit & PO Fit \\
\hline & Attraction to Org & Attraction to Org & Attraction to Org & Attraction to Org \\
\hline & Acceptance Intentions & Acceptance Intentions & Acceptance Intentions & Acceptance Intentions \\
\hline & Trustworthiness & Trustworthiness & Trustworthiness & Trustworthiness \\
\hline & Timeliness & Timeliness & Timeliness & Timeliness \\
\hline & 84 Items Assessed & 84 Items Assessed & 84 Items Assessed & 84 Items Assessed \\
\hline
\end{tabular}


Table A2: Means, Standard Deviations, Intercorrelations, and Reliabilities

\begin{tabular}{|c|c|c|c|c|c|c|c|c|c|c|c|c|c|c|c|c|c|c|c|}
\hline & Variables & $M$ & $S D$ & 1 & 2 & 3 & 4 & 5 & 6 & 7 & 8 & 9 & 10 & 11 & 12 & 13 & 14 & 15 & 16 \\
\hline 1. & GPA & 3.70 & 0.23 & --- & & & & & & & & & & & & & & & \\
\hline 2. & Timeliness (T1) & 3.17 & 0.52 & $.13^{* *}$ & (.95) & & & & & & & & & & & & & & \\
\hline 3 . & Timeliness (T2) & 3.22 & 0.60 & .04 & $.72^{* *}$ & $(.98)$ & & & & & & & & & & & & & \\
\hline 4. & Timeliness (T3) & 3.27 & 0.58 & .05 & $.68^{* *}$ & $.61^{* *}$ & $(.96)$ & & & & & & & & & & & & \\
\hline 5. & Timeliness (T4) & 3.33 & 0.62 & .08 & $.51^{* *}$ & $.47^{* *}$ & $.64^{* *}$ & (.96) & & & & & & & & & & & \\
\hline 6. & Timeliness (T5) & 3.63 & 0.69 & -.02 & $.38^{* *}$ & $.37^{* *}$ & $.56^{* *}$ & $.59^{* *}$ & $(.98)$ & & & & & & & & & & \\
\hline 7. & Timeliness (T6) & 4.22 & 0.66 & .01 & $.20^{* *}$ & $.21^{* *}$ & $.22^{* *}$ & $.26^{* *}$ & $.36^{* *}$ & (.97) & & & & & & & & & \\
\hline 8. & Timeliness (T7) & 4.41 & 0.59 & .09 & .03 & .01 & .06 & .02 & .11 & $.28^{* * *}$ & $(.95)$ & & & & & & & & \\
\hline 9. & Timeliness (T8) & 4.38 & 0.60 & .06 & .08 & .07 & $.15^{*}$ & $.20^{* *}$ & $.21^{* *}$ & $.26^{* *}$ & $.50^{* *}$ & $(.96)$ & & & & & & & \\
\hline 10. & Trustworthiness (T1) & 3.18 & 0.53 & $.14^{* *}$ & $.87^{* *}$ & $.61^{* *}$ & $.56^{* *}$ & $.47^{* *}$ & $.34^{* *}$ & $.15^{* *}$ & .03 & .07 & $(.92)$ & & & & & & \\
\hline 11. & Trustworthiness (T2) & 3.22 & 0.60 & .06 & $.71^{* *}$ & $.95^{* *}$ & $.61^{* *}$ & $.46^{* *}$ & $.34^{* *}$ & $.15^{* *}$ & .01 & .06 & $.63^{* *}$ & (.94) & & & & & \\
\hline 12. & Trustworthiness (T3) & 3.29 & 0.59 & .08 & $.64^{* *}$ & $.61^{* *}$ & $.94^{* *}$ & $.61^{* *}$ & $.54^{* *}$ & $.21^{* *}$ & .07 & $.15^{* *}$ & $.53^{* *}$ & $.61^{* * *}$ & (.90) & & & & \\
\hline 13. & Trustworthiness (T4) & 3.34 & 0.61 & .09 & $.51^{* *}$ & $.44^{* *}$ & $.58^{* *}$ & $.86^{* *}$ & $.53^{* *}$ & $.24^{* *}$ & .04 & $.18^{* *}$ & $.48^{* *}$ & $.43^{* *}$ & $.58^{* * *}$ & $(.80)$ & & & \\
\hline 14. & Trustworthiness (T5) & 3.68 & 0.66 & .05 & $.32^{* *}$ & $.31^{* *}$ & $.45^{* *}$ & $.51^{* *}$ & $.84^{* *}$ & $.37^{* *}$ & $.14^{*}$ & $.18^{* *}$ & $.31^{* *}$ & $.29^{* *}$ & $.45^{* *}$ & $.50^{* * *}$ & (.84) & & \\
\hline 15. & Trustworthiness (T6) & 4.19 & 0.64 & .09 & $.18^{* *}$ & $.17^{* * *}$ & $.50^{* *}$ & $.22^{* *}$ & $.32^{* *}$ & $.81^{* *}$ & $.30^{* *}$ & $.29^{* *}$ & $.15^{* *}$ & $.13^{*}$ & $.19^{* *}$ & $.21^{* *}$ & $.37^{* * *}$ & $(.80)$ & \\
\hline 16. & Trustworthiness (T7) & 4.33 & 0.59 & .01 & -.01 & .05 & -.01 & -.02 & $.12^{*}$ & $.27^{* *}$ & $.59^{* *}$ & $.39^{* *}$ & .01 & .04 & -.02 & .03 & $.14^{*}$ & $.33^{* *}$ & $(.86)$ \\
\hline 17. & Trustworthiness (T8) & 4.28 & 0.67 & .04 & -.01 & .02 & .04 & $.13^{*}$ & $.15^{*}$ & $.31^{* *}$ & $.39^{* *}$ & $.70^{* *}$ & -.02 & .00 & .03 & $.16^{* *}$ & $.19^{* * *}$ & $.36^{* *}$ & $.51^{* *}$ \\
\hline 18. & Image (T1) & 4.17 & 0.77 & .06 & $.14^{* *}$ & $.21^{* *}$ & $.21^{* *}$ & $.15^{* *}$ & .08 & $.12^{*}$ & $.17^{* *}$ & $.18^{* *}$ & $.15^{* *}$ & $.22^{* *}$ & $.21^{* *}$ & $.10^{*}$ & .00 & $.13^{*}$ & $.13^{*}$ \\
\hline 19. & Image (T2) & 3.93 & 0.80 & .05 & $.19^{* *}$ & $.30^{* *}$ & $.27^{* *}$ & $.24^{* *}$ & $.22^{* *}$ & $.21^{* *}$ & $.26^{* *}$ & $.24^{* *}$ & $.15^{* *}$ & $.30^{* *}$ & $.27^{* *}$ & $.23^{* *}$ & $.20^{* *}$ & $.23^{* *}$ & $.18^{* *}$ \\
\hline 20. & Image (T3) & 3.81 & 0.75 & .01 & $.22^{* *}$ & $.23^{* *}$ & $.39^{* *}$ & $.33^{* *}$ & $.42^{* *}$ & $.25^{* *}$ & $.24^{* *}$ & $.27^{* *}$ & $.19^{* *}$ & $.20^{* *}$ & $.39^{* *}$ & $.30^{* *}$ & $.36^{* *}$ & $.23^{* *}$ & $.17^{* *}$ \\
\hline 21. & Image (T4) & 3.77 & 0.74 & .03 & $.22^{* *}$ & $.22^{* *}$ & $.28^{* *}$ & $.44^{* *}$ & $.36^{* *}$ & $.28^{* *}$ & $.24^{* *}$ & $.25^{* *}$ & $.22^{* *}$ & $.21^{* *}$ & $.28^{* *}$ & $.41^{* *}$ & $.37^{* *}$ & $.28^{* *}$ & $.13^{*}$ \\
\hline 22 . & Image (T5) & 4.14 & 0.66 & .03 & $.11^{*}$ & .10 & $.20^{* *}$ & $.21^{* *}$ & $.41^{* *}$ & $.30^{* *}$ & $.31^{* *}$ & $.22^{* *}$ & $.12^{*}$ & .06 & $.19^{* *}$ & $.22^{* *}$ & $.39^{* *}$ & $.28^{* *}$ & $.28^{* *}$ \\
\hline 23. & Image (T6) & 4.35 & 0.66 & $.19^{* *}$ & .08 & .04 & $.11^{*}$ & $.20^{* *}$ & $.23^{* *}$ & $.53^{* *}$ & $.29^{* * *}$ & $.30^{* *}$ & $.10^{*}$ & .04 & $.11^{*}$ & $.18^{* *}$ & $.25^{* *}$ & $.56^{* *}$ & $.28^{* *}$ \\
\hline 24. & Image (T7) & 4.41 & 0.60 & .03 & .06 & .09 & $.127^{*}$ & .10 & $.19^{* *}$ & $.39^{* *}$ & $.44^{* *}$ & $.27^{* *}$ & .08 & .05 & $.11^{*}$ & .10 & $.17^{* *}$ & $.42^{* *}$ & $.45^{* *}$ \\
\hline 25. & Image (T8) & 4.37 & 0.61 & .04 & .01 & .03 & $.12^{*}$ & $.14^{*}$ & $.14^{*}$ & $.30^{* *}$ & $.33^{* *}$ & $.57^{* *}$ & .03 & .02 & .11 & .09 & .12 & $.36^{* *}$ & $.31^{* *}$ \\
\hline 26. & PO Fit (T1) & 3.43 & 0.72 & .03 & $.50^{* *}$ & $.53^{* *}$ & $.46^{* *}$ & $.37^{* *}$ & $.23^{* *}$ & $.23^{* *}$ & .04 & .02 & $.46^{* *}$ & $.56^{* *}$ & $.41^{* *}$ & $.34^{* *}$ & $.11^{*}$ & $.19^{* *}$ & .03 \\
\hline 27. & PO Fit (T2) & 3.36 & 0.67 & .04 & $.51^{* *}$ & $.58^{* *}$ & $.56^{* *}$ & $.45^{* *}$ & $.35^{* *}$ & $.15^{* *}$ & .05 & $.16^{* *}$ & $.44^{* *}$ & $.59^{* *}$ & $.53^{* *}$ & $.39^{* *}$ & $.27^{* *}$ & $.13^{*}$ & .03 \\
\hline 28. & PO Fit (T3) & 3.39 & 0.65 & -.10 & $.43^{* *}$ & $.48^{* *}$ & $.62^{* *}$ & $.46^{* *}$ & $.42^{* *}$ & $.22^{* *}$ & .08 & $.15^{*}$ & $.34^{* *}$ & $.48^{* *}$ & $.60^{* *}$ & $.45^{* *}$ & $.34^{* *}$ & $.20^{* *}$ & .06 \\
\hline 29. & PO Fit (T4) & 3.41 & 0.68 & -.02 & $.40^{* *}$ & $.42^{* *}$ & $.50^{* *}$ & $.63^{* *}$ & $.44^{* *}$ & $.30^{* *}$ & $.17^{* *}$ & $.24^{* *}$ & $.38^{* *}$ & $.41^{* *}$ & $.47^{* *}$ & $.57^{* *}$ & $.36^{* *}$ & $.31^{* *}$ & .07 \\
\hline 30. & PO Fit (T5) & 3.83 & 0.70 & .00 & $.24^{* *}$ & $.21^{* *}$ & $.34^{* *}$ & $.33^{* *}$ & $.58^{* *}$ & $.26^{* *}$ & $.17^{* *}$ & .11 & $.23^{* *}$ & $.19^{* *}$ & $.30^{* *}$ & $.36^{* *}$ & $.54^{* * *}$ & $.22^{* *}$ & $.16^{* *}$ \\
\hline 31. & PO Fit (T6) & 4.24 & 0.68 & .09 & $.14^{* *}$ & $.12^{*}$ & $.16^{* *}$ & $.23^{* *}$ & $.28^{* *}$ & $.60^{* *}$ & $.30^{* *}$ & $.27^{* *}$ & $.17^{* *}$ & $.12^{*}$ & $.15^{* *}$ & $.24^{* *}$ & $.29^{* * *}$ & $.58^{* *}$ & $.31^{* *}$ \\
\hline 32. & PO Fit (T7) & 4.34 & 0.68 & .03 & .04 & .09 & $.16^{* *}$ & .10 & $.16^{* *}$ & $.34^{* *}$ & $.53^{* *}$ & $.34^{* *}$ & .03 & .08 & $.15^{* *}$ & .08 & $.14^{*}$ & $.36^{* *}$ & $.45^{* *}$ \\
\hline 33. & PO Fit (T8) & 4.22 & 0.77 & .07 & .09 & .08 & $.17^{* *}$ & $.21^{* *}$ & .12 & $.28^{* *}$ & $.40^{* *}$ & $.52^{* *}$ & .07 & .08 & $.19^{* *}$ & $.17^{* *}$ & .07 & $.33^{* *}$ & $.29^{* *}$ \\
\hline 34. & Attraction (T1) & 3.94 & 0.77 & .07 & $.28^{* *}$ & $.35^{* *}$ & $.35^{* *}$ & $.22^{* *}$ & $.24^{* *}$ & $.23^{* *}$ & $.14^{*}$ & $.18^{* *}$ & $.30^{* *}$ & $.37^{* *}$ & $.35^{* *}$ & $.19^{* *}$ & $.18^{* * *}$ & $.23^{* *}$ & $.15^{* *}$ \\
\hline 35. & Attraction (T2) & 3.66 & 0.74 & .03 & $.36^{* *}$ & $.45^{* *}$ & $.43^{* *}$ & $.33^{* *}$ & $.29^{* *}$ & $.20^{* *}$ & $.18^{* *}$ & $.21^{* *}$ & $.32^{* *}$ & $.45^{* *}$ & $.43^{* *}$ & $.31^{* *}$ & $.25^{* *}$ & $.21^{* *}$ & $.12^{*}$ \\
\hline 36. & Attraction (T3) & 3.65 & 0.72 & -.01 & $.30^{* *}$ & $.33^{* *}$ & $.52^{* *}$ & $.39^{* *}$ & $.44^{* *}$ & $.28^{* *}$ & $.18^{* *}$ & $.28^{* *}$ & $.28^{* *}$ & $.31^{* *}$ & $.53^{* *}$ & $.40^{* *}$ & $.40^{* *}$ & $.28^{* *}$ & .08 \\
\hline 37. & Attraction (T4) & 3.67 & 0.72 & -.03 & $.29^{* *}$ & $.33^{* *}$ & $.39^{* *}$ & $.52^{* *}$ & $.39^{* *}$ & $.35^{* *}$ & $.24^{* *}$ & $.24^{* *}$ & $.29^{* *}$ & $.30^{* *}$ & $.39^{* *}$ & $.49^{* *}$ & $.36^{* *}$ & $.31^{* *}$ & $.12^{*}$ \\
\hline 38. & Attraction (T5) & 4.06 & 0.69 & .01 & $.14^{*}$ & .10 & $.25^{* *}$ & $.26^{* *}$ & $.44^{* *}$ & $.33^{* *}$ & $.24^{* *}$ & $.16^{*}$ & $.14^{* *}$ & .07 & $.23^{* *}$ & $.27^{* *}$ & $.44^{* *}$ & $.29^{* *}$ & $.21^{* *}$ \\
\hline 39. & Attraction (T6) & 4.31 & 0.68 & .03 & $.13^{*}$ & .09 & $.15^{* *}$ & $.17^{* *}$ & $.26^{* *}$ & $.56^{* *}$ & $.31^{* * *}$ & $.28^{* * *}$ & $.15^{* *}$ & .09 & $.15^{* *}$ & $.16^{* *}$ & $.30^{* * *}$ & $.57^{* *}$ & $.30^{* *}$ \\
\hline 40. & Attraction (T7) & 4.35 & 0.70 & .01 & .04 & .07 & $.13^{*}$ & .08 & $.12^{*}$ & $.36^{* *}$ & $.53^{* *}$ & $.39^{* *}$ & .02 & .05 & $.15^{* *}$ & .06 & $.12^{*}$ & $.39^{* *}$ & $.45^{* *}$ \\
\hline 41. & Attraction (T8) & 4.15 & 0.80 & .05 & .08 & $.12^{*}$ & $.20^{* *}$ & $.22^{* *}$ & $.16^{*}$ & $.29^{* *}$ & $.33^{* *}$ & $.48^{* *}$ & $.12^{*}$ & .10 & $.23^{* *}$ & $.19^{* *}$ & $.13^{*}$ & $.32^{* *}$ & $.26^{* *}$ \\
\hline 42. & Acceptance Intentions (T1) & 3.52 & 0.63 & .04 & $.34^{* *}$ & $.44^{* *}$ & $.45^{* *}$ & $.33^{* *}$ & $.26^{* *}$ & $.18^{* *}$ & .08 & .11 & $.30^{* *}$ & $.43^{* *}$ & $.42^{* *}$ & $.27^{* *}$ & $.16^{* *}$ & $.19^{* *}$ & .06 \\
\hline 43. & Acceptance Intentions (T2) & 3.46 & 0.66 & .00 & $.41^{* *}$ & $.51^{* *}$ & $.50^{* *}$ & $.38^{* *}$ & $.33^{* *}$ & $.21^{* *}$ & $.14^{*}$ & $.24^{* *}$ & $.34^{* *}$ & $.50^{* *}$ & $.48^{* *}$ & $.32^{* *}$ & $.27^{* *}$ & $.20^{* *}$ & .08 \\
\hline 44. & Acceptance Intentions (T3) & 3.47 & 0.67 & -.03 & $.34^{* *}$ & $.38^{* *}$ & $.59^{* *}$ & $.41^{* *}$ & $.44^{* *}$ & $.23^{* *}$ & $.16^{* *}$ & $.26^{* *}$ & $.31^{* *}$ & $.36^{* *}$ & $.57^{* *}$ & $.36^{* *}$ & $.38^{* *}$ & $.25^{* *}$ & .04 \\
\hline 45. & Acceptance Intentions (T4) & 3.48 & 0.67 & -.07 & $.24^{* *}$ & $.28^{* *}$ & $.39^{* *}$ & $.47^{* *}$ & $.34^{* *}$ & $.33^{* *}$ & $.18^{* *}$ & $.28^{* *}$ & $.25^{* *}$ & $.24^{* *}$ & $.37^{* *}$ & $.41^{* *}$ & $.30^{* * *}$ & $.31^{* *}$ & .07 \\
\hline 46. & Acceptance Intentions (T5) & 3.70 & 0.68 & -.07 & $.16^{* *}$ & $.14^{* *}$ & $.35^{* *}$ & $.28^{* *}$ & $.40^{* *}$ & $.29^{* *}$ & $.17^{* *}$ & $.17^{* *}$ & $.17^{* *}$ & $.12^{*}$ & $.27^{* *}$ & $.26^{* *}$ & $.38^{* *}$ & $.27^{* *}$ & $.12^{*}$ \\
\hline 47. & Acceptance Intentions (T6) & 3.96 & 0.74 & -.04 & $.13^{*}$ & .10 & $.18^{* *}$ & $.16^{* *}$ & $.27^{* *}$ & $.56^{* *}$ & $.28^{* *}$ & $.28^{* *}$ & $.15^{* *}$ & .07 & $.16^{* *}$ & $.17^{* *}$ & $.26^{* *}$ & $.54^{* *}$ & $.29^{* *}$ \\
\hline 48. & Acceptance Intentions (T7) & 3.97 & 0.74 & -.02 & .02 & .10 & $.18^{* *}$ & .10 & $.14^{*}$ & $.26^{* *}$ & $.37^{* *}$ & $.33^{* *}$ & .00 & .07 & $.18^{* *}$ & .08 & .08 & $.27^{* *}$ & $.30^{* *}$ \\
\hline 49. & Acceptance Intentions (T8) & 3.88 & 0.88 & .02 & .11 & $.16^{* *}$ & $.23^{* *}$ & $.22^{* *}$ & .10 & $.18^{* *}$ & $.28^{* *}$ & $.38^{* *}$ & $.12^{*}$ & $.14^{*}$ & $.25^{* *}$ & $.17^{* *}$ & .03 & $.17^{* *}$ & $.12^{*}$ \\
\hline 50. & Job Choice & 0.41 & 0.49 & -.09 & $.11^{*}$ & $.13^{* *}$ & $.12^{*}$ & $.14^{* *}$ & .08 & $.11^{*}$ & $.24^{* *}$ & $.29^{* *}$ & $.11^{*}$ & $.11^{*}$ & $.14^{* *}$ & $.14^{* *}$ & .08 & .10 & $.20^{* *}$ \\
\hline
\end{tabular}


Table A2, Continued

\begin{tabular}{|c|c|c|c|c|c|c|c|c|c|c|c|c|c|c|c|c|c|c|c|}
\hline & Variables & $M$ & $S D$ & 1 & 2 & 3 & 4 & 5 & 6 & 7 & 8 & 9 & 10 & 11 & 12 & 13 & 14 & 15 & 16 \\
\hline 17. & Trustworthiness (T8) & 4.28 & 0.67 & .04 & -.01 & .02 & .04 & $.13^{*}$ & $.15^{*}$ & $.31^{* *}$ & $.39^{* *}$ & $.70^{* *}$ & -.02 & .00 & .03 & $.16^{* *}$ & $.19^{* * *}$ & $.36^{* *}$ & $.51^{* *}$ \\
\hline 18. & Image (T1) & 4.17 & 0.77 & .06 & $.14^{* *}$ & $.21^{* *}$ & $.21^{* *}$ & $.15^{* *}$ & .08 & $.12^{*}$ & $.17^{* *}$ & $.18^{* *}$ & $.15^{* *}$ & $.22^{* *}$ & $.21^{* *}$ & $.10^{*}$ & .00 & $.13^{*}$ & $.13^{*}$ \\
\hline 19. & Image (T2) & 3.93 & 0.80 & .05 & $.19^{* *}$ & $.30^{* *}$ & $.27^{* *}$ & $.24^{* *}$ & $.22^{* *}$ & $.21^{* *}$ & $.26^{* *}$ & $.24^{* *}$ & $.15^{* *}$ & $.30^{* *}$ & $.27^{* *}$ & $.23^{* *}$ & $.20^{* *}$ & $.23^{* *}$ & $.18^{* *}$ \\
\hline 20. & Image (T3) & 3.81 & 0.75 & .01 & $.22^{* *}$ & $.23^{* *}$ & $.39^{* *}$ & $.33^{* *}$ & $.42^{* *}$ & $.25^{* *}$ & $.24^{* *}$ & $.27^{* *}$ & $.19^{* *}$ & $.20^{* *}$ & $.39^{* *}$ & $.30^{* *}$ & $.36^{* *}$ & $.23^{* *}$ & $.17^{* *}$ \\
\hline 21. & Image (T4) & 3.77 & 0.74 & .03 & $.22^{* *}$ & $.22^{* *}$ & $.28^{* *}$ & $.44^{* *}$ & $.36^{* *}$ & $.28^{* *}$ & $.24^{* *}$ & $.25^{* *}$ & $.22^{* *}$ & $.21^{* *}$ & $.28^{* *}$ & $.41^{* *}$ & $.37^{* * *}$ & $.28^{* *}$ & $.13^{*}$ \\
\hline 22 . & Image (T5) & 4.14 & 0.66 & .03 & $.11^{*}$ & .10 & $.20^{* *}$ & $.21^{* *}$ & $.41^{* *}$ & $.30^{* *}$ & $.31^{* *}$ & $.22^{* *}$ & $.12^{*}$ & .06 & $.19^{* *}$ & $.22^{* *}$ & $.39^{* *}$ & $.28^{* *}$ & $.28^{* *}$ \\
\hline 23. & Image (T6) & 4.35 & 0.66 & $.19^{* *}$ & .08 & .04 & $.11^{*}$ & $.20^{* *}$ & $.23^{* *}$ & $.53^{* *}$ & $.29^{* *}$ & $.30^{* *}$ & $.10^{*}$ & .04 & $.11^{*}$ & $.18^{* *}$ & $.25^{* *}$ & $.566^{* *}$ & $.28 * *$ \\
\hline 24. & Image (T7) & 4.41 & 0.60 & .03 & .06 & .09 & $.127^{*}$ & .10 & $.19^{* *}$ & $.39^{* *}$ & $.44^{* *}$ & $.27^{* *}$ & .08 & .05 & $.11^{*}$ & .10 & $.17^{* *}$ & $.42^{* * *}$ & $.45^{* *}$ \\
\hline 25. & Image (T8) & 4.37 & 0.61 & .04 & .01 & .03 & $.12^{*}$ & $.14^{*}$ & $.14^{*}$ & $.30^{* * *}$ & $.33^{* *}$ & $.57^{* *}$ & .03 & .02 & .11 & .09 & .12 & $.36 * *$ & $.31^{* * *}$ \\
\hline 26. & PO Fit (T1) & 3.43 & 0.72 & .03 & $.50^{* * *}$ & $.53^{* *}$ & $.46^{* *}$ & $.37^{* *}$ & $.23^{* *}$ & $.23^{* *}$ & .04 & .02 & $.46^{* *}$ & $.56^{* *}$ & $.41^{* *}$ & $.34^{* *}$ & $.11^{*}$ & $.19^{* *}$ & .03 \\
\hline 27. & PO Fit (T2) & 3.36 & 0.67 & .04 & $.51^{* *}$ & $.58^{* *}$ & $.56^{* *}$ & $.45^{* *}$ & $.35^{* *}$ & $.15^{* *}$ & .05 & $.16^{* *}$ & $.44^{* *}$ & $.59^{* *}$ & $.53^{* *}$ & $.39^{* * *}$ & $.27^{* * *}$ & $.13^{*}$ & .03 \\
\hline 28. & PO Fit (T3) & 3.39 & 0.65 & -.10 & $.43^{* *}$ & $.48^{* *}$ & $.62^{* *}$ & $.46^{* *}$ & $.42^{* *}$ & $.22^{* *}$ & .08 & $.15^{*}$ & $.34^{* *}$ & $.48^{* *}$ & $.60^{* * *}$ & $45^{* *}$ & $.34^{* * *}$ & $.20^{* * *}$ & .06 \\
\hline 29. & PO Fit (T4) & 3.41 & 0.68 & -.02 & $.40^{* *}$ & $.42^{* *}$ & $.50^{* *}$ & $.63^{* *}$ & $.44^{* *}$ & $.30^{* *}$ & $.17^{* *}$ & $.24^{* *}$ & $.38^{* *}$ & $.41^{* *}$ & $.47^{* *}$ & $.57^{* *}$ & $.36^{* *}$ & $.31^{* *}$ & .07 \\
\hline 30. & PO Fit (T5) & 3.83 & 0.70 & .00 & $.24^{* *}$ & $.21^{* *}$ & $.34^{* *}$ & $.33^{* *}$ & $.58^{* *}$ & $.26^{* *}$ & $.17^{* *}$ & .11 & $.23^{* *}$ & $.19^{* *}$ & $.30^{* *}$ & $.36^{* *}$ & $.54^{* *}$ & $.22^{* *}$ & $.16^{* *}$ \\
\hline 31. & PO Fit (T6) & 4.24 & 0.68 & .09 & $.14^{* *}$ & $.12^{*}$ & $.16^{* *}$ & $.23^{* *}$ & $.28^{* *}$ & $.60^{* *}$ & $.30^{* *}$ & $.27^{* *}$ & $.17^{* *}$ & $.12^{*}$ & $.15^{* *}$ & $.24^{* *}$ & $.29^{* * *}$ & $.58^{* *}$ & $.31^{* *}$ \\
\hline 32. & PO Fit (T7) & 4.34 & 0.68 & .03 & .04 & .09 & $.16^{* *}$ & .10 & $.16^{* *}$ & $.34^{* *}$ & $.53^{* *}$ & $.34^{* *}$ & .03 & .08 & $.15^{* *}$ & .08 & $.14^{*}$ & $.36^{* *}$ & $.45^{* *}$ \\
\hline 33. & PO Fit (T8) & 4.22 & 0.77 & .07 & .09 & .08 & $.17^{* *}$ & $.21^{* *}$ & .12 & $.28^{* *}$ & $.40^{* *}$ & $.52^{* *}$ & .07 & .08 & $.19^{* *}$ & $.17^{* *}$ & .07 & $.33^{* *}$ & $.29^{* * *}$ \\
\hline 34. & Attraction (T1) & 3.94 & 0.77 & .07 & $.28^{* *}$ & $.35^{* *}$ & $.35^{* *}$ & $.22^{* *}$ & $.24^{* *}$ & $.23^{* *}$ & $.14^{*}$ & $.18^{* *}$ & $.30^{* *}$ & $.37^{* *}$ & $.35^{* *}$ & $.19^{* *}$ & $.18^{* * *}$ & $.23^{* *}$ & $.15^{* * *}$ \\
\hline 35. & Attraction (T2) & 3.66 & 0.74 & .03 & $.36^{* *}$ & $.45^{* *}$ & $.43^{* *}$ & $.33^{* *}$ & $.29^{* *}$ & $.20^{* *}$ & $.18^{* *}$ & $.21^{* *}$ & $.32^{* *}$ & $.45^{* *}$ & $.43^{* *}$ & $.31^{* *}$ & $.25^{* *}$ & $.21^{* *}$ & $.12^{*}$ \\
\hline 36. & Attraction (T3) & 3.65 & 0.72 & -.01 & $.30^{* *}$ & $.33^{* *}$ & $.52^{* *}$ & $.39^{* *}$ & $.44^{* *}$ & $.28^{* *}$ & $.18^{* *}$ & $.28^{* *}$ & $.28^{* *}$ & $.31^{* *}$ & $.53^{* *}$ & $.40^{* *}$ & $.40^{* * *}$ & $.28^{* *}$ & .08 \\
\hline 37. & Attraction (T4) & 3.67 & 0.72 & $\begin{array}{l}-.03 \\
-.03\end{array}$ & $.29^{* *}$ & $.33^{* *}$ & $.39^{* *}$ & $.52^{* *}$ & $.39^{* *}$ & $.35^{* *}$ & $.24^{* *}$ & $.24^{* *}$ & $.29^{* *}$ & $.30^{* * *}$ & $.39^{* *}$ & $49^{* *}$ & $.36^{* * *}$ & $.31^{* *}$ & $.12^{*}$ \\
\hline 38. & Attraction (T5) & 4.06 & 0.69 & .01 & $.14^{*}$ & .10 & $.25^{* *}$ & $.26^{* *}$ & $.44^{* *}$ & $.33^{* *}$ & $.24^{* *}$ & $.16^{*}$ & $.14^{* *}$ & .07 & $.23^{* *}$ & $.27^{* *}$ & $.44^{* *}$ & $.29^{* * *}$ & $.21^{* * *}$ \\
\hline 39. & Attraction (T6) & 4.31 & 0.68 & .03 & $.13^{*}$ & .09 & $.15^{* *}$ & $.17^{* *}$ & $.26^{* *}$ & $.56^{* *}$ & $.31^{* *}$ & $.28^{* *}$ & $.15^{* *}$ & .09 & $.15^{* *}$ & $16^{* *}$ & $.30^{* * *}$ & $.57^{* *}$ & $.30^{* *}$ \\
\hline 40. & Attraction (T7) & 4.35 & 0.70 & .01 & .04 & .07 & $.13^{*}$ & .08 & $.12^{*}$ & $.36^{* *}$ & $.53^{* *}$ & $.39^{* *}$ & .02 & .05 & $.15^{* *}$ & .06 & $.12^{*}$ & $.39^{* *}$ & $.45^{* *}$ \\
\hline 41. & Attraction (T8) & 4.15 & 0.80 & .05 & .08 & $.12^{*}$ & $.20^{* *}$ & $.22^{* *}$ & $.16^{*}$ & $.29^{* *}$ & $.33^{* *}$ & $.48^{* *}$ & $.12^{*}$ & .10 & $.23^{* *}$ & $.19^{* *}$ & $.13^{*}$ & $.32^{* * *}$ & $.26 * *$ \\
\hline 42. & Acceptance Intentions (T1) & 3.52 & 0.63 & .04 & $.34^{* *}$ & $.12 * *$ & $.45^{* *}$ & $.33^{* *}$ & $.26^{* *}$ & $.18^{* *}$ & .08 & .11 & $.30^{* *}$ & $.43^{* *}$ & $.42^{* *}$ & $.27^{* *}$ & $.16^{* *}$ & $.19^{* * *}$ & .06 \\
\hline 43. & Acceptance Intentions (T2) & 3.46 & 0.66 & .00 & $.41^{* *}$ & $.51^{* *}$ & $.50^{* *}$ & $.38^{* *}$ & $.33^{* *}$ & $.21^{* *}$ & $.14^{*}$ & $.24^{* *}$ & $.34^{* *}$ & $.50^{* *}$ & $.48^{* *}$ & $.32^{* *}$ & $.27^{* *}$ & $.20^{* *}$ & .08 \\
\hline 44. & Acceptance Intentions (T3) & 3.47 & 0.67 & -.03 & $.34^{* *}$ & $.38^{* *}$ & $.59^{* *}$ & $.41^{* *}$ & $.44^{* *}$ & $.23^{* *}$ & $.16^{* *}$ & $.26^{* *}$ & $.31^{* *}$ & $.36 * *$ & $.57^{* *}$ & $.36 *$ & $.38^{* *}$ & $.25^{* *}$ & .04 \\
\hline 45 . & Acceptance Intentions (T4) & 3.48 & 0.67 & -.07 & $.24^{* *}$ & $.28^{* *}$ & $.39^{* *}$ & $.47^{* *}$ & $.34^{* *}$ & $.33^{* *}$ & $.18^{* *}$ & $.28^{* *}$ & $.25^{* *}$ & $.24^{* *}$ & $.37^{* *}$ & $.41^{* *}$ & $.30^{* *}$ & $.31^{* *}$ & .07 \\
\hline 46. & Acceptance Intentions (T5) & 3.70 & 0.68 & -.07 & $.16^{* *}$ & $.14^{* *}$ & $.35^{* *}$ & $.28^{* *}$ & $.40^{* *}$ & $.29^{* *}$ & $.17^{* *}$ & $.17^{* *}$ & $.17^{* *}$ & $.12^{*}$ & $.27^{* *}$ & $.26^{* *}$ & $.38^{* *}$ & $.27^{* *}$ & $.12^{*}$ \\
\hline 47. & Acceptance Intentions (T6) & 3.96 & 0.74 & $\begin{array}{l}-.04 \\
-.04\end{array}$ & $.13^{*}$ & .10 & $.18^{* *}$ & $.16^{* *}$ & $.27^{* *}$ & $.56^{* *}$ & $.28^{* *}$ & $.28^{* *}$ & $.15^{* *}$ & .07 & $.16^{* *}$ & $.17^{* *}$ & $.26^{* *}$ & $.54^{* *}$ & $.29^{* *}$ \\
\hline 48. & Acceptance Intentions (T7) & 3.97 & 0.74 & $\begin{array}{l}-.02 \\
-.02\end{array}$ & .02 & .10 & $.18^{* *}$ & .10 & $.14^{*}$ & $.26 * *$ & $.37^{* *}$ & $.33^{* *}$ & .00 & .07 & $.18^{* *}$ & .08 & .08 & $.27^{* * *}$ & $.30^{* * *}$ \\
\hline 49. & Acceptance Intentions (T8) & 3.88 & 0.88 & .02 & .11 & $.16^{* *}$ & $.23^{* *}$ & $.22^{* *}$ & .10 & $.18^{* *}$ & $.28^{* *}$ & $.38^{* *}$ & $.12^{*}$ & $.14^{*}$ & $.25^{* *}$ & $.17^{* *}$ & .03 & $.17^{* *}$ & $.12^{*}$ \\
\hline 50. & Job Choice & 0.41 & 0.49 & $\begin{array}{l}.02 \\
-.09\end{array}$ & $.11^{*}$ & $.13^{* *}$ & $.12^{*}$ & $.14^{* *}$ & .08 & $.11^{*}$ & $.24^{* *}$ & $.29^{* *}$ & $.11^{*}$ & $.11^{*}$ & $.14^{* *}$ & $.14^{* *}$ & .08 & .10 & $.20^{* * *}$ \\
\hline
\end{tabular}


Table A2, Continued

\begin{tabular}{|c|c|c|c|c|c|c|c|c|c|c|c|c|c|c|c|c|c|c|c|}
\hline & Variables & $M$ & $S D$ & 17 & 18 & 19 & 20 & 21 & 22 & 23 & 24 & 25 & 26 & 27 & 28 & 29 & 30 & 31 & 32 \\
\hline 17. & Trustworthiness (T8) & 4.28 & 0.67 & $(.86)$ & & & & & & & & & & & & & & & \\
\hline 18. & Image (T1) & 4.17 & 0.77 & $.15^{* *}$ & $(.95)$ & & & & & & & & & & & & & & \\
\hline 19. & Image (T2) & 3.93 & 0.80 & $.24^{* *}$ & $.51^{* *}$ & (.98) & & & & & & & & & & & & & \\
\hline 20. & Image (T3) & 3.81 & 0.75 & $.17^{* *}$ & $.42^{* *}$ & $.64^{* *}$ & (.99) & & & & & & & & & & & & \\
\hline 21. & Image (T4) & 3.77 & 0.74 & $.24^{* *}$ & $.30^{* *}$ & $.57^{* *}$ & $.64^{* *}$ & (.99) & & & & & & & & & & & \\
\hline 22 . & Image (T5) & 4.14 & 0.66 & $.21^{* *}$ & $.31^{* *}$ & $.47^{* *}$ & $.52^{* *}$ & $.43^{* *}$ & $(.98)$ & & & & & & & & & & \\
\hline 23. & Image (T6) & 4.35 & 0.66 & $.29^{* *}$ & $.28^{* *}$ & $.33^{* *}$ & $.37^{* *}$ & $.39^{* *}$ & $.43^{* *}$ & (.99) & & & & & & & & & \\
\hline 24. & Image (T7) & 4.41 & 0.60 & $.27^{* *}$ & $.36^{* *}$ & $.40^{* *}$ & $.40^{* *}$ & $.33^{* *}$ & $.43^{* *}$ & $.52^{* *}$ & $(.96)$ & & & & & & & & \\
\hline 25. & Image (T8) & 4.37 & 0.61 & $.49^{* *}$ & $.29^{* *}$ & $.31^{* *}$ & $.34^{* *}$ & $.29^{* *}$ & $.32^{* *}$ & $.46^{* *}$ & $.52^{* *}$ & (.95) & & & & & & & \\
\hline 26. & PO Fit (T1) & 3.43 & 0.72 & .00 & $.44^{* *}$ & $.33^{* *}$ & $.31^{* *}$ & $.26 *$ & .09 & $.14^{* *}$ & .08 & .05 & $(.98)$ & & & & & & \\
\hline 27. & PO Fit (T2) & 3.36 & 0.67 & .09 & $.31^{* *}$ & $.49^{* *}$ & $.45^{* *}$ & $.37^{* *}$ & $.14^{* *}$ & $.15^{* *}$ & $.15^{*}$ & $.14^{*}$ & $.60^{* *}$ & $(.97)$ & & & & & \\
\hline 28. & PO Fit (T3) & 3.39 & 0.65 & .09 & $.26^{* *}$ & $.36^{* *}$ & $.54^{* *}$ & $.42^{* *}$ & $.30^{* *}$ & $.15^{* *}$ & $.18^{* *}$ & .11 & $.56^{* *}$ & $.66^{* *}$ & (.98) & & & & \\
\hline 29. & PO Fit (T4) & 3.41 & 0.68 & $.18^{* *}$ & $.27^{* *}$ & $.36^{* *}$ & $.41^{* *}$ & $.60^{* *}$ & $.26^{* *}$ & $.28^{* *}$ & $.21^{* *}$ & $.16^{* *}$ & $.55^{* *}$ & $.56^{* *}$ & $.68^{* * *}$ & (.99) & & & \\
\hline 30. & PO Fit (T5) & 3.83 & 0.70 & $.13^{*}$ & $.18^{* *}$ & $.27^{* *}$ & $.34^{* *}$ & $.29^{* *}$ & $.61^{* *}$ & $.27^{* *}$ & $.25^{* *}$ & .11 & $.33^{* *}$ & $.28^{* *}$ & $.45^{* *}$ & $49^{* * *}$ & (.97) & & \\
\hline 31. & PO Fit (T6) & 4.24 & 0.68 & $.32^{* * *}$ & $.18^{* *}$ & $.20^{* *}$ & $.22^{* *}$ & $.31^{* *}$ & $.28^{* * *}$ & $.74^{* *}$ & $.38^{* *}$ & $.31^{* *}$ & $.27^{* * *}$ & $.21^{* * *}$ & $.28^{* *}$ & $.40^{* *}$ & $.37^{* * *}$ & $(.98)$ & \\
\hline 32. & PO Fit (T7) & 4.34 & 0.68 & $.28^{* *}$ & $.30^{* *}$ & $.33^{* *}$ & $.28^{* *}$ & $.19^{* *}$ & $.33^{* *}$ & $.48^{* *}$ & $.70^{* *}$ & $.41^{* *}$ & $.12^{*}$ & $.20^{* *}$ & $.22^{* *}$ & $.25^{* *}$ & $.32^{* *}$ & $.53^{* *}$ & $(.98)$ \\
\hline 33. & PO Fit (T8) & 4.22 & 0.77 & $.47^{* *}$ & $.24^{* *}$ & $.18^{* *}$ & $.22^{* *}$ & $.18^{* *}$ & $.24^{* *}$ & $.39^{* *}$ & $.45^{* *}$ & $.58^{* *}$ & .05 & $.13^{*}$ & $.18^{* *}$ & $.20^{* *}$ & $.17^{* *}$ & $.39^{* *}$ & $.55^{* *}$ \\
\hline 34. & Attraction (T1) & 3.94 & 0.77 & $.16^{* *}$ & $.68^{* *}$ & $.52^{* *}$ & $.45^{* *}$ & $.35^{* *}$ & $.33^{* *}$ & $.21^{* *}$ & $.31^{* *}$ & $.30^{* *}$ & $.56^{* *}$ & $.42^{* * *}$ & $.42^{* *}$ & $.38^{* *}$ & $.30^{* *}$ & $.23^{* *}$ & $.24^{* *}$ \\
\hline 35. & Attraction (T2) & 3.66 & 0.74 & $.14^{*}$ & $.37^{* *}$ & $.71^{* *}$ & $.54^{* *}$ & $.48^{* *}$ & $.34^{* *}$ & $.21^{* *}$ & $.28^{* *}$ & $.24^{* *}$ & $.44^{* *}$ & $.68^{* *}$ & $.52^{* *}$ & $.48^{* *}$ & $.29^{* * *}$ & $.18^{* *}$ & $.23^{* *}$ \\
\hline 36. & Attraction (T3) & 3.65 & 0.72 & $.12^{*}$ & $.30^{* *}$ & $.49^{* *}$ & $.74^{* *}$ & $.58^{* *}$ & $.38^{* *}$ & $.21^{* *}$ & $.27^{* *}$ & $.29^{* *}$ & $.38^{* *}$ & $.49^{* *}$ & $.71^{* *}$ & $.57^{* *}$ & $.37^{* *}$ & $.24^{* *}$ & $.21^{* *}$ \\
\hline 37. & Attraction (T4) & 3.67 & 0.72 & $.19^{* * *}$ & $.26^{* *}$ & $.42^{* *}$ & $.53^{* *}$ & $.76^{* *}$ & $.39^{* *}$ & $.29^{* *}$ & $.28^{* *}$ & $.21^{* *}$ & $.35^{* *}$ & $.40^{* *}$ & $.52^{* *}$ & $.73^{* *}$ & $.37^{* *}$ & $.34^{* *}$ & $.20^{* *}$ \\
\hline 38. & Attraction (T5) & 4.06 & 0.69 & $.13^{*}$ & $.23^{* *}$ & $.33^{* *}$ & $.42^{* *}$ & $.40^{* *}$ & $.74^{* *}$ & $.38^{* *}$ & $.38^{* *}$ & $.23^{* *}$ & $.13^{*}$ & $.18^{* *}$ & $.36^{* *}$ & $.37^{* *}$ & $.69^{* * *}$ & $.34^{* *}$ & $.35^{* *}$ \\
\hline 39. & Attraction (T6) & 4.31 & 0.68 & $.29^{* *}$ & $.13^{* *}$ & $.17^{* *}$ & $.17^{* *}$ & $.31^{* *}$ & $.30^{* *}$ & $.71^{* *}$ & $.45^{* *}$ & $.35^{* *}$ & $.21^{* * *}$ & $.16^{* *}$ & $.25^{* *}$ & $.34^{* *}$ & $.32 * *$ & $.83^{* *}$ & $.47^{* *}$ \\
\hline 40. & Attraction (T7) & 4.35 & 0.70 & $.31^{* *}$ & $.22^{* *}$ & $.26^{* *}$ & $.29^{* *}$ & $.25^{* *}$ & $.31^{* *}$ & $.45^{* *}$ & $.69^{* *}$ & $.48^{* *}$ & .05 & $.15^{* *}$ & $.20^{* *}$ & $.22^{* *}$ & $.21^{* *}$ & $.47^{* *}$ & $.80^{* *}$ \\
\hline 41. & Attraction (T8) & 4.15 & 0.80 & $.42^{* *}$ & $.29^{* *}$ & $.17^{* *}$ & $.22^{* *}$ & $.18^{* *}$ & $.27^{* *}$ & $.39^{* *}$ & $.42^{* * *}$ & $.58^{* *}$ & .06 & $.13^{*}$ & $.21^{* *}$ & $.21^{* *}$ & $.14^{*}$ & $.38^{* *}$ & $.46^{* *}$ \\
\hline 42. & Acceptance Intentions (T1) & 3.52 & 0.63 & .11 & $.52^{* *}$ & $.47^{* *}$ & $.40^{* *}$ & $.31^{* *}$ & $.23^{* *}$ & $.19^{* *}$ & $.19^{* *}$ & $.19^{* *}$ & $.06^{* *}$ & $.52^{* *}$ & $.52^{* *}$ & $.44^{* *}$ & $.29^{* *}$ & $.23^{* *}$ & $.48^{* *}$ \\
\hline 43. & Acceptance Intentions (T2) & 3.46 & 0.66 & $.14^{*}$ & $.34^{* *}$ & $.55^{* *}$ & $.49^{* *}$ & $.43^{* *}$ & $.23^{* *}$ & $.18^{* *}$ & $.24^{* *}$ & $.24^{* *}$ & $.50^{* *}$ & $.77^{* *}$ & $.60^{* *}$ & $.53^{* *}$ & $.25^{* *}$ & $.22^{* *}$ & $.22^{* *}$ \\
\hline 44. & Acceptance Intentions (T3) & 3.47 & 0.67 & .09 & $.28^{* *}$ & $.41^{* *}$ & $.65^{* *}$ & $.48^{* *}$ & $.29^{* *}$ & $.19^{* *}$ & $.26^{* *}$ & $.25^{* *}$ & $.44^{* *}$ & $.57^{* *}$ & $.72^{* *}$ & $.63^{* *}$ & $.35^{* *}$ & $.25^{* *}$ & $.21^{* *}$ \\
\hline 45 . & Acceptance Intentions (T4) & 3.48 & 0.67 & $.21^{* * *}$ & $.24^{* *}$ & $.33^{* *}$ & $.48^{* *}$ & $.62^{* *}$ & $.29^{* *}$ & $.27^{* *}$ & $.25^{* *}$ & $.24^{* *}$ & $.38^{* *}$ & $.44^{* *}$ & $.56^{* *}$ & $.74^{* *}$ & $.34^{* *}$ & $.32^{* *}$ & $.19^{* *}$ \\
\hline 46. & Acceptance Intentions (T5) & 3.70 & 0.68 & $.13^{*}$ & .10 & $.16^{* *}$ & $.26^{* *}$ & $.23^{* *}$ & $.48^{* *}$ & $.32^{* *}$ & $.34^{* *}$ & $.21^{* *}$ & $.21^{* *}$ & $.26^{* *}$ & $.40^{* *}$ & $.45^{* *}$ & $.58^{* *}$ & $.36^{* *}$ & $.34^{* *}$ \\
\hline 47. & Acceptance Intentions (T6) & 3.96 & 0.74 & $.29^{* *}$ & .08 & $.10^{*}$ & $.15^{* *}$ & $.22^{* *}$ & $.21^{* *}$ & $.58^{* *}$ & $.39^{* *}$ & $.32^{* *}$ & $.21^{* *}$ & $.17^{* *}$ & $.27^{* *}$ & $.38^{* *}$ & $.28^{* *}$ & $.75^{* *}$ & $.43^{* *}$ \\
\hline 48. & Acceptance Intentions (T7) & 3.97 & 0.74 & $.21^{* *}$ & $.20^{* *}$ & $.16^{* *}$ & $.22^{* *}$ & .09 & $.26^{* *}$ & $.39^{* *}$ & $.50^{* *}$ & $.37^{* *}$ & .05 & $.20^{* *}$ & $.28^{* *}$ & $.21^{* *}$ & $.23^{* *}$ & $44^{* *}$ & $.65^{* *}$ \\
\hline 49. & Acceptance Intentions (T8) & 3.88 & 0.88 & $.27^{* *}$ & $.21^{* *}$ & $.16^{* *}$ & $.17^{* *}$ & .06 & $.14^{*}$ & $.26^{* *}$ & $.31^{* *}$ & $.41^{* *}$ & .11 & $.13^{*}$ & $.20^{* *}$ & $.15^{*}$ & .04 & $.31^{* *}$ & $.42^{* *}$ \\
\hline 50. & Job Choice & 0.41 & 0.49 & $.26^{* *}$ & .08 & .06 & .07 & .05 & .07 & $.14^{* *}$ & $.18^{* *}$ & $.25^{* *}$ & .03 & .09 & .09 & .07 & .05 & $.23^{* *}$ & $.33^{* *}$ \\
\hline
\end{tabular}


Table A2, Continued

\begin{tabular}{|c|c|c|c|c|c|c|c|c|c|c|c|c|c|c|c|c|c|c|c|}
\hline & Variables & $M$ & $S D$ & 33 & 34 & 35 & 36 & 37 & 38 & 39 & 40 & 41 & 42 & 43 & 44 & 45 & 46 & 47 & 48 \\
\hline 33. & PO Fit (T8) & 4.22 & 0.77 & $(.97)$ & & & & & & & & & & & & & & & \\
\hline 34. & Attraction (T1) & 3.94 & 0.77 & $.24^{* *}$ & $(.92)$ & & & & & & & & & & & & & & \\
\hline 35. & Attraction (T2) & 3.66 & 0.74 & $.19^{* *}$ & $.57^{* *}$ & (.95) & & & & & & & & & & & & & \\
\hline 36. & Attraction (T3) & 3.65 & 0.72 & $.23^{* *}$ & $.51^{* *}$ & $.66^{* *}$ & (.96) & & & & & & & & & & & & \\
\hline 37. & Attraction (T4) & 3.67 & 0.72 & $.19^{* *}$ & $.44^{* *}$ & $.56^{* *}$ & $.68^{* *}$ & $(.96)$ & & & & & & & & & & & \\
\hline 38. & Attraction (T5) & 4.06 & 0.69 & $.25^{* *}$ & $.39^{* *}$ & $.37^{* *}$ & $.47^{* *}$ & $.50^{* *}$ & $(.96)$ & & & & & & & & & & \\
\hline 39. & Attraction (T6) & 4.31 & 0.68 & $.39^{* *}$ & $.31^{* *}$ & $.22^{* *}$ & $.28^{* *}$ & $.37^{* *}$ & $.42^{* *}$ & $(.98)$ & & & & & & & & & \\
\hline 40. & Attraction (T7) & 4.35 & 0.70 & $.58^{* *}$ & $.25^{* *}$ & $.23^{* *}$ & $.27^{* *}$ & $.27^{* *}$ & $.40^{* *}$ & $.53^{* *}$ & $(.96)$ & & & & & & & & \\
\hline 41. & Attraction (T8) & 4.15 & 0.80 & $.80^{* *}$ & $.28^{* *}$ & $.20^{* *}$ & $.27^{* *}$ & $.23^{* *}$ & $.30^{* *}$ & $.41^{* *}$ & $.61^{* *}$ & (.95) & & & & & & & \\
\hline 42 . & Acceptance Intentions (T1) & 3.52 & 0.63 & $.18^{* *}$ & $.75^{* *}$ & $.55^{* *}$ & $.46^{* *}$ & $.41^{* *}$ & $.31^{* *}$ & $.24^{* *}$ & $.17^{* *}$ & $24^{* *}$ & $(.75)$ & & & & & & \\
\hline 43. & Acceptance Intentions (T2) & 3.46 & 0.66 & $.19^{* *}$ & $.50^{* *}$ & $.79^{* *}$ & $.60^{* *}$ & $.50^{* *}$ & $.29^{* *}$ & $.22^{* *}$ & $.21^{* *}$ & $.20^{* *}$ & $.63^{* *}$ & (.85) & & & & & \\
\hline 44. & Acceptance Intentions (T3) & 3.47 & 0.67 & $.22^{* *}$ & $.49^{* *}$ & $.62^{* *}$ & $.85^{* *}$ & $.60^{* *}$ & $.43^{* *}$ & $.28^{* *}$ & $.24^{* *}$ & $.26 * *$ & $.56^{* *}$ & $.70^{* * *}$ & $(.89)$ & & & & \\
\hline 45. & Acceptance Intentions (T4) & 3.48 & 0.67 & $.20^{* *}$ & $.41^{* *}$ & $.50^{* *}$ & $.63^{* *}$ & $.83^{* *}$ & $.44^{* *}$ & $.34^{* *}$ & $.25^{* *}$ & $.26^{* *}$ & $.46^{* *}$ & $.57^{* *}$ & $.70^{* * *}$ & $(.90)$ & & & \\
\hline 46. & Acceptance Intentions (T5) & 3.70 & 0.68 & $.24^{* *}$ & $.32^{* *}$ & $.33^{* *}$ & $.41^{* *}$ & $.39^{* *}$ & $.71^{* *}$ & $.40^{* *}$ & $.35^{* *}$ & $.29^{* *}$ & $.39^{* *}$ & $.40^{* *}$ & $.56^{* *}$ & $.53^{* * *}$ & $(.84)$ & & \\
\hline 47. & Acceptance Intentions (T6) & 3.96 & 0.74 & $.37^{* *}$ & $.28^{* *}$ & $.20^{* *}$ & $.30^{* *}$ & $.32^{* *}$ & $.39^{* *}$ & $.81^{* *}$ & $.48^{* *}$ & $.41^{* *}$ & $.34^{* *}$ & $.28^{* *}$ & $.38^{* *}$ & $.42^{* *}$ & $.50^{* *}$ & $(.88)$ & \\
\hline 48. & Acceptance Intentions (T7) & 3.97 & 0.74 & $.53^{* *}$ & $.22^{* *}$ & $.23^{* *}$ & $.24^{* *}$ & $.20^{* *}$ & $.35^{* *}$ & $.45^{* *}$ & $.77^{* *}$ & $.59^{* *}$ & $.24^{* *}$ & $.28^{* *}$ & $.29^{* *}$ & $.27^{* *}$ & $.43^{* *}$ & $.49^{* * *}$ & $(.85)$ \\
\hline 49. & Acceptance Intentions (T8) & 3.88 & 0.88 & $.64^{* *}$ & $.19^{* *}$ & $.15^{*}$ & $.21^{* *}$ & $.13^{*}$ & $.14^{*}$ & $.26^{* *}$ & $.48^{* *}$ & $.80^{* *}$ & $.24^{* *}$ & $.17^{* *}$ & $.23^{* *}$ & $.18^{* *}$ & $.23^{* *}$ & $.28^{* *}$ & $.56^{* *}$ \\
\hline 50. & Job Choice & 0.41 & 0.49 & $.48^{* *}$ & .05 & .06 & .09 & .09 & .08 & $.19^{* *}$ & $.40^{* *}$ & $.59^{* *}$ & .08 & .09 & .08 & .07 & .10 & $.22^{* *}$ & $.43^{* *}$ \\
\hline
\end{tabular}


Table A2, Continued

\begin{tabular}{llccc}
\hline \multicolumn{1}{c}{ Variables } & $M$ & $S D$ & 49 & 50 \\
\hline $49 . \quad$ Acceptance Intentions (T8) & 3.88 & 0.88 & $(.83)$ & \\
$50 . \quad$ Job Choice & 0.41 & 0.49 & $.71^{* *}$ & -- \\
\hline
\end{tabular}


Table A3: HLM Results for Recruiter Timeliness Over Time

\begin{tabular}{|c|c|c|}
\hline \multirow[b]{2}{*}{ Variable } & \multicolumn{2}{|c|}{ Timeliness } \\
\hline & Coef. & Coef. $S E$ \\
\hline \multicolumn{3}{|l|}{$\overline{\text { Level } 3}$} \\
\hline GPA & .19 & .10 \\
\hline \multicolumn{3}{|l|}{ Level 2} \\
\hline Dummy 1 & -.05 & $.03 \dagger$ \\
\hline Dummy 2 & -.01 & .03 \\
\hline Dummy 3 & .08 & $.03 * *$ \\
\hline TakeOffer & .04 & .03 \\
\hline \multicolumn{3}{|l|}{ Level 1} \\
\hline Time & .010 & $.001 * *$ \\
\hline Time X TakeOffer & .002 & $.001 * *$ \\
\hline
\end{tabular}


Table A4: HLM Results for Recruiter Trustworthiness Over Time

\begin{tabular}{|c|c|c|}
\hline \multirow[b]{2}{*}{ Variable } & \multicolumn{2}{|c|}{ Trustworthiness } \\
\hline & Coef. & Coef. $S E$ \\
\hline \multicolumn{3}{|l|}{ Level 3} \\
\hline GPA & .25 & $.10^{*}$ \\
\hline \multicolumn{3}{|l|}{ Level 2} \\
\hline Dummy 1 & -.04 & .03 \\
\hline Dummy 2 & -.04 & .03 \\
\hline Dummy 3 & .07 & $.03 *$ \\
\hline TakeOffer & .05 & $.03 \dagger$ \\
\hline \multicolumn{3}{|l|}{ Level 1} \\
\hline Time & .009 & $.001 * *$ \\
\hline Time X TakeOffer & .002 & $.001 * *$ \\
\hline
\end{tabular}


Table A5: HLM Results for Organizational Image Over Time

\begin{tabular}{|c|c|c|}
\hline \multirow[b]{2}{*}{ Variable } & \multicolumn{2}{|c|}{ Org. Image } \\
\hline & Coef. & Coef. $S E$ \\
\hline \multicolumn{3}{|l|}{ Level 3} \\
\hline GPA & .41 & $.12 * *$ \\
\hline \multicolumn{3}{|l|}{ Level 2} \\
\hline Dummy 1 & .13 & $.04 * *$ \\
\hline Dummy 2 & -.12 & $.04 * *$ \\
\hline Dummy 3 & .21 & $.04 * *$ \\
\hline TakeOffer & .11 & $.04 * *$ \\
\hline \multicolumn{3}{|l|}{ Level 1} \\
\hline Time & .002 & $.001 * *$ \\
\hline Time X TakeOffer & .002 & $.001 * *$ \\
\hline
\end{tabular}


Table A6: HLM Results for PO Fit Over Time

\begin{tabular}{|c|c|c|}
\hline \multirow[b]{2}{*}{ Variable } & \multicolumn{2}{|c|}{ PO Fit } \\
\hline & Coef. & Coef. $S E$ \\
\hline \multicolumn{3}{|l|}{ Level 3} \\
\hline GPA & .24 & $.11 *$ \\
\hline \multicolumn{3}{|l|}{ Level 2} \\
\hline Dummy 1 & .02 & .04 \\
\hline Dummy 2 & -.06 & .04 \\
\hline Dummy 3 & .13 & $.04 * *$ \\
\hline TakeOffer & -.04 & .04 \\
\hline \multicolumn{3}{|l|}{ Level 1} \\
\hline Time & .005 & $.001 * *$ \\
\hline Time X TakeOffer & .005 & $.001 * *$ \\
\hline
\end{tabular}


Table A7: HLM Results for Organizational Attraction Over Time

\begin{tabular}{|c|c|c|}
\hline \multirow[b]{2}{*}{ Variable } & \multicolumn{2}{|c|}{ Org Attractiveness } \\
\hline & Coef. & Coef. $S E$ \\
\hline \multicolumn{3}{|l|}{ Level 3} \\
\hline GPA & .22 & $.12 \dagger$ \\
\hline \multicolumn{3}{|l|}{ Level 2} \\
\hline Dummy 1 & .13 & $.04 * *$ \\
\hline Dummy 2 & -.08 & $.05 \dagger$ \\
\hline Dummy 3 & .20 & $.04 * *$ \\
\hline TakeOffer & -.01 & .04 \\
\hline \multicolumn{3}{|l|}{ Level 1} \\
\hline Time & .001 & .001 \\
\hline Time X TakeOffer & .006 & $.001 * *$ \\
\hline
\end{tabular}


Table A8: HLM Results for Intentions to Accept Over Time

\begin{tabular}{|c|c|c|}
\hline \multirow[b]{2}{*}{ Variable } & \multicolumn{2}{|c|}{ Intentions to Accept } \\
\hline & Coef. & Coef. $S E$ \\
\hline \multicolumn{3}{|l|}{ Level 3} \\
\hline GPA & .10 & .12 \\
\hline \multicolumn{3}{|l|}{ Level 2} \\
\hline Dummy 1 & .08 & $.04 *$ \\
\hline Dummy 2 & -.06 & .04 \\
\hline Dummy 3 & .14 & $.04 * *$ \\
\hline TakeOffer & -.09 & $.04 *$ \\
\hline \multicolumn{3}{|l|}{ Level 1} \\
\hline Time & .001 & .001 \\
\hline Time X TakeOffer & .008 & $.001 * *$ \\
\hline
\end{tabular}


APPENDIX A

FIGURES 


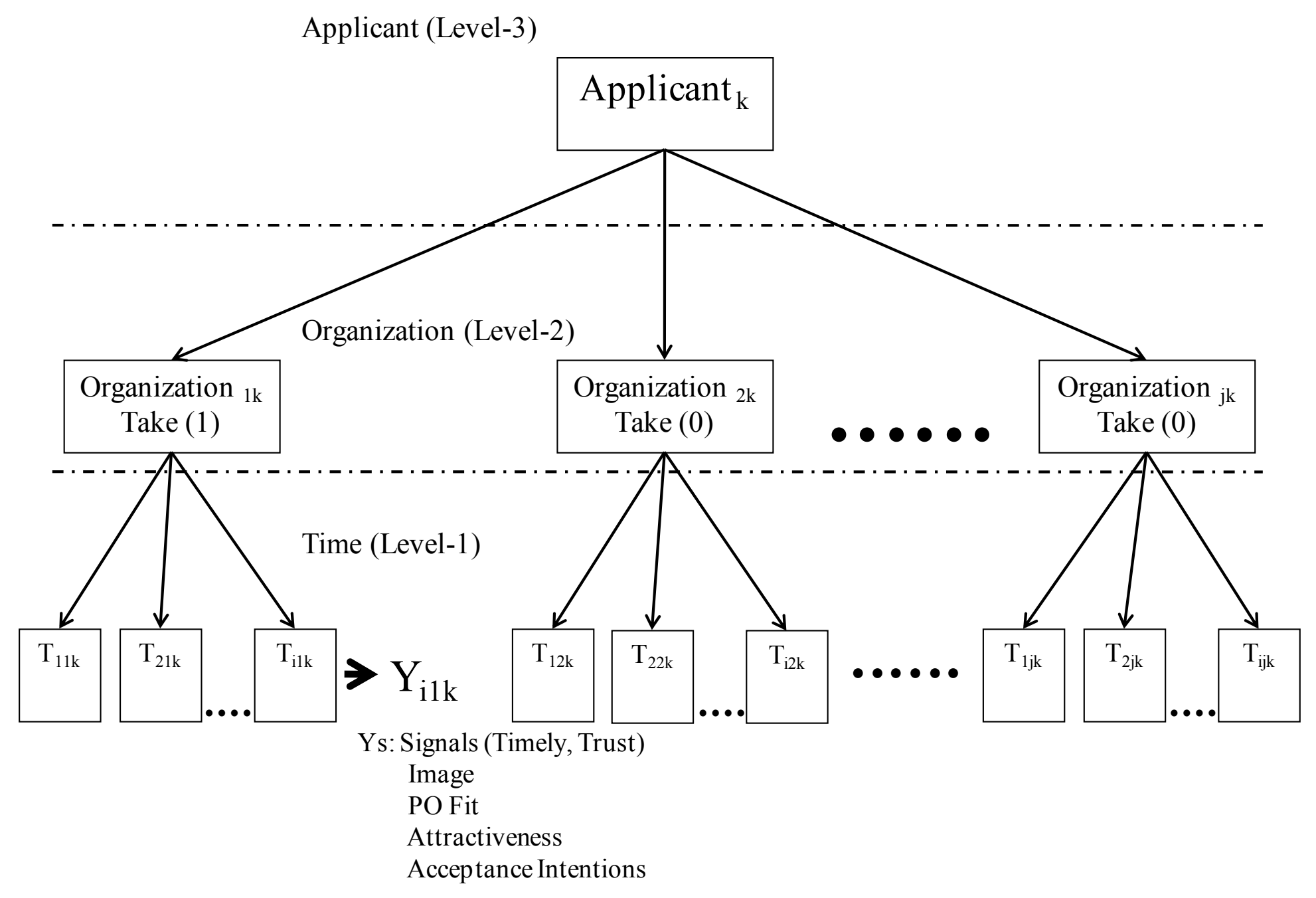

Figure B1: Proposed Model 
Level-1 Model:

$Y_{i j k}=\pi_{0 j k}+\pi_{1 j k}{ }^{*}(\mathrm{TIME})+e_{i j k}$

Level-2 Model:

$\pi_{0 j k}=\beta_{00 k}+\beta_{01 k} *(\mathrm{D} 1)+\beta_{02 k} *(\mathrm{D} 2)+\beta_{03 k} *(\mathrm{D} 3)+\beta_{04 k} *(\mathrm{TAKE})+r_{0 j k}$

$\pi_{1 j k}=\beta_{10 k}+\beta_{11 k} *(\mathrm{TAKE})+r_{1 j k}$

Level-3 Model:

$\beta_{00 k}=\gamma_{000}+\gamma_{001} *(\mathrm{GPA})+u_{00 k}$

$\beta_{01 k}=\gamma_{010}$

$\beta_{02 k}=\gamma_{020}$

$\beta_{03 k}=\gamma_{030}$

$\beta_{04 k}=\gamma_{040}$

$\beta_{10 k}=\gamma_{100}+u_{10 k}$

$\beta_{11 k}=\gamma_{110}$

Combined Model:

$Y_{i j k}=\gamma_{000}+\gamma_{001} *(\mathrm{GPA})+\gamma_{010} *(\mathrm{D} 1)+\gamma_{020} *(\mathrm{D} 2)+\gamma_{030} *(\mathrm{D} 3)+\gamma_{040} *(\mathrm{TAKE})+\gamma_{100} *(\mathrm{TIME})$

$+\gamma_{010} *(\mathrm{TAKE})+\gamma_{110} *(\mathrm{TAKE}) *(\mathrm{TIME})+e_{i j k}+r_{0 j k}+u_{00 k}+r_{1 j k} *(\mathrm{TIME})+u_{10 k} *$ (TIME)

Figure B2: Model Specifications 


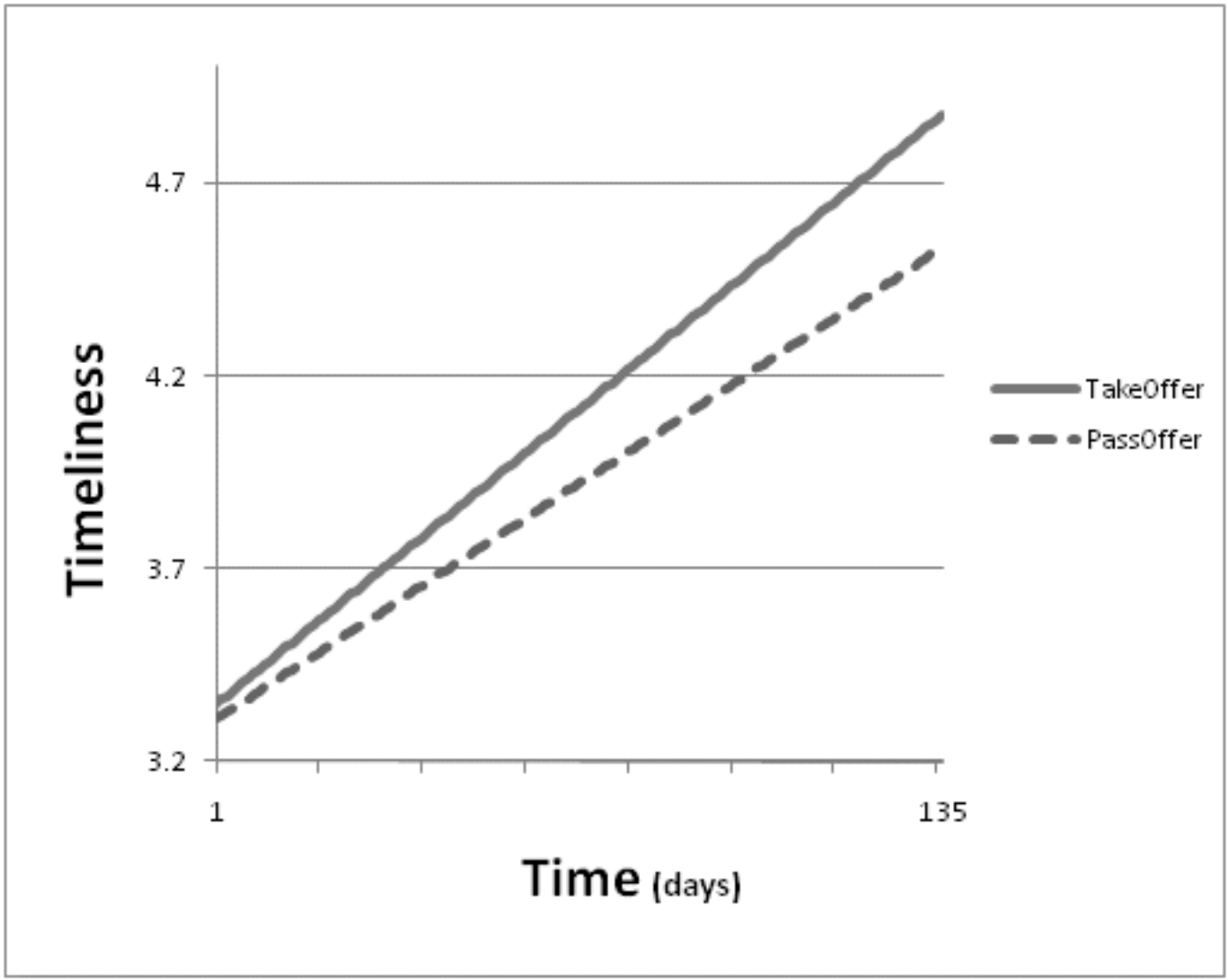

Figure B3: Applicant Perceptions of Recruiter Timeliness 


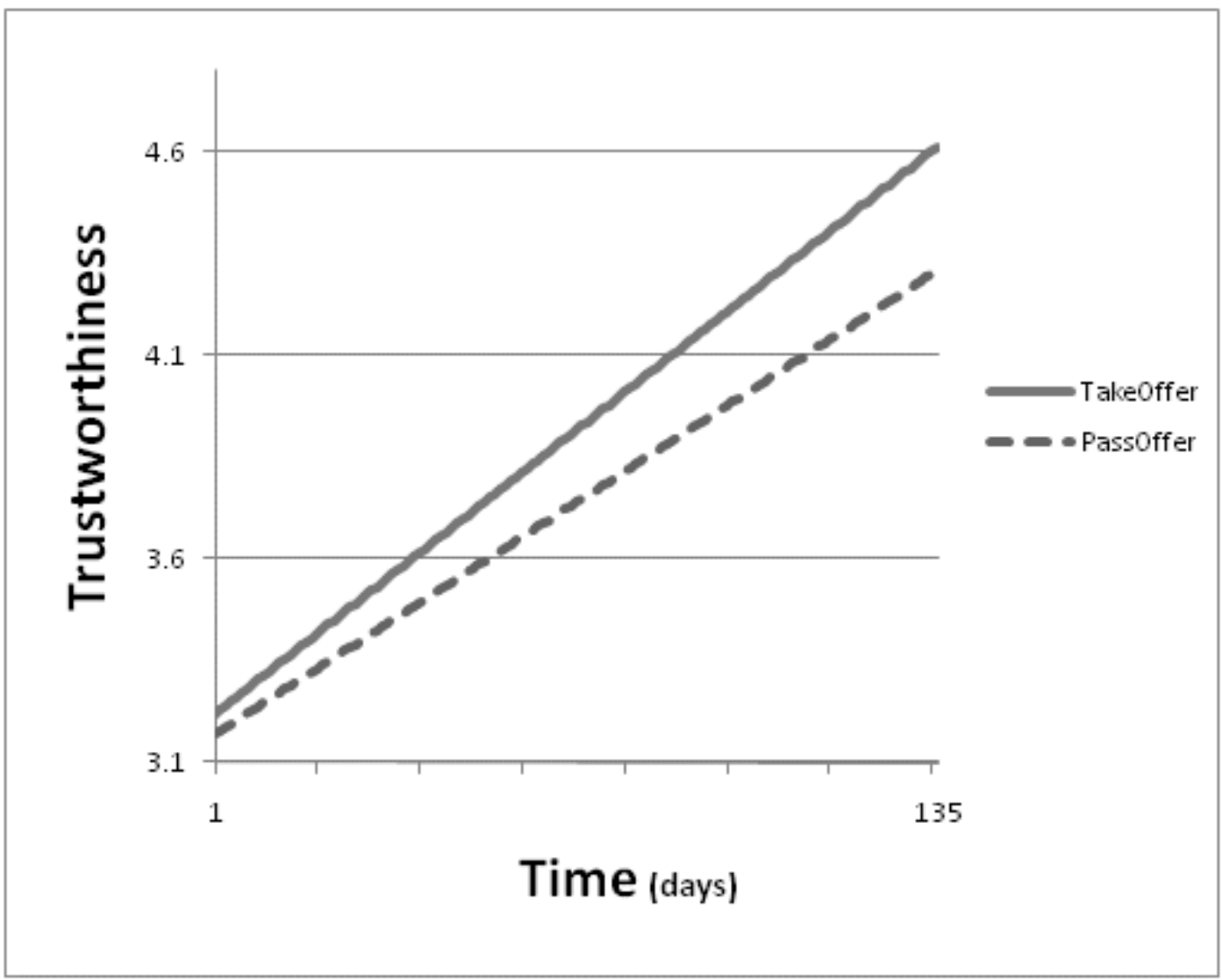

Figure B4: Applicant Perceptions of Recruiter Trustworthiness 


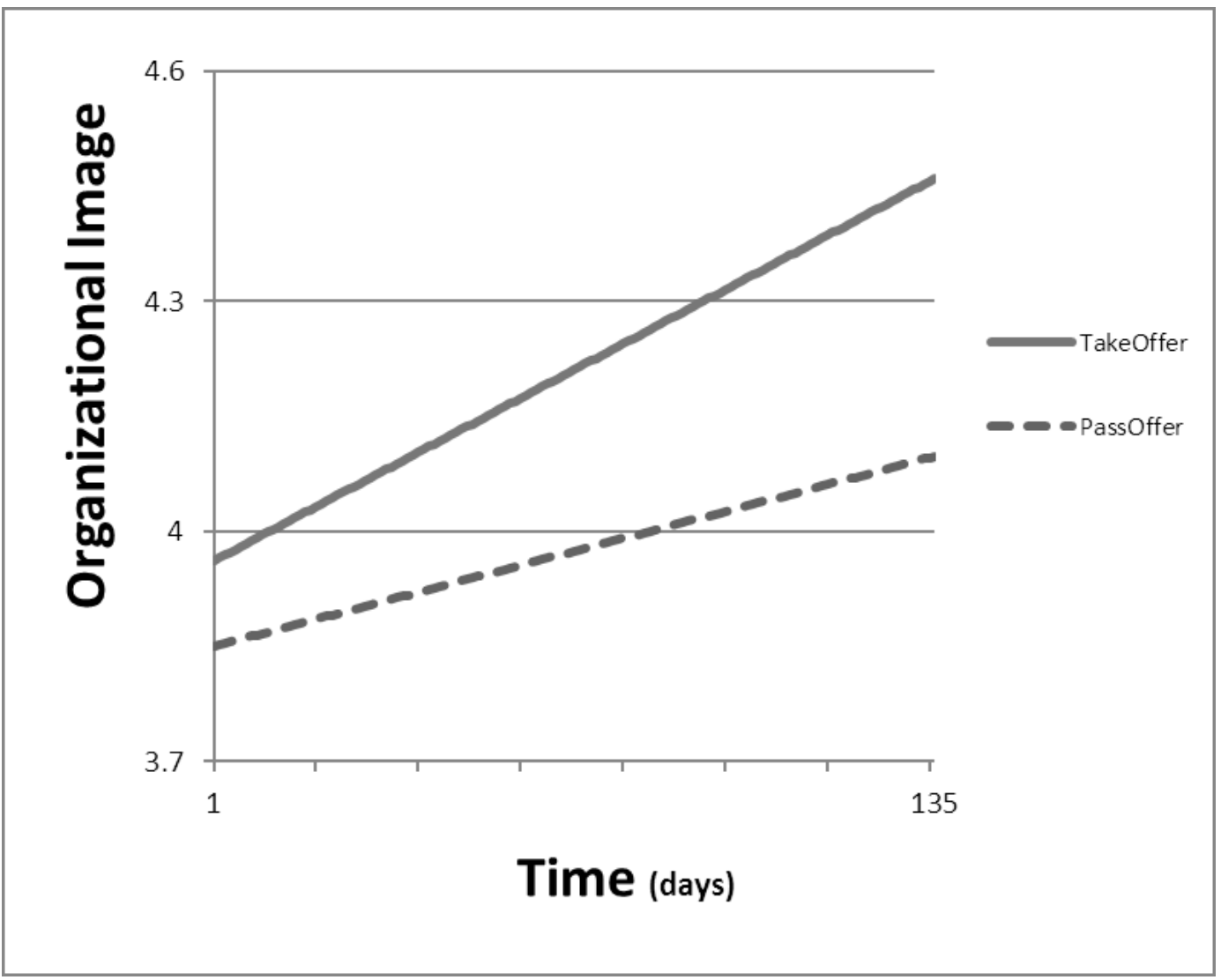

Figure B5: Applicant Perceptions of Organizational Image 


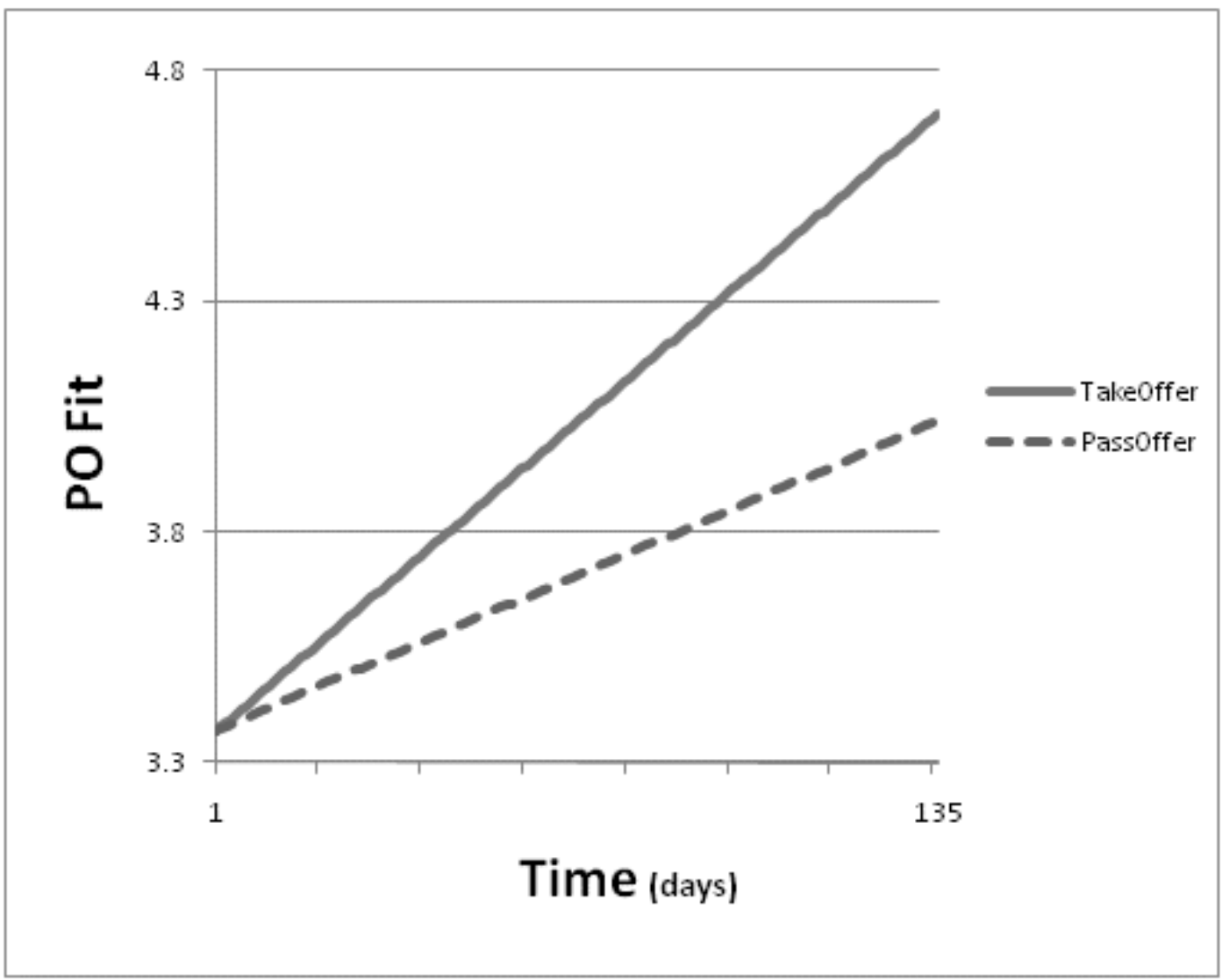

Figure B6: Applicant Perceptions of PO Fit 


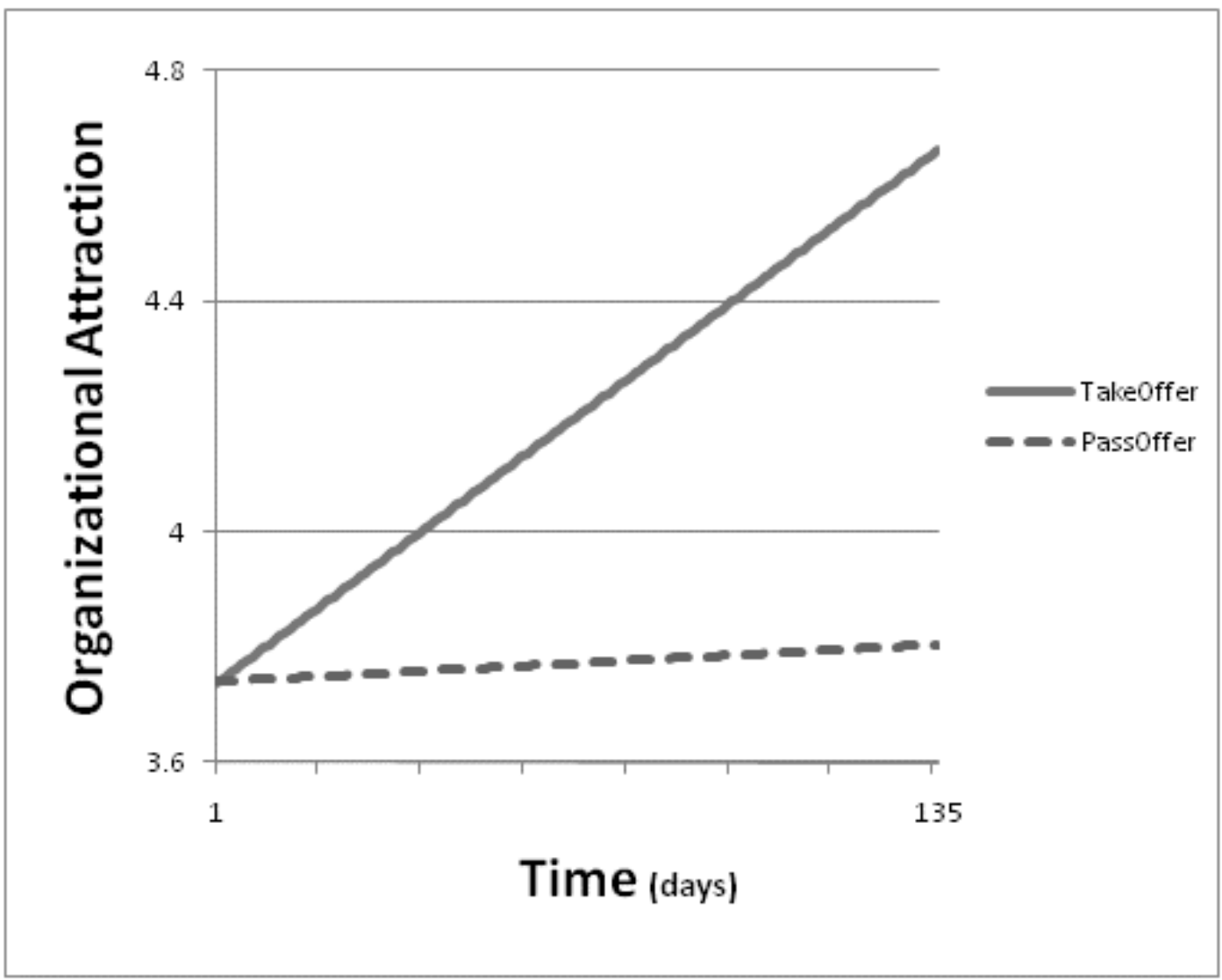

Figure B7: Applicant Perceptions of Organizational Attraction 


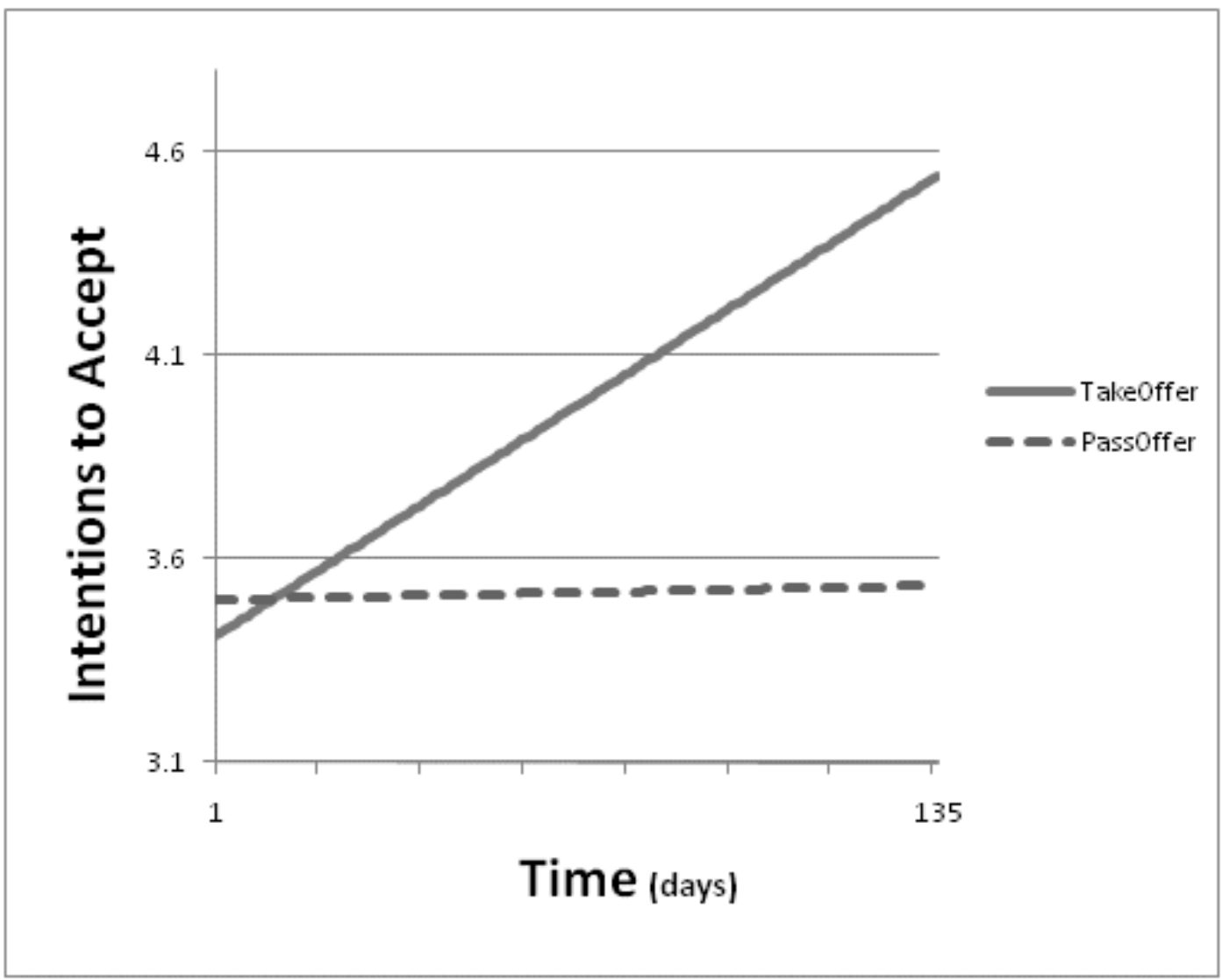

Figure B8: Applicant Perceptions of Intentions to Accept 


\section{VITA}

Name:

Address:

Email Address:

Education:
Brian William Swider

Texas A\&M University

Mays Business School

407 Wehner Building

4221 TAMU

College Station, TX 77843

bwswider@gmail.com

B.S.B.A, University of Florida, 2007

Ph.D., Management, Texas A\&M University, 2012 